\title{
The Status Quo and Perceptions of Fairness: How Income Inequality Influences Public Opinion
}

\section{Citation}

Trump, Kris-Stella. 2013. The Status Quo and Perceptions of Fairness: How Income Inequality Influences Public Opinion. Doctoral dissertation, Harvard University.

\section{Permanent link}

http://nrs.harvard.edu/urn-3:HUL.InstRepos:11158265

\section{Terms of Use}

This article was downloaded from Harvard University's DASH repository, and is made available under the terms and conditions applicable to Other Posted Material, as set forth at http:// nrs.harvard.edu/urn-3:HUL.InstRepos:dash.current.terms-of-use\#LAA

\section{Share Your Story}

The Harvard community has made this article openly available.

Please share how this access benefits you. Submit a story.

\section{Accessibility}




\title{
The Status Quo and Perceptions of Fairness: How Income Inequality Influences Public Opinion
}

\author{
A DISSERTATION PRESENTED \\ BY \\ KRIS-STELla TRUMP \\ TO \\ The Government Department \\ IN PARTIAL FULFILLMENT OF THE REQUIREMENTS \\ FOR THE DEGREE OF \\ Doctor of PhILOSOPHY \\ IN THE SUBJECT OF \\ Political Science \\ HARVARD UNIVERSITY \\ Cambridge, Massachusetts \\ MAY 2013
}


(C) 2013 - KRIS-STELLA TRUMP

All Rights Reserved. 


\title{
The Status Quo and Perceptions of Fairness: How Income Inequality Influences Public Opinion
}

\author{
Abstract \\ This dissertation argues that public opinion regarding the acceptability and \\ desirability of income differences is affected by actual income inequality. \\ Cross-national survey evidence is combined with laboratory and survey \\ experiments to show that estimates regarding appropriate income differences \\ depend on (perceptions of) real income differences. When income inequality \\ changes, public opinion "habituates" by adjusting expectations for fair levels of \\ inequality in the same direction as the factual change. This adjustment effect \\ occurs because humans are subject to status quo bias and have a motivated \\ tendency to believe in a just world. In the context of increasing inequality in \\ developed democracies over the last 40 years, the implication is that normative \\ expectations for appropriate levels of inequality have adjusted up. This \\ habituation process helps explain why increases in inequality have not been \\ accompanied by increased demands for redistribution and why cross-national \\ variation in income inequality is not clearly linked to public opposition to such \\ inequality. \\ The dissertation starts by showing that in each of 32 countries, perceptions of \\ occupational income inequality predict inequality ideals. The causal relationship \\ is then established in a series of experiments. In a laboratory experiment, \\ participants who take part in a game with unequal money prizes subsequently
}


recommend a more unequal split of prize money than participants who play a more equal game. A survey experiment shows that the predicted adjustment also occurs for perceptions of real income inequality: survey respondents who receive information regarding true income inequality in the United States recommend larger occupational income differences as ideal than do individuals who do not receive this information. The final chapter shows that the habituation phenomenon is affected by the motivation to think of the social system as fair: activating the system justification motive among Democrats reduces the otherwise robust partisan gap in ideal income inequalities to statistically insignificant levels. This last finding implies that the broader political context can affect the strength of the habituation process in public opinion. 


\section{Contents}

1 Introduction. 1

1.1 Outline of the argument $\ldots \ldots \ldots \ldots$

2 Why Inequality? On the Consequences of Economic Inequal-

ITY. $\quad 11$

2.1 The inherent desirability and undesirability of economic inequality 13

2.2 Will the poor soak the rich? . . . . . . . . . . 15

2.3 Does inequality harm the quality of democracy? . . . . . . . 18

2.4 Other social consequences of economic inequality . . . . . 21

2.5 Why now $\ldots \ldots \ldots \ldots \ldots \ldots$

2.6 Conclusion: the importance of understanding attitudes toward

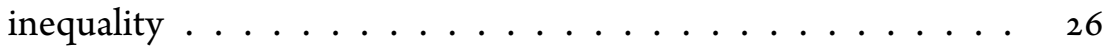

3 ATTITUDES TOWARD ECONOMIC INEQUALITY: WHAT DO WE KNOW? $\mathbf{2 7}$

3.1 Attitudes toward redistribution in comparative perspective ... 30

3.2 American attitudes toward economic inequality and redistribution 34

3.3 Comparative attitudes toward income inequality . . . . . . 39

3.4 Conclusion .................... 44

4 The PSychology of The STATUS QUO AND InCOME INeQUality. $\quad \mathbf{4 6}$

4.1 Thinking about income differences . . . . . . . . . . 47

4.2 Status quo bias . . . . . . . . . . . . . . 49 
4.3 Belief in a just world ................ 51

4.4 The habituation hypothesis . . . . . . . . . . . 55

4.5 Individual differences . . . . . . . . . . . 56

4.6 Social context and system justification . . . . . . . 57

4.7 Conclusion ..................... 60

5 Perceptions of inequality Predict Inequality ideals. 61

5.1 Measuring inequality attitudes . . . . . . . . . . . 62

5.2 Methodology . . . . . . . . . . . . . . . . . . . . 64

5.3 Perceptions of inequality strongly predict ideal levels of inequality 65

5.4 Conclusion ....................... 72

6 ACTUAL INEQUALITY INFLUENCES INEQUALITY IDEALS. 77

6.1 Experiment 1: Experiences of inequality influence preferences

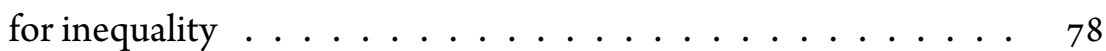

6.2 Experiment 2: Information regarding existing inequality influences inequality ideals . . . . . . . . . . . 87

6.3 Information about inequality and attitudes toward redistribution $\quad 98$

7 Changing the LANDSCAPE: SOCIETy AND STATUS QUo ACCEPTANCE. 102 7.1 Motivation: changing the strength of the habituation effect . . . 104

7.2 Study design: activating the system justification motivation . . . 106

7.3 Results: activating the system justification motive reduces the partisan gap in inequality ideals . . . . . . . . . . . . . 109

7.4 Conclusion ..................... 114

8 Discussion AND CONCLUSION $\quad 119$

8.1 Limitations . . . . . . . . . . . . . . . . 121

8.2 Implications for interpretations of inequality attitudes . . . . . 122

8.3 Implications for public discourse about income inequality . . . . 123

8.4 Future directions . . . . . . . . . . . . . . . 125 
REFERENCES

128 


\section{List of figures}

5.1 Coefficients for the relationship between inequality perceptions and ideals, ordered by size. . . . . . . . . . . . . 71

5.2 Coefficients for the relationship between inequality perceptions and ideals, by income inequality. . . . . . . . . . . . . 73

5.3 Coefficients for the relationship between inequality perceptions and ideals, by ethnic fractionalization. . . . . . . . . . . 74

5.4 Coefficients for the relationship between inequality perceptions and ideals, by unionization rate. . . . . . . . . . . 75

6.1 Laboratory experiment results: money allocation to the winner by inequality condition. . . . . . . . . . . . . 83

6.2 Laboratory experiment results: money allocation to the winner by inequality and belief in just world. . . . . . . . . 85

6.3 Information treatment in survey experiment. . . . . . . . . 91

6.4 Survey experiment results: recommended inequality by informa-

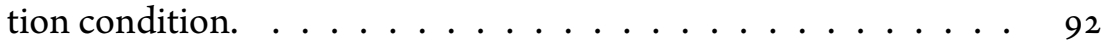

6.5 Survey experiment results: recommended inequality by information condition and belief in just world. . . . . . . . . . 9 95

6.6 Survey experiment results: recommended inequality by information condition and partisanship. . . . . . . . . . . . 96

6.7 Survey experiment results: support for redistribution by partisanship and experimental condition. . . . . . . . . . 100 
7.1 Survey experiment results by belief in just world and system justification manipulation. . . . . . . . . . . . . . 111

7.2 Survey experiment results by partisanship and system justification manipulation. . . . . . . . . . . . . 115 


\section{List of Tables}

5.1 Country-specific regressions predicting respondents' ideal levels of inequality. . . . . . . . . . . . . 66

6.1 Survey experiment results: regression coefficients predicting inequality ideals. . . . . . . . . . . . . . . 93

7.1 Survey experiment results: regression coefficients for the impact of system justification manipulations on inequality preferences. . 110 


\section{Acknowledgments}

THANK YOU TO...

...Nancy Bermeo, for helping me make the leap across the ocean.

...my research assistants, without whom I would not have been able to complete the experiments in this dissertation. Thank you to Ben Brondsky, Teresa Gaille Puguon Teo, Ian Lundberg, Younghoon Moon, Adrian Pforzheimer, Ola Topczewska, Elizabeth Horton and Beverly Duperly-Boos for your dedication, reliability, and for great conversations in the hours inevitably spent waiting for experimental subjects who do not show up.

...the Tobin Foundation, the Center for American Political Studies at Harvard University and the Mind/Brain/Behavior Interfaculty Initiative at Harvard University for generously providing funding for the experiments and research in this dissertation.

...everyone I have met at conferences, workshops and speaker series, everyone who has given me feedback on my ideas and papers, everyone who has encouraged me to keep going and everyone who has pointed out weaknesses in my arguments. You are too many to mention, but without you, this dissertation would have twice the flaws and half the insights.

...my friends and colleagues in graduate school. My fellow graduate students have been a reliable source of encouragement, support, friendship, ideas, criticism, co-authorship and humor. This dissertation would not be the same, or 
perhaps would not be at all, without my wonderful colleagues-turned-friends. In particular, I would like to acknowledge the warm support and friendship of Mai Hassan, Sparsha Saha, Amanda Johnson, Emily Clough, Alisha Holland, Joan Cho, Charlotte Cavaille, Bernard Fraga, Vanessa Williamson, Katie Einstein, Kyle Jaros, Sam Barrows, Jennifer Sheehy-Skeffington, Nour Kteily, Arnold Ho, Sarah Cotterill and Rachel Arnett.

...Ariel Phillips, for helping me hold on to the steering wheel.

...Steve Levitsky and Claudine Gay, for being faculty mentors whose door was always open to me, and whose courses helped me clarify my thoughts and give structure to my questions. Thank you for your guidance and support throughout this project.

...Steve Ansolabehere, for always-straight-to-the-point, invaluable feedback on my writing, for encouraging me to keep up the pace throughout graduate school, and for allowing me to take my own direction through coursework, explore tangential ideas, and pursue research leads in any direction they took me.

...Jim Sidanius, for welcoming me to your lab, making me feel fully part of your small community, and for always being warm, understanding and encouraging. Most of all, thank you for your inimitable ability to deliver important and fundamental criticism in a constructive and friendly manner.

...Ryan Enos, for being my mentor and friend. Your generous open door policy has helped me through more tough graduate school moments than I can count. You have encouraged me to overcome my limitations, trust my instincts, and pursue research that I find worthwhile. Your good example has taught me a lot about the importance of integrity, honesty and priorities - academic and otherwise.

...my parents, Tõnu and Heli Trump, for sacrificing so much to make sure their children got the best chances life has to offer. You gave me a childhood that encouraged my love of books, supported my curiosity to figure out everything about the world, and helped me develop the tenaciousness required to finish a project like this. Gifts like these are invaluable; this dissertation is only a small manifestation of everything you've given me. 
...my sister, Karolin Trump, for unfailing support throughout my life. For all the moments of perspective and comic relief, for always believing in me, and above all, just for being you.

...Thomas Kempa, for being my biggest fan and strongest critic, for pushing me to be a better version of myself and accepting me when I am not, for teaching me what love can mean. 
We must make our choice. We may have democracy, or we may have wealth concentrated in the hands of a few, but we can't have both.

Louis C. Brandeis

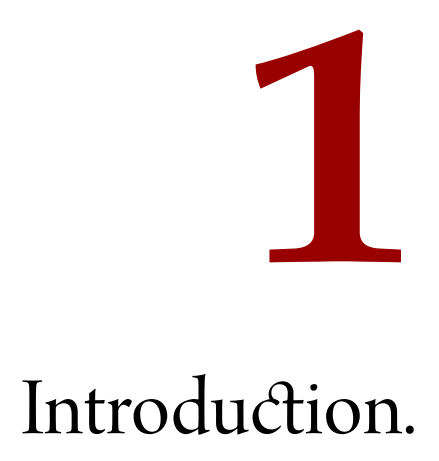

THE STUDY OF ATTITUDES TOWARD ECONOMIC INEQUALITY can be characterized as a study of whether the glass is half full or half empty. ${ }^{1}$ Do the poor and the middle class oppose economic inequality and support redistribution, as we would expect them to if they were acting in their economic

\footnotetext{
${ }^{1}$ The simile is borrowed from Bartels (2008, p.148).
} 
self-interest? Or do the poor and the middle class act against their economic interests by not noticing, not caring about, or caring about something other than economic inequality?

On the one hand, the glass is half-full: the poor tend to be more in favor of redistribution than the rich and they are also more likely to vote for left-wing parties (Gelman et al. 2008, Brooks et al. 2006). On the other hand, the glass is half-empty: inequality does not always produce popular opposition to it, and in fact it is almost never opposed to the extent that we would predict if citizens acted only in their economic self-interest (Ladd and Bowman 1998, Kluegel and Smith 1986, Page and Jacobs 2009). In cross-national comparisons, more unequal countries do not exhibit systematically higher popular opposition to inequality (Alesina and Glaeser 2004, Kenworthy and McCall 2008), and increasing inequality over time in the United States has not systematically resulted in increasing opposition to it ( $\mathrm{McCall} \mathrm{2013}$ ). This is true even though the vast majority of citizens do not benefit from recent increases in income inequality, the gains of which are concentrated at the very top of the income distribution (Atkinson, Piketty and Saez 2011 ). This dissertation is about better understanding why the glass is half empty: why do we not observe more opposition to economic inequality?

We have a strong theoretical reason to expect the glass to be half-full: economic self-interest. In an unequal economy where incomes are skewed toward the top, economic self-interest predicts that the majority of citizens should support the redistribution of income and the flattening of income 
differences (Meltzer and Richard, 1981). It is more challenging to explain why the glass is half-empty. Variables such as political mobilization, awareness of inequalities, racial heterogeneity and electoral institutions are among the 'usual suspects' covered in the literature. This dissertation proposes, without disputing the relevance of other variables, that there is a general human tendency - similar to but in the opposite direction of economic self-interest - that causes humans to interpret economic inequality as deserved and therefore acceptable.

I will argue that the tendency to interpret inequality as deserved exists because attitudes toward economic inequality are subject to status quo bias and the motivation to believe that the world is just. These two psychological tendencies are, as far as we know, universal. I will argue that when we are asked to make normative judgments about economic inequality, these two features of the human mind intersect with notions of 'fair desert' (which are by definition imprecise) and result in interpretations of existing (as well as recently increased or decreased) levels of economic inequality as desirable and just.

The core hypothesis throughout the dissertation is this: as economic inequality changes, estimates of fair and appropriate levels of inequality move in the same direction as the factual change in inequality. I will refer to this as the 'habituation' hypothesis: people habituate to existing inequality by adjusting their expectations for which inequalities are deserved and fair in the applicable direction. ${ }^{2}$ Throughout the dissertation, the term 'inequality' will refer to

\footnotetext{
${ }^{2} \mathrm{~A}$ similar concept, the adaptation hypothesis, has been previously discussed by Listhaug and Aalberg (1999) to describe a phenomenon akin to the one described here, albeit without discussing the possible psychological reasons for it.
} 
economic inequality, and the empirical evidence all refers to (some form of) income inequality. It is possible that the tendencies discussed here also apply to other forms of economic inequality, particularly wealth inequality, but that possibility is not explored here. Thus, my results refer specifically to attitudes toward income differences. Throughout the dissertation, I will refer to 'ideal', 'preferred' and 'fair' inequality as a shorthand to the income differences that are recommended by respondents when they are asked what the income distribution ought to look like.

\subsection{OUtLine OF THE ARgument}

Recent increases in income inequality in the United States as well as other developed nations (Atkinson 2003) have spurred a renewed interest in understanding public attitudes toward income inequality. Increased inequality is frequently thought of as problematic for the quality of the democratic process: American democratic institutions are more responsive to the voices of well-off citizens (Gilens 2012), and it appears that (as might be expected) the policy preferences of the very wealthy diverge in important respects from those of most Americans (Page et al. 2013). More generally, high economic inequality has been linked to numerous important outcomes in the comparative politics literature, including democratic and/or regime instability (Karl 2000, Muller 1995, Acemoglu and Robinson 2006, Boix 2003), reduced public goods provision (Anderson et al. 2004) and increased levels of violence in war (Nepal et al. $2011)$. Some of these proposed outcomes hinge on the population noticing and 
objecting to inequality (e.g. the social unrest hypotheses), others are thought to occur even in the absence of awareness and/or concern from the wider public (e.g. erosion of the democratic process). Regardless of which of these two types of outcome we are looking at, understanding public opinion toward income inequality is one important piece of the puzzle. If the habituation hypothesis is correct, then social unrest hypotheses appear less likely to be true, while concerns regarding the more automatic consequences of inequality appear increasingly pressing. The reasons for studying attitudes toward income inequality, and the connection of this research question to the broader literature on the consequences of economic inequality are the subject matter of Chapter 2.

The third chapter discusses what we know - and do not know - about attitudes toward economic inequality. Studies of American public opinion as well as comparative studies of public attitudes are summarized to flesh out the observation that the 'glass is half-full as well as half-empty'. Between these literatures, there are some strong explanations for why inequality attitudes vary between countries; in particular, racial heterogeneity features prominently as an explanation of the 'half-empty' glass (Gilens 2000, Alesina and Glaeser 2004). However, expectations for how public opinion reacts to changing inequality, holding constant factors like heterogeneity and institutional environment, are not straight-forward to derive from these theories. The habituation hypothesis speaks to static as well as moving levels of inequality, enabling clear predictions for public opinion regarding the increasing levels of inequality experienced by developed nations at the moment. Chapter 3 also highlights that the theme of 
'fair desert' figures prominently both in the American and comparative literatures on attitudes toward income differences; this observation is used to link existing studies of inequality attitudes to the psychological mechanisms that are introduced in Chapter 4.

Status quo bias and the motivation to believe in a just world are previously established concepts, frequently used in social psychology and occasionally incorporated into behavioral economics studies. This dissertation links these two concepts directly to attitudes toward income inequality. Status quo bias refers to the human tendency to prefer the existing state of affairs to hypothetical alternatives; it is an umbrella term for numerous psychological mechanisms including the mere exposure effect, primacy effects and anchoring effects (Eidelman and Crandall, 2009). The belief-in-a-just-world hypothesis states that human beings are motivated to believe that their social environment is, at least to some extent, predictable and fair. When we are faced with evidence to the contrary, we have a subconscious motivation to re-interpret such evidence so that it does not challenge our belief that the world is fair (Lerner and Miller 1978, Jost and Banaji 1994). Chapter 4 links these psychological phenomena to attitudes regarding income inequality.

In addition to summarizing relevant research from social psychology, Chapter 4 presents my hypotheses in more detail. I will argue that when we are faced with information regarding unexpectedly high income inequality in our society, we can conclude either that our social world is more unfair than we previously thought, or that these income differences were probably deserved. Because it is 
psychologically more uncomfortable to think of our social system as unfair than it is to adjust our expectations for what 'deserved' income inequalities look like, we are (subconsciously) motivated to do the latter as opposed to the former. This process is partly enabled by the fact that mapping the concept of 'desert' onto specific numeric estimates of income is an inherently subjective process; there is no single, correct answer to the question of how much more money is 'deserved' by someone who 'works hard'. This malleability of 'desert' estimates is further increased by the fact that in most cases 'hard work' is difficult to observe from a distance: most citizens have no access to detailed accounts of the 'hard work' or 'value added' of, say, CEO's. ${ }^{3}$ Thus, when we receive new information regarding income differences, we are a) motivated to assign the departure from expected levels to something other than systemic unfairness and b) have an alternative adjustment - our expectations for what 'fair desert' entails - readily available. As a result, when a citizen learns that income inequality in their country is higher than they previously thought - either because they were previously misinformed or because income inequality has changed - they adjust their expectations for 'fair' levels of income inequality up. Perceptions of fairness thus move together with (perceived) inequality, and changes in inequality do not directly produce dissatisfaction with it.

In Chapter 5, I present empirical evidence from the International Social Survey Project (ISSP); analysis of 32 countries confirms that individual perceptions

\footnotetext{
${ }^{3}$ This observation is not intended to imply that the 'value added' by CEO's is lower or higher than estimated by most citizens. I am noting that information about this is unavailable, which renders estimates of how hard CEO's work difficult to make, quite regardless of their actual work and value added.
} 
regarding income differences are a strong predictor of ideal income differences.

Having established a correlation between perceived and ideal levels of inequality, Chapter 6 turns to experimental tests of the hypothesized causal direction: that perceptions affect ideals. In one laboratory and one survey experiment, I manipulate (perceptions of) existing income inequality and show that as a consequence, estimates of ideal inequality move in the same direction as the manipulated inequality. In the laboratory experiment, subjects take part in a competition where the inequality of prizes is manipulated. The results demonstrate that the participants' recommendations for appropriate divisions of prize money are affected, in the expected direction, by the division they experience when taking part in the competition. In the survey experiment, participants who receive information regarding the (for most participants, unexpectedly) high levels of income inequality in the United States adjust their estimates of ideal income inequality up, i.e. in the direction of more income inequality. Their attitudes toward the importance of government intervention to reduce income differences, meanwhile, remain unchanged. These results hold for Democrats and Republicans alike. The result is that while partisan differences in endorsements of income inequalities do not change (the opinion 'landscape' remains unchanged), there is an overall upward shift in visions of ideal income inequality.

The mechanisms that lead to the habituation effect are further explored in a follow-up survey experiment, described in Chapter 7. This experiment shows that when the motivation to believe in a just world is experimentally activated, 
preferences for income inequality move in the expected direction: up. Previous studies have shown that the motivation to think of the world as fair is situation-dependent: among individuals who are chronically low on this motivation, it is possible to experimentally activate it. I use two previously validated experimental manipulations of the motivation to believe in a just world in a replication and extension of the survey experiment in Chapter 6. When the motivation to believe that the world is fair is activated, preferences for income inequality are adjusted up; this effect occurs above and beyond the effect of the information treatment. Because individuals who are chronically low on this motivation are more likely to identify as Democrats, this treatment has an interesting impact on the partisan 'landscape' of opinion: in the treatment condition, otherwise robust differences in inequality ideals between Republicans and Democrats are reduced to insignificance. This finding opens up potentially important research questions regarding the impact of the broader political environment on the dynamics of public opinion formation; these research questions are discussed at the end of Chapter 7 and in the concluding Chapter 8. In sum, this dissertation uses pre-existing surveys and original experimental data to argue in favor of the habituation hypothesis: when income inequality changes, estimates of acceptable levels of inequality adjust in the same direction. The existence of habituation can help us understand why 'the glass is half full': why there are fewer demands for redistribution than we would otherwise expect, and why changes in income inequality do not necessarily result in increased opposition to it. The habituation hypothesis is, by definition, one-sided: just as 
the material self-interest hypothesis cannot explain why people accept inequality, the habituation hypothesis cannot explain why people oppose it. Undoubtedly, both acceptance and resistance occur in real-life politics. We know very little, so far, about the social determinants and the situational limits of status quo bias and system justification, the role that the prevalence of 'just desert ideologies' may play in the habituation process, and what happens when economic self-interest conflicts with the habituation process. Future research is necessary to better understand when and how one of the motives outweighs the other. Hopefully, having a systematic, psychologically-founded explanation of why the glass is 'half-empty' will contribute to future research on these important questions. 


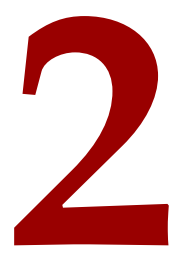

\section{Why Inequality? On the Consequences of Economic Inequality.}

ECONOMIC INEQUALITY IS A CENTRAL FEATURE of societies where an economic surplus is produced. As such, it has been a topic of interest for observers of 
politics at least since Aristotle. In addition to philosophical and empirical debates regarding its inherent (un)desirability, economic inequality has been linked to numerous (desirable as well as undesirable) society-level outcomes. Understanding the consequences of economic inequality involves, among other things, understanding public opinion regarding its legitimacy and desirability. In this chapter, I will discuss the consequences of economic inequality and why, if we care about these consequences, we should care about better understanding public opinion regarding the appropriateness of economic inequality.

Some consequences of economic inequality are predicated on the public perceiving and reacting to economic inequality; examples include social unrest and demands for redistribution. I will start by discussing these consequences, drawing (as I will throughout this literature review) primarily from the comparative politics and American politics literatures. Other potential consequences of economic inequality do not require the wider public to be aware of (or upset by) economic inequality; prominent examples include the erosion of democratic responsiveness and undesirable public health outcomes; these are discussed next in the chapter. Even though these latter consequences may occur without public awareness, fully understanding how these consequences can be prevented or reversed requires a better understanding of how public opinion toward economic inequality is formed. I will conclude this introductory chapter with a brief overview of why the topic of economic (and particularly income) inequality is a relevant topic right now. 


\subsection{THE INHERENT DESIRABILITY AND UNDESIRABILITY OF ECONOMIC}

\section{INEQUALITY}

The research summarized below primarily discusses negative consequences of economic inequality. It is therefore worth pointing out right at the outset that not all economic inequality is necessarily bad, and some is probably desirable. Many of the studies discussed in this chapter have been inspired by the historically high and increasing levels of economic and income inequality currently experienced by wealthy industrialized countries (as well as some of their poorer counterparts). Such queries into the consequences of increasing and/or historically high economic inequality do not imply that the ideal is no inequality at all. Some of the research cited below has been carried out by economists, many of whom are likely to agree with defenses of inequality such as the one put forth by Freeman (2012), who argues that the incentives produced by unequal rewards are an important, indeed crucial, part of human society. That the notion of 'fair inequality' resonates beyond economists can be seen in survey data, where cross-national samples of individuals (in capitalist as well as state socialist economies) tend to agree not only that some income differences are desirable, but are also largely in agreement regarding the 'pecking order' of occupations (Kelley and Evans 1993, Marshall et al. 1999). The same surveys ${ }^{1}$ also show that

\footnotetext{
${ }^{1}$ I am referring here to data from the International Social Survey Project (ISSP), in particular questions regarding appropriate earnings for occupations. In Chapter 5 of this dissertation, I will question just how literally we ought to interpret the answers to questions like the ones referred to here. However, I consider it indisputable that in every country for which ISSP data is available, the population on average thinks that the current level of income inequality in their country is too high.
} 
most people would prefer the income gaps in their country to be smaller than they actually are, which supports the suggestion that when we talk about 'the consequences of economic inequality', due to the historical position we find ourselves in, what we frequently mean is 'the consequences of too much economic inequality'.

In addition to the consequences of economic inequality, discussed below, we may care about economic inequality as a good (or bad) in and of itself. Jones and Klenow (2010), for example, include a measure of economic inequality in their measure of well-being (which is intended to be a complement/alternative to GDP). Inequality is reverse-scored in their proposed measure, indicating that we live in a time where the suggestion that inequality is too high carries more appeal than the suggestion that inequality is too low. Green (2013) argues that paying attention to inequality reduction, and a focus on the 'super-rich' in particular, is no more out of place in a liberal, Rawlsian society than a focus on the least well off. If rising economic inequality is viewed as an inherently negative phenomenon, then understanding how public opinion reacts to this negative development is important for a fuller understanding of democratic dynamics in modern societies. However, the reasons for pursuing a better understanding of public opinion toward economic inequality do not stop at the inherent (un)desirability of inequality; I turn to more instrumental reasons for pursuing this knowledge in the rest of this chapter. 


\subsection{WILL THE POOR SOAK THE RICH?}

As noted by Shapiro (2002), if the poor are to "soak the rich", they need to be aware of and object to economic inequality first. ${ }^{2}$ The hypotheses discussed in this section all share the fact that they depend on some form of awareness of and rebellion against inequality on behalf of the disadvantaged; as such, these hypotheses are all forms of the "the poor will soak the rich" argument.

Already Aristotle expressed the concern that if the poor were to hold political power, they would use it to expropriate the rich. The intuition behind this concern has not become any less relevant with the passage of time: the observation that in an unequal economic system, the poor have a material incentive to demand redistribution of wealth is a common starting point for lay as well as scholarly writings on economic inequality. The precise conditions for such demands, and the form in which the frustration of the poor is expected to manifest itself varies. The arguments below have in common not only the expectation that the poor will reject inequality, but also that they are supported by mixed empirical evidence. Studying how attitudes toward inequality are formed can help us evaluate the plausibility of mechanisms that are expected to link economic inequality to the outcomes discussed below. This, in turn, may help us better understand why the empirical evidence in favor of these hypotheses has so far been inconclusive.

$\operatorname{Marx}(1993[1848])$ expected that, as the gap in the standards of living

\footnotetext{
${ }^{2}$ See also Dahl (1971, p.95)
} 
between the bourgeoisie and the proletariat grew, and as the proletariat became increasingly impoverished, the proletariat would rise up in a revolution and violently claim material resources for themselves. Modern political science no longer conceptualizes inequality as a (sufficient) cause of social revolutions, but the expectation that inequality has a destabilizing effect on political regimes remains relevant in studies of comparative politics.

Muller $(1988,1995)$ observed that there is an inverse cross-national relationship between income inequality and regime stability. He used this observation to argue that income inequality, by virtue of exacerbating conflicts between the poor and the rich, is bad for democratic stability. More recently, high levels of income inequality in Latin America have been linked to the relative instability of democratic regimes in the region (Karl, 2000). In two prominent works, Boix (2003) and Acemoglu and Robinson (2006) also argue that economic inequality (via demands for redistribution by the poor) leads to regime change, although they disagree about the precise functional relationship between the variables. ${ }^{3}$ Empirically, it is as of yet unclear which prediction, if either, is correct and whether inequality is a (necessary or sufficient) cause of political instability. What is clear is that a dissatisfied reaction by the poor is a necessary component of the underlying logic in all the above arguments. Insofar as we don't yet know whether inequality does cause regime instability, understanding the formation of popular reactions to inequality can help us unpack the empirical accuracy of the assumptions behind these causal claims.

\footnotetext{
${ }^{3}$ The debate regarding the empirical predictive ability of these predictions is ongoing; see for example Soifer (2009) who qualifies the argument with state strength as a moderator.
} 
In democratic regimes, short of threatening the stability of the political system, the dissatisfaction of the poor is expected to be translated into votes in favor of redistribution. This expectation has been widely used in formalized form (Meltzer and Richard 1981), but also forms an explicit starting point for qualitative studies into the political attitudes of the poor. Lane (1959) and Hochschild (1981), for example, base their inquiries into why the poor do not object more to their deprived position on the explicit assumption that it would make economic sense for the poor to do so. More recently, debates regarding the voting patterns of the American poor (Frank 2005, Gelman et al. 2008) utilize the same assumption: that the poor should vote in their economic self-interest, and if they do not, this needs to be explained.

As I will discuss in more detail in the chapter on attitudes toward inequality, empirical support for the assumption (or normative expectation) that the poor (should) vote in favor of redistribution is mixed: on the one hand, poor people do vote in favor of more redistribution than the rich, but on the other hand they do not vote for redistribution to the extent that a pure material incentives framework would predict. I will argue that in order to complete the picture and understand endorsement of inequality as well as opposition to it, we need to seriously examine the possibility that humans are predisposed to habituate to economic inequality by (re-)interpreting it as fair and desirable.

In sum, as long as the mechanisms that form political opposition to inequality remain poorly understood, we will not fully understand social outcomes whose occurrence theoretically hinges on popular rejection of inequality. 


\subsection{DOES INEQUALITY HARM THE QUALITY OF DEMOCRACY?}

High economic inequality most likely harms the functioning of democratic institutions - and the existence of this particular consequence of inequality does not hinge on popular opposition to income differences. We know that democratic systems tend to be more responsive to the opinions and preferences of their wealthy citizens. Solt (2008) concludes, based on a cross-national analysis, that "higher levels of income inequality powerfully depress political interest, the frequency of political discussion, and participation in elections among all but the most affluent citizens". In addition, Solt (2010) shows that income inequality in U.S. states is associated with lower turnout and a greater income bias in the electorate. Karabarbounis (2011) uses a panel of OECD countries to show that "when the income of a group of citizens increases, aggregate redistributive policies tilt towards this group's most preferred policies".5 Much of the detailed evidence in support of this argument is based on the United States: Bartels (2008, Ch.9) shows that senators are more responsive to the interests of their wealthier constituents and Gilens (2012) demonstrates that American public policy corresponds to the preferences of the wealthy, and sometimes the middle class, but not the poor - at least not in circumstances when the poor disagree with the wealthy. Based on the best available preliminary evidence (Page et al. 2013), it appears that the super-rich hold preferences that occasionally diverge in important ways from those of the average American

\footnotetext{
${ }^{4}$ Solt (2008, p.48).

${ }^{5}$ Karabarbounis (2011, p.621).
} 
citizen; this makes the observation of disproportionate political influence by the rich particularly consequential for the democratic health of the system.

There is some evidence to suggest that increasing economic inequality in the US is related to the disproportionate political influence of the wealthy. On the encouraging side of the picture, Schlozman et al. (2012) show that while rates of voting, attending meetings and doing campaign work are all related to socio-economic status, these well-known disparities have not increased over the period of increasing economic inequality (from the 1970's to the present). However, there is an enduring and strong association of income with the frequency of campaign contributions: "those in the top quintile are approximately eight times more likely to make a donation to a campaign than those in the bottom quintile" and "it is reasonable to infer that, when it comes to the most expandable and most unequal form of individual political participation, making campaign contributions, inequality has grown over time in a way that is related to the increase in income inequality." ${ }^{6}$ Manza (2012) reaches the same conclusion, pointing out that giving (for all purposes, including political) among the wealthy has increased in the era of rising inequality, and that this has enabled the super-rich to increase their "investment" in politics. ${ }^{7}$ Both Bartels (2008, Ch.9) and Gilens (2012, Ch.8), conclude that the differential responsiveness of elected representatives to the policy preferences of their constituents is consistent with disproportionate campaign donations being the driving factor. These findings are disconcerting in the face of increasing concentration of

${ }^{6}$ Schlozman et al. (2012, pp.174-5).

${ }^{7}$ Manza (2012, pp.148-9). 
economic fortunes in the hands of a few; Gilens concludes that "redressing the imbalance in political influence will be difficult if the trend toward increased economic inequality continues unabated". Perhaps the most resounding conclusion regarding the negative impact of economic inequality on American democracy comes from the 2004 APSA Task Force on Economic Inequality:

Today, however, the voices of American citizens are raised and heard unequally. The privileged participate more than others and are increasingly well organized to press their demands on government. Public officials, in turn, are much more responsive to the privileged than to average citizens and the least affluent. Citizens with low or moderate incomes speak with a whisper that is lost on the ears of inattentive government, while the advantaged roar with a clarity and consistency that policy makers readily heed. The scourge of overt discrimination against African Americans and women has been replaced by a more subtle but still potent threat the growing concentration of the country's wealth and income in the hands of the few. ${ }^{9}$

As political scientists, and as members of a democratic society, it is concerning to note that the quality of democratic processes may be eroding due to increasing economic inequality. If we are interested in stopping this trend, then one possible avenue for reversal would be the mobilization of popular opinion against

${ }^{8}$ Gilens (2012, p.251).

${ }^{9}$ APSA Task Force Report (2004, p.651). 
inequality. This option brings us back to the need to better understand the impact that (information about) economic inequality has on public opinion, and how opinion in favor of either increasing or decreasing economic inequality is formed.

\subsection{OTHER SOCIAL CONSEQUENCES OF ECONOMIC INEQUALITY}

In addition to the challenges that economic inequality poses to political equality, inequality has been linked to a number of other society-level outcomes, described below. Most of these potential consequences of inequality are considered to be undesirable from a social perspective, and because of this, fighting these consequences could benefit from better understanding how attitudes in favor of reducing economic inequality are formed. It should be noted that most of the studies summarized in this section rely on correlations found in cross-sectional data, providing us a glimpse of what unequal countries look like but leaving the direction of causality open for dispute. This limitation of the current state of knowledge is frequently due to the difficulty of acquiring good

over-time data on numerous cross-national variables. However, even if only some of the hypothesized causal effects hold up to scrutiny as better data becomes available in the future, the social implications of the current increases in economic inequality may be considerable.

In terms of its influence on political attitudes, economic inequality has been linked to lower levels of social trust (You 2012), reduced social solidarity and willingness to help others (Paskov and Dewilde 2012), reduced support for secularization of public office holders and more support for the influence of 
religious leaders in politics (Karakoc and Baskan 2012), reduced tolerance of homosexuality (Andersen and Fetner 2008), reduced social affinity across social classes (Lupu and Pontusson 2011) and increased nationalism among the (ethnically divided) poor, resulting in less support for redistribution (Shayo 2009). It is a common assumption among these studies that the experience of being on the 'losing' side of inequality is uncomfortable, and that looking for psychological defenses (e.g. identification with an alternative social group, security derived from religion, reduced reliance on society and more focus on one's ingroup) is the mechanism that links economic inequality to attitude changes.

In addition to attitudinal variables, economic inequality has also been hypothesized to influence non-attitudinal outcomes. For example, economists have studied the relationship of economic growth and economic inequality with mixed results (see Thorbecke 2002, Pontusson 2012, or Voitchovsky 2009 for reviews) and it is as of now unclear what the relationship is and which factors may moderate it. In comparative politics, Nepal et al. (2011) show that inequality is related to increased levels of violence in the Nepali civil war, while Fearon and Laitin (2003) argue that inequality is not related to the likelihood of a civil war breakout. In the American setting, Frank (2007) has argued that rising inequality pushes the middle class into an unaffordable race for positional goods by shifting the frame of reference that defines consumption standards (see also Frank et al. 2011).

The debate concerning the impact of economic inequality on public health has 
recently caught the public eye and has become one of the most well-known academic debates about inequality outside the realm of academic commentary. Due to its public prominence, this argument is worth addressing separately. Wilkinson and Pickett (2010) have, with their best-selling book The Spirit Level, popularized the notion that high economic inequality is related to a series of negative public health outcomes, including life expectancy, infant and maternal mortality, mental health and obesity. Their assertions rely on their own data analysis as well as other academic studies that support this notion. For example, Galea et al. (2011) find that income inequality is linked to increased mortality rates, Kennedy et al. (1998) show that there is an association of state income inequality with poor health outcomes on the individual level, and Kahn et al. (2000) find that inequality is associated with worse health outcomes for poor mothers. However, Deaton and Lubitsky $(2003,2009)$ argue that the relationship of economic inequality and public health is spurious and, in the context of U.S. states, disappears when controlling for proportion black in the population. While Subramanian and Kawachi (2003) include state proportion black and still find a relationship between income inequality and health outcomes in the U.S., Beckfield (2004) uses a large cross-national sample and finds no connection between population health and income inequality once country fixed-effects are included. Mellor and Milyo (2002) control for individual- as well as regional-level characteristics and find no relationship between health status and income inequality in the United States. Careful reviews (see Neckerman and Torche 2007, Kawachi and Kennedy 2003 and Leigh et al. 2011) conclude that 
there is currently no solid evidence that inequality itself affects health outcomes.

Leigh et al. (2011) suggest that while current evidence for a link is weak and inconsistent, firm conclusions will have to wait for "more work with better data and better methods." ${ }^{\prime 10}$ In other words, while we know that social status (and, of course, poverty), affect individual health, ${ }^{11}$ the jury is still out on the relationship between economic inequality and public health.

\subsection{WHY NOW?}

Inequality may have been of interest to observers of politics since the time of Aristotle, but the wealth of recent studies about its impact (and just as broad a literature, not reviewed here, on its origins) ${ }^{12}$ is inspired by a distinctly modern development: the increase in income inequality in developed countries since the 1970's. Starting after the $1969-70$ recession, top incomes in the US have increased together with the share of incomes captured by the top of the distribution (Gottschalk and Danziger, 1995, Ch.4). This pattern holds up with several different operationalizations of income (Brandolini 2010). Similar changes have been documented across English-speaking countries (Piketty and Saez 2006), and more recently also in parts of continental Europe (Smeeding 2005). Top income shares have also increased in welfare states like Norway

\footnotetext{
${ }^{10}$ Leigh et al. (2009, p.400).

${ }^{11}$ For example, Falk et al. (2011) show that experiencing an unfair payment has adverse cardiovascular consequences. Mendelson et al (2008) show that being assigned to a low status condition has a negative impact on stress-related physiological systems. Kondo et al (2008) find that relative deprivation among Japanese adults is associated with poor self-rated health.

${ }^{12}$ For reviews on the origins of the increase in economic inequality, see Mahler (2004), Stepan and Linz (2011) and Hacker and Pierson (2010).
} 
(Atkinson 2003) and, if capital gains are included in the definition of income, the experience of Sweden looks similar to that of the US and the UK (Roine and Walderstrom 2006).

The increase in top incomes has not been a case of "lifting all boats" with the rising tide. In the United States, where most of the income growth has been captured by the top 1 percent (Atkinson, Piketty and Saez 2011 ), there has been little trickle-down of wealth, leading commentators to name this phenomenon “winner-take-all inequality” (Hacker and Pierson 2010, Ayres 2004). Inequality has also been increasing within U.S. states (McNichol et al. 2012), and while adjusting for post-transfer incomes and household size ameliorates the size of the changes, income inequality has still increased even after these adjustments (Burkhauser 2011), as has consumption inequality (Attanasio 2009, 2012). Finally, increasing inequality in the United States has not been offset by increases in social mobility (Bradbury and Katz 2002).

Today, the United States is one of the most unequal rich- and middle-income countries, with unusually high levels of CEO pay (McCall and Percheski 2010). This makes the question of public reactions to and the consequences of income inequality particularly pressing for the United States. However, as summarized above, these questions are not by any means uniquely applicable to the experience of the United States. Income inequality is increasing in many developed countries, as it has since the 1970 's in the United States, and this fact gives increased urgency to research questions aimed at understanding public reactions to, and habituation with, these new levels of income inequality. 


\subsection{CONCLUSION: THE IMPORTANCE OF UNDERSTANDING ATTITUDES} TOWARD INEQUALITY

Our understanding of the consequences of economic inequality is, as of now, still inconclusive with respect to several important variables. Understanding popular reactions to (increases) in economic inequality is important not just in its own right but also in order to shed more light on the psychological mechanisms through which economic inequality is expected to change society. Even when the potential consequences of inequality are not themselves dependent on changes in public opinion, such changes may be required to slow or reverse the increase of inequality and/or the negative consequences it may bring. Improving our understanding of beliefs regarding the acceptability of inequality is the next step in research into the political fall-out of increasing inequality. In the words of Kaufman (2009), "the divergent claims about the effects of economic inequality indicate that we still have a way to go if we are to understand how, or whether, it matters politically. Moving forward will require a closer examination of the social-psychological foundations of beliefs about inequality and the way these articulate with the broader social and political environment." ${ }^{13}$ The next chapter will introduce the examination of social-psychological foundations of beliefs about inequality by summarizing what is (and is not) currently known about the formation of these attitudes.

\footnotetext{
${ }^{13} \operatorname{Kaufman}(2009$, p.657).
} 


\section{3 \\ Attitudes toward economic inequality: \\ what do we know?}

IN MODERN SOCIETIES, the poor and the middle class tend to be more in favor of redistribution than the rich, but there also tends to be substantial agreement 
regarding the fairness of at least some income inequalities. This chapter summarizes current explanations for the existence of opposition to and acceptance of income inequalities, again drawing primarily on comparative and American politics literatures. I will argue that, as of now, we have an incomplete understanding of the formation of preferences in favor of inequality, and that while the existence of a habituation mechanism (whereby individuals habituate to existing income inequality by adjusting their preferences for inequality) has been previously discussed, we do not have systematic tests of this hypothesis nor is there a rigorous theoretical explanation for why we should expect habituation to occur.

The literature on attitudes toward economic inequality is here divided into three sections: comparative work on attitudes toward redistribution, the literature on American attitudes toward economic inequality and redistribution, and comparative work on attitudes toward income inequality. Each of these literatures has somewhat different objectives and methods, but they share the aim of better understanding public opinion regarding fairness in questions of income, taxation, and redistribution. The notion that the glass of popular resistance to inequality is half-full (objections to inequality are common) and half-empty (acceptance of inequality is also common) is clear both in a cross-national and a U.S. perspective. The habituation hypothesis provides a psychologically founded, universal explanation for the 'half-empty glass' and explains why changes in income inequalities, ceteris paribus, do not systematically lead to increased objections to inequality. 
The chapter starts with an overview of comparative research on attitudes toward redistribution, followed by American attitudes toward redistribution and then comparative research on attitudes toward income inequalities. In the first two sections, redistributive preferences will be treated as a straight-forward extension of economic self-interest and as a subset of the broader category "attitudes toward economic inequality". The third section addresses what we know about attitudes toward income inequality specifically, as distinct from attitudes toward government redistribution.

To foreshadow the argument of this chapter, it is a robust cross-national finding that class membership is linked to redistributive preferences. However, national indicators of income inequality are at best imperfectly linked to cross-national variation in demands for redistribution, and changes in income inequality do not systematically predict redistributive demands. The literature on American attitudes toward inequality and redistribution echoes this finding: Americans are, to some extent, concerned about too high inequality, but recent increases in inequality have not resulted in higher levels of dissatisfaction. In both cases, we find rates of inequality acceptance that are not explained by material self-interest, and that we currently don't have a single, psychologically informed explanation for.

Both comparative and American politics writings point to perceptions of 'fair desert' as an important variable that determines opposition to and acceptance of inequality. But how are perceptions of how much inequality is 'deserved' and how much inequality is too much (or too little) formed? The comparative 
literature on attitudes toward income differences looks at this question and arrives at a surprising conclusion: perceptions of how large income differences are 'deserved' are strongly related to perceptions of how large income differences really are. In addition, in post-Communist countries, where income inequalities rapidly increased during the transformation to capitalist market economies, perceptions of income inequalities increased, and perceptions of how large income differences are 'deserved' increased also: perceptions of reality and concepts of the ideal were changing together. These observations have led some commentators to suggest that popular opinion regarding the acceptability of specific income differences 'habituates' to existing levels of income inequality. However, so far we do not have a strong theoretical explanation of why we would expect a habituation effect to occur. This observation is a prelude to the discussion, in Chapter 5, of how human psychology, the status quo, and perceptions of desert interact to produce the habituation effect.

\subsection{ATTITUDES TOWARD REDISTRIBUTION IN COMPARATIVE PERSPEC- TIVE}

The comparative study of preferences for redistribution has been strongly influenced by the material self-interest hypothesis, or in other words, the expectation that people should demand redistribution when it is in their economic self-interest to do so. Empirical evidence in favor of this interpretation is mixed; the poor in most countries do support more inequality than the wealthy, but there are also broadly accepted economic inequalities everywhere. 
Numerous confounding variables, which are thought to interfere with the otherwise-expected manifestations of material self-interest, have been proposed in the literature; among them (and highlighted below) are hypotheses about habituation and just world beliefs.

The material self-interest hypothesis predicts that those who stand to benefit from income redistribution should support it: in modern societies, the median earner has a below-mean income, and should therefore support redistribution (Meltzer and Richard 1981). Cross-nationally, there are persistent class-based voting cleavages (Brooks et al. 2006) and redistributive preferences systematically vary by social class (Svallfors 1997). However, nowhere do below-mean earners prefer the total leveling of incomes in the way that a literal interpretation of the Meltzer-Richard hypothesis would predict. Instead of pursuing a literal interpretation of the hypothesis that predicts preferences for fully leveling of incomes, it is more common to acknowledge that several other factors also influence preferences for redistribution, and to re-interpret the material self-interest hypothesis in light of this. This common (re-)interpretation of material self-interest predicts that, ceteris paribus, times and places with higher income inequality should exhibit higher demands for (and therefore higher levels of) redistribution (Kelly and Enns 2010, Milanovic 2000, Finseraas 2009, Kenworthy and McCall 2008).

Empirical support for the latter, over-time hypothesis is mixed. On the confirmatory side, Milanovic (2000) analyzes redistributive preferences in developed countries and finds that the median voter is responsive to inequality in 
the expected direction (higher inequality correlates with more support for redistribution). Dallinger (2010) also finds that inequality increases demand for redistribution, but only when GDP is held constant, and Finseraas (2009) performs a multi-level hierarchical analysis with cross-national data, also finding a positive relationship between inequality and the median voter's support for redistribution. However, Kenworthy and McCall (2008) find no relationship between inequality and support for redistribution across eight industrialized countries and a 20 year period. Alesina and Glaeser (2004) argue that in a comparison of wealthy countries, more unequal countries tend to exhibit less demand for redistribution. Turning to over-time analyses, Kelly and Enns (2010) argue that in the US, increasing inequality has decreased support for redistribution, and Georgiadis and Manning (2012) find a similar pattern in the UK. Further complicating the picture, Dion and Birchfield (2010) argue that in countries with low levels of economic development or high levels of income inequality, individual-level income does not systematically explain support for redistribution.

Overall, then, there is substantially less redistribution than a pure material self-interest motive would predict, and demand for redistribution is at best imperfectly linked to changes in inequality across times and places. Given this mixed picture, there is a substantial literature that asks: why is there not more demand for inequality? Much of this literature can be thought of as a search for confounding variables to the material interest expectation: it is assumed that were it not for some other, intervening variable then material self-interest would 
produce the expected attitudinal outcomes. The number of confounders that have been suggested and/or shown to exist is remarkable, testifying to the enduring strength of the question: why do people not react more strongly against inequality? Most of these confounding variables are not the primary object of study in this dissertation, but they are relevant to the issue at hand because they directly explain aspects of why 'the glass is half-empty'. Proposed variables that influence (electoral) opposition to inequality include: electoral institutions (Iversen and Soskice 2006), elite discourse (Wegner and Pellicer 2011), the skew of the income distribution (Lupu and Pontusson 2011), racial heterogeneity (Alesina and Glaeser 2004, Gilens 2000), unionization rates (Rueda and Pontusson 2000), culture (Luttmer and Singhal 2008), welfare regime type (Svallfors 1997), religiosity (Scheve and Stasavage 2006), (perceptions of) the possibility of upward mobility (Benabou and Ok 2001 , Benabou and Tirole 2006, Piketty 1995, McCall 2008, Lu 2010) and trust in government capability (Mares 2005) among others. In this dissertation, I argue that there exists a human tendency to interpret existing inequality as acceptable and that this tendency can help us explain why there is less opposition to inequality than we would otherwise expect. I emphasize here that this hypothesis is intended as a complement, not a direct challenge, to the variables listed above, as each of the hypothesized variables may very well have independent effects on preferences for inequality and redistribution.

One significant variable not mentioned in the list above is the concept of desert: the belief that income differences are 'fair and deserved' may interfere 
with the formation of redistributive demands. For example, society-level variations in perceptions of the role of luck vs. hard work have been hypothesized to affect differences in redistributive equilibria between the United States and European countries (Alesina and Angeletos 2002). Georgiadis and Manning (2012) find that inequality itself does not impact support for redistribution, but one of the variables that does is other-regarding preferences, for example feeling that others live in need due to injustice. Perceptions of 'fair desert' are thus thought to influence preferences for redistribution: when income differences are perceived to be disproportionate to desert, it is expected that demands for redistribution are formed, whereas popular opinion would hesitate to request redistribution of 'earned rewards'. But how does the public form opinions on how large income differences are 'earned' and 'fair', and which income differences are unacceptably low or high? The comparative literature on preferred income differences suggests that these estimates of ideal incomes are significantly influenced by (perceptions of) existing income inequality. Before addressing that literature, however, the next section gives an overview of American attitudes toward inequality, where the themes of material self-interest and perceptions of desert are every bit as relevant as they are in the comparative literature.

\subsection{AMERICAN ATTITUDES TOWARD ECONOMIC INEQUALITY AND RE- DISTRIBUTION}

It is popular to paint a picture of Americans as uniquely accepting of economic inequalities and opposed to income redistribution. This comparison underlies 
the approach of Alesina and Glaeser (2004) and is echoed by Jacobs and Skocpol (2005) who write that "Americans are much more likely than Europeans to accept substantial disparities of income and wealth. In the United States, unequal outcomes are seen as largely reflecting differences among individuals rather than flaws in the economic system." At the same time, other commentators argue that Americans are not particularly exceptional in their preferences for inequality (Osberg and Smeeding 2006). While studies of American attitudes toward inequality have reached various conclusions, there is at least some broad agreement that Americans' attitudes toward inequality and redistribution are mixed (see e.g. Page and Jacobs 2009 or Kluegel and Smith 1986). Paralleling the findings from comparative studies of inequality attitudes, in America there is more popular acceptance of economic inequality than material self-interest would predict, and dissatisfaction with inequality has not increased in tandem with increases in de facto inequality since the 1970's (McCall 2013).

Since American attitudes toward economic inequality and government redistribution are mixed, Americans have been described as "ambivalent egalitarians" (Schlozman et al. 2012, Ch. 2), or else "conservative egalitarians" (Page and Jacobs, 2009). It was with respect to American opinion about inequality that Bartels (2008) remarked that "it is easy to disagree about whether the glass is half full or half empty", ${ }^{2}$ an observation that I have used in dissertation with respect to opinion regarding inequality more generally. On the one hand, there is widespread dissatisfaction with inequality in America: Page and Jacobs

${ }^{1}$ Jacobs and Skocpol (2005, p.7).

${ }^{2}$ Bartels (2008, p.148). 
(2009, p.40-41) find that $72 \%$ of Americans, including a majority of Republicans, agree that "differences in income in America are too large", and 68\% reject the notion that the current distribution of money is "fair"; this pattern has been evident since the mid-1980's. Poor Americans are more likely to vote for left-wing parties and to vote based on economic issues (Bartels 2008, Gelman et al. 2008), and most Americans would prefer the wealth distribution to be more equal than it is (Norton and Ariely 2010).

On the other hand, substantial endorsements of the economic status quo can also be found in American public opinion. There is the by-now familiar observation that not all poor- and middle class respondents support (full or partial) redistribution of incomes, and that the economic self-interest hypothesis therefore needs complementing in order to explain the remaining variation in redistributive opinion. Ladd and Bowman (1998) conclude their comprehensive survey of public opinion on economic inequality with the observation that while most Americans consider themselves middle class, exhibit suspicion toward the rich and feel some unease with inequality, they also oppose redistribution of wealth. According to Kluegel and Smith (1986), a majority (52\%) of Americans endorse "about the present level of income inequality" 3 while Page and Jacobs (2009) find that most Americans reject the notion that the government should narrow the gap between the rich and the poor. ${ }^{4}$

Several of the most common explanations for this dualism in American attitudes toward inequality were already mentioned among the explanations for

${ }^{3}$ Kluegel and Smith (1986, pp.112-3).

${ }^{4}$ Page and Jacobs (2009, p.54). 
comparative differences in attitudes. For example, racial heterogeneity combined with the (perception of) the minority group being disproportionately poor can reduce support for redistribution (Alesina and Glaeser 2004, Gilens 2000). Variables such as electoral institutions (Iversen and Soskice 2006) and religiosity (Scheve and Stasavage 2006) also apply to the US as much as other cases in comparative perspective. In addition to these variables, a prominent 'suspect' for the lack of stronger redistributive demands in the US is a lack of public awareness about economic inequality.

Is it possible that ignorance of true levels of inequality is responsible for American acceptance of existing inequalities? The claim that Americans are unaware of the extent of inequality in their country is well supported. Norton and Ariely (2010) directly show that Americans underestimate wealth inequality even as they believe there is too much of it. Bartels (2008, Ch.5) argues that while Americans survey respondents say that they believe inequality has risen in the last 20 years, this apparent knowledge reflects folk wisdom rather than genuine awareness. Survey data used in Chapters 5 and 6 of this dissertation also confirms that most Americans underestimate occupational income inequality. However, there is some amount of signal hidden in the noise of folk wisdom. $\mathrm{Xu}$ and Garand (2010) find that people who reside in more unequal US states are more likely to perceive large increases in income inequality over the last 20 years, and those from lower income strata are more likely to translate state income inequality into inequality perceptions. McCall (2013) shows that in 2010, Americans' estimates of the amount of money earned by CEO's increased sharply 
as compared to 2008 , indicating some awareness of increasing top incomes. It is unclear whether this rise makes up for the comparative lack of accurate perceptions regarding CEO pay that Osberg and Smeeding (2006) document when they compare the US to other developed nations, but the trend in perceptions is in the correct direction. I will return to the question of awareness of occupational income inequalities, in the United States and other countries, in Chapter 5 below. But, even if we allow for the fact that American respondents underestimate the true extent of income inequality, the more relevant question is whether higher awareness would result in increased objections to inequality. The habituation hypothesis suggests that this is not necessarily the case; in fact, the opposite may occur, and higher awareness of inequality could result in upward revision of preferences for inequality. Accurate knowledge regarding inequality, in other words, may be scarce, but even when it is available, the consequences for public opinion do not necessarily imply increased redistributive demand.

In a final echo of the comparative literature, beliefs in fair desert and equality of opportunity (frequently used in the comparative literature to explain the outlier status of the U.S. in terms of levels of redistribution) are commonly used in the American politics literature to explain why Americans do not object more to economic inequality. Lane (1959) emphasizes the importance of beliefs in opportunity and the accompanying perception of economic differences as deserved in the political thought of working class Americans. Hochschild (1981) argues that for Americans, the notion of earned - and therefore deserved differences in economic rewards make notions of economic inequality more 
acceptable than notions of social and/or political inequality. The themes of desert are also used in later, quantitative studies on inequality attitudes: both Page and Jacobs (2009) and Kluegel and Smith (1986) remark that Americans agree with the statement that opportunity is available to everyone in America, and that beliefs in opportunity lead to perceptions of income differences as 'deserved'. However, the evaluation of which inequalities are deserved, and which are not, is an imperfect calculation at best: how do citizens come to judgments regarding incomes that they are prepared to accept as deserved, and incomes that they deem too low or too high? The comparative literature on attitudes toward income differences has looked precisely at this question.

\subsection{COMPARATIVE ATTITUDES TOWARD INCOME INEQUALITY}

Making judgments about fair desert in incomes is an inherently imprecise activity: information regarding variables like 'hard work', 'talent' and 'value added' is hard to quantify and observe. Cross-national surveys show that most people, in state socialist as well as market capitalist societies, agree that at least some income inequality is desirable and suggest a very similar hierarchical ordering of occupations by suggested income (Kelley and Evans 1993). The best predictor for the precise income differences that are suggested by respondents as ideal is their perception of existing income differences (Gijsberts 2002, Kelley and Zagorski 2004, Austen 2002). If we accept that perceptions of whether income inequalities are 'deserved' and 'fair' impact redistributive demand, then

\footnotetext{
${ }^{5}$ Page and Jacobs (2009, p.51), Kluegel and Smith (1986, p.77).
} 
factual inequality itself may attenuate redistributive demands, provided that the population to some degree perceives income inequalities and these perceptions influence preferences for inequality. The studies surveyed in this section suggest that this causal chain is a plausible interpretation of the data.

The literature on comparative attitudes toward inequality of incomes is not as cohesive or well-developed as the literature on redistributive attitudes, and the data it can draw on is more sparse. Nonetheless, there is an identifiable literature on perceptions of income differences and preferences for them, in which most studies rely on data from the International Social Survey Project (ISSP). Here, as in the broader redistributive attitudes literature, perceptions of fairness loom large as an explanatory factor, but so does another interesting variable: perceptions of income differences, which have repeatedly been shown to predict preferences for income differences.

The Social Inequality Module, fielded regularly by the ISSP, asks questions regarding the respondent's perception of occupational income inequality and their preference for ideal levels of occupational income inequality; both are probed by asking the respondent to give estimates of and preferences for ideal incomes in a list of occupations. The most frequent use of the occupational inequality questions is through the construction of a justice index (formalized in Jasso 1999) by capturing the relationship of perceptions to ideals as a log ratio (ln(income of high prestige occupations / income of low prestige occupations). This formulation, or some modification thereof, has been used in numerous 
studies $^{6}$ to estimate the relationship between perceptions of income inequality and ideal levels of income inequality, as well as to analyze over-time changes in desired levels of inequality.

Given that the ISSP Social Inequality module was fielded in 1987 and 1992, and that the sampled countries included communist as well as capitalist countries, it was possible to carry out studies that tracked attitudes toward income inequality as formerly Communist countries transitioned to capitalist systems and experienced rapid increases in income inequality (Heyns 2005). Gijsberts (2002) looks at ideal levels of income inequality between 1987-1992 and finds that ideal income differences increased in both capitalist and post-communist countries, but the increase was particularly marked in post-communist economies. Kelley and Zagorski (2004) also find that transitions from communism to capitalism result in higher ideal levels of income inequality. These patterns of changing preferences are not well explained by demographic variables in either communist/post-communist or capitalist countries, ${ }^{7}$ but are very well predicted by (also increasing) perceptions of income inequality (Gijsberts 2000, Austen 2002, Kelley and Zagorski 2004). Kelley and Zagorski (2004) hypothesize that the new, higher income differences are perceived by the population and accepted as legitimate because they are ascribed

\footnotetext{
${ }^{6}$ See for example Austen 2002, Gijsberts 2002, Hadler 2005, Kelley and Evans 1993, Kelley and Zagorski 2004, Kenworthy and McCall 2008, Osberg and Smeeding 2006, and Verwiebe and Wegener 2000.

${ }^{7}$ Demographic variables do predict variation in occupation-specific estimates; for example, high socio-economic status predicts preferring higher pay as ideal for top earners (Kelley and Evans, 1993). However, demographic variables do not predict the ideal level of income inequality particularly well (analysis in Chapter 5 of this dissertation).
} 
to outcomes of productivity and/or effort. Osberg and Smeeding (2006) confirm that there is a strong correlation between the 'perceived' and the 'preferred' measures when a Gini index operationalization is used instead of the Jasso (1999) justice index measure.

Even as inequality ideals have risen alongside perceptions of inequality, it is unclear how these changes relate to popular (dis)approval of the new levels of inequality and to demands for redistribution. Loveless and Whitefield (2011) find that even though inequality increased in new Central-European democracies, attitudes on whether there is too much social inequality were not affected by indices of actual inequality. In Estonia between 1991 and 2004, for example, agreement with the statement "income differences are too large" did not change despite increasing income inequality (Saar 2008). It does appear that the gap between ideal and perceived levels of inequality widened during this period (Verwiebe and Wegener 2000, Jasso 2000), and in overall preferences, post-Communist countries remained more egalitarian than capitalist countries (Kelley and Evans 1993) but these changes have not substantially changed the strong predictive ability of inequality perceptions on ideals.

The predictive relationship between perceptions and preferences is also found in cross-national comparisons that do not focus on the post-Communist experience, including analyses of the United States (Osberg and Smeeding 2006, Svallfors 1993). In comparative perspective, Americans do not stand out as preferring exceptionally high levels of inequality, but they are also particularly likely to underestimate the level of CEO pay in their country (Osberg and 
Smeeding 2006). ${ }^{8}$ Subjective perceptions of inequality in the United States are therefore somewhat below the average of all countries, and in preferred inequality, the United States is in the middle. Evans and Kelley (2007) use an alternative specification (they use a question on ideal earnings for people in the respondent's own occupation) and confirm that Americans prefer somewhat more inequality than other nations but are not exceptional. If the adjustment hypothesis is true and the public rationalizes perceived income differences, then improving Americans' inaccurate perceptions of income inequality may push American preferences for inequality up, making them appear more exceptional in comparative perspective.

While the relationship between perceptions and ideals in occupational income inequality has been well documented, this literature has not proposed strong psychologically or politically grounded theories as to why this pattern occurs. Listhaug and Aalberg (1999) suggest the "adjustment hypothesis" that individuals acclimate to changing inequality, and Kelley and Zagorski (2004) suggest that perceptions of fairness may be involved in the adjustment process, but no direct tests of these hypotheses have been carried out to date. While the post-Communist experience suggests that the causality behind this correlation may run from perceptions to preferences, survey data cannot answer this question definitively. What these data can tell us is that perceptions and ideals of

\footnotetext{
${ }^{8} \mathrm{McCall}$ (2013) shows that in 2010, when these questions were asked in the United States as part of the General Social Survey, perceptions of CEO pay had increased markedly from the previous survey wave in 2008; it is unclear whether this increase has kept pace with the actual increases in CEO pay during this period or whether Americans are still comparatively likely to underestimate $\mathrm{CEO}$ pay.
} 
income inequality move together, and that these changes are not systematically linked to perceptions that inequality is “too high”. In the next chapters, I will specify and test the habituation hypothesis, derived from these observations.

\subsection{CONCLUSION}

There is an elegant and straight-forward theoretical reason to expect individuals to support redistribution: we expect human beings to act according to their material self-interest. This expectation is partly confirmed in comparative and U.S. focused research on public opinion. At the same time, popular demands for redistribution are less intense than we would expect if material self-interest were the only motive at work. While numerous confounding variables have been proposed to account for this 'shortfall' in redistributive demand, we do not have a straight-forward, human-nature type explanation that could serve as a complementary and opposite hypothesis to the material self-interest hypothesis (although we do know that perceptions of 'fair desert' are implicated in the lack of redistributive demands).

Comparative studies of attitudes toward income inequality ask what variables influence popular notions of 'deserved' income differences, and consistently conclude that perceptions of income inequality are strongly predictive of inequality ideals. These studies have also shown that when income inequality dramatically increases, perceptions and preferences both move in the direction of higher inequality. These observations are strongly suggestive of a habituation hypothesis: individuals habituate to changes in inequality by adjusting their 
expectations for what 'fair desert' involves and as a consequence, any changes in redistributive demands that might otherwise be expected are muted.

Why is it plausible to think that human beings systematically habituate to inequality instead of rejecting it? In the next chapter, I will turn to social psychology to expand the argument of habituation and specify my hypotheses. 


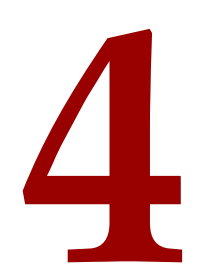

\section{The psychology of the status quo and income inequality.}

The hyPothesis THAT PEOPLE ADJUST to income differences, and that increasing income differences may push perceptions of acceptable income 
differences up, is supported by features of human psychology, primarily status quo bias and the motivation to believe in a just world. This chapter covers social psychological research on these two features of the human mind, and uses this research to create a psychologically informed, theoretically sound background to the habituation hypothesis. The habituation hypothesis, as well as two follow-up hypotheses on individual variation and the role of political context are derived in this chapter and empirically tested in the following three chapters.

\subsection{ThINKING ABOUT INCOME DIFFERENCES}

Desert, fair earnings, and appropriate rewards for hard work are recurring concepts in studies of public opinion about income inequality. The notion that hard work deserves to be rewarded are widely shared across different cultures and economic systems (Kelley and Evans 1993, Marshall et al. 1999). Beyond the initial agreement that some level of inequality is desirable, there are significant cross-national and individual-level differences in reported ideal levels of income inequality (Osberg and Smeeding, 2006). This raises the question: how do individuals move from the abstract notion of desert to an evaluation of the appropriateness of specific incomes, and of specific income differences? The notion of 'desert' is a fundamentally imprecise tool for making decisions about numeric rewards for complicated tasks in complicated economic environments. We may all agree that a doctor should earn more than an unskilled factory worker (Verba and Orren 1985, Kelley and Evans 1993), but how many times more? If we suspect that, as the literature on the importance of 'desert' perceptions in the 
formation of redistributive attitudes suggests, demands for redistribution are more likely to occur when income differences are deemed too large to be deserved, it becomes politically very relevant to know how individuals arrive at evaluations of incomes as 'deserved' or 'not deserved'.

In cross-national survey data, the strongest predictor of ideal income differences is perceived income differences. This suggests that existing (or perceived) income inequality may influence estimates of fairness. The imprecise nature of concepts of desert does not, by itself, produce this effect of the (perceived) status quo: the imprecision of estimates based on desert could, ceteris paribus, result in a high degree of variation in desert estimates between individuals, but does not imply that such estimates should be systematically influenced by perceptions of inequality. However, once we take features of human psychology into account, the plausibility of status quo influence on preferences for inequality becomes clear. Status quo bias states that human estimates for the 'good' or 'preferred' state of the world are systematically biased toward the existing state of the world. Belief in just world theory, further, states that humans are motivated to hold on to their belief that the social system is fair, and in order to maintain this belief they are prone to adjusting other beliefs - in this case, perceptions of the deservedness of income differences. Together, status quo bias and belief in just world theory predict the observed correlation between perceived and ideal income differences. 


\subsection{STATUS QUO BIAS}

Status quo bias is an umbrella term that covers numerous cognitive and motivational mechanisms, all of which pre-dispose individuals to prefer existing items and social arrangements (the status quo) over hypothetical alternatives. Eidelman and Crandall (2009) summarize status quo bias as the observation that "the legitimate consideration and endorsement of alternatives may require more effort, control, awareness, or intention than does supporting the status quo" and that "status quo maintenance is more ubiquitous and subtle than often believed." Below, I describe this phenomenon in more detail and apply it to preferences for income differences.

The cognitive reasons for a psychological advantage for the status quo are numerous, and only a subset of them is covered here. Samuelson and Zeckhauser (1988) show that describing one set of choices (for example, a choice between investment portfolios) as the status quo makes individuals more likely to select the alternative that is described as the status quo. The mere exposure effect (Zajonc 1968) states that brief exposures to neutral stimuli (such as photos of individual faces) causes individuals to later rate these now-familiar stimuli more favorably than new stimuli. Assuming that individuals are exposed to existing social arrangements more often than hypothetical alternatives, the mere exposure effect serves to enhance status quo bias. Primacy effects (Asch 1946, Anderson

\footnotetext{
${ }^{1}$ Eidelman and Crandall (2009, Ch.4, p.85). This chapter provides an overview of the various
} mechanisms at work in producing status quo bias; the information in this paragraph and the next is based on their summary. 
1996) occur because information that is received and processed first has an advantage over subsequent information. Because existing arrangements are typically processed before hypothetical alternatives are considered, this phenomenon also results in a status quo advantage. Loss aversion (Kahneman and Tversky 1979) can be thought of as another potential source of status quo bias, as it increases individuals' probability, under specific circumstances, of choosing the safe status quo over a riskier alternative. Finally, the anchoring effect (Tversky and Kahneman 1974) contributes to status quo bias. Due to the anchoring effect, which is particularly prominent in unit-based estimation, "people insufficiently adjust from that which is mentally accessible." An example is provided by LeBoeuf and Shafir (2009), who show that "when people generate unit-based estimates of uncertain dates or distances, they may anchor on the 'here' or 'now' and adjust incrementally by the unit; such adjustment, however, is often insufficient and yields systematic underestimation."3 Estimates of income are, of course, unit-based in currency and therefore likely candidates for anchoring effects in the here and now (i.e. in perceptions of existing inequality).

Usually, status quo bias is expected to be neutral with respect to content, but it is possible that this neutrality is undermined by the fact that certain types of stimuli are processed more easily than others. Zitek and Tiedens (2011) show that information regarding social hierarchies is processed more easily than other types of social information, and that this information comes to be evaluated more positively as a result of the faster processing. To the extent that income

${ }^{2}$ Eidelman and Crandall (2009, p.88).

${ }^{3}$ LeBoeuf and Shafir (2009, p.81). 
differences provide information about social hierarchies, they may therefore enjoy an added boost to their status quo advantage.

Status quo bias thus predicts that comparisons of real and hypothetical alternatives start with an appraisal of the status quo, from which we then (insufficiently) adjust toward our preferred states of the world. Because of status quo bias, our preferences for ideal states of the world are systematically influenced by the existing state of the world - in the direction of preferring that which already exists. When it comes to appraisals of income differences, the prediction is that (perceptions of) actual income differences systematically influence our perceptions of ideal income differences in the direction of existing inequality. Note that this prediction is not dependent on the content of the status quo, which means that it can be applied to 'low' as well as 'high' inequality. It is also important to point out that status quo bias does not predict complete adjustment to the status quo; rather, it predicts insufficient adjustment away from it. In other words, even when we are actively trying to move away from the status quo (for example, because we think that income differences should be lower than they currently are), our estimates of ideal income differences will be influenced by the real state of the world.

\subsection{BELIEF IN A JUST WORLD}

While status quo bias is an umbrella term for mainly (though not exclusively) cognitive mechanisms, belief in a just world theory posits a motivated mechanism that leads to similar predictions as status quo bias. The original 
formulation of the just world hypothesis is that "people have a need to believe that their environment is a just and orderly place where people usually get what they deserve." ${ }^{4}$ This need causes individuals to think of their social environment as just and fair - as the type of environment in which incomes, low or high, are deserved. Thus, the just world motive may cause us to accept perceived income inequalities as legitimate - even when similar inequalities would be rejected as unfair if they were presented as hypothetical. At the margin, this implies that as (perceived) income differences increase, we adjust our expectations for desirable income differences up. Because belief in just world is an individual difference variable, this theory also predicts that some people will be more accepting of perceived inequality than others. In addition, the strength of the motive to believe in a just world is also situationally determined, which means that by manipulating specific elements of the social situation, the tendency to accept the status quo as legitimate can be strengthened. Below, I will use both of these predictions to create further testable implications of the habituation hypothesis.

The original just world hypothesis refers only to our judgments of individuals. Lerner and Miller (1978) show that when observers see an unjust event happening to an innocent victim, and the observer is unable to help the victim, then the observer will tend to derogate the victim's personality. The derogation, which occurs by associating negative traits with the victim, serves the purpose of making the victim appear more deserving of their fate, thus helping to uphold the observer's belief that the world is just. This derogation takes place even if the

${ }^{4}$ Lerner and Miller (1978, p.1030). 
observer themselves is the victim (i.e. the observer then engages in self-derogation).

While the original formulation of belief in just world theory is mainly concerned with our appraisals of individuals, the notion can also be applied to our appraisals of social systems. System justification theory (Jost and Banaji, 1994) does just this: it builds on belief in just world theory and extends its implications to include evaluations of social systems. System justification theory argues that when we are faced with facts that threaten our belief in the fairness of our social system, we subconsciously adjust our expectations for what a fair system would look like, in order to avoid compromising the belief that our social system is fair. The system justification motive is summarized in a review article as follows: "there is a general (but not insurmountable) system justification motive to defend and justify the status quo and to bolster the legitimacy of the existing social order."5

The need to believe in a fair social environment is hypothesized to have evolutionary roots: "the system justification goal has likely evolved in humans because of its adaptive value, and its pursuit serves the essential functions of alleviating negative affect associated with potential physical and psychological threats, offering coherence, structure, and meaning to one's life, and facilitating interpersonal relationships with other members of the same society." ${ }^{6}$ In particular, "'belief in a just world" is a universal need arising (solely or primarily)

${ }^{5}$ Jost et al. (2004, p.887).

${ }^{6}$ Liviatan and Jost (2011, p.232). 
from the desire to perceive that one has control over one's environment." ${ }^{7}$ Belief in a just world serves a motivating function: the ability to self-regulate in the pursuit of long-term goals depends on the belief that one's social environment is fair (Laurin et al. $2010 a$ ). Because of the link to self-motivation, and the alleviation of negative affect, belief in a just world is a valuable state of mind to human beings; the maintenance of belief in a just world is therefore an important subconscious goal.

The originators of system justification theory derive several hypotheses from this broad motivation, including the prediction that individuals are motivated to rationalize the status quo as fair and desirable. The authors themselves suggest, but do not test, that "a system justification perspective helps to understand why people who are economically disadvantaged often oppose income redistribution." Jost and Hunyady (2002) directly suggest that one consequence of system justification is that a) people rationalize the status quo and b) in the process of doing so, they internalize (come to accept) inequalities even when these do not benefit them. A system justification perspective thus suggests that, when people receive information regarding the status quo of income inequality in their society, they are motivated to rationalize this state of the status quo as fair so as to maintain their pre-existing level of belief in a just world. The ambiguity inherent in the concept of 'desert' provides a convenient alternative adjustment: changing one's estimate of how large income differences are fair is a relatively 'painless' adjustment when compared with a reduction in one's belief that the

${ }^{7}$ Jost and Hunyady (2002, p.116).

${ }^{8}$ Jost et al. (2004, p.908). 
social system is fair. This trade-off, and the ease with which concepts of 'desert' can be adjusted, lies behind the expectation that the status quo of information differences changes inequality ideals.

\subsection{THE HABITUATION HYPOTHESIS}

Status quo bias and the motivation to believe in a just world approaches thus both predict that existing income differences (the status quo) impact our estimates of ideal income differences.

The habituation hypothesis: Estimates of ideal income inequality are systematically skewed toward the (perceived) status quo in income differences. Therefore, when the status quo of income differences changes, desired differences in income change in the same direction.

Because status quo bias and just world theory produce the same prediction with respect to the influence of existing income differences on ideals of income differences, testing this hypothesis cannot speak to the relative strengths of the two explanations in producing the predicted outcome. It is likely that both cognitive and motivational mechanisms are at work, but showing that there is a main effect of the status quo cannot tease the two mechanisms apart. Below, I use the fact that the system justification motive is an individual-level variable to predict individual variation in habituation to the status quo. This individual variation prediction speaks directly to the existence of a system justifying tendency in the habituation phenomenon. In addition, I use previously established situational variation in the system justification motive to hypothesize 
that the strength of the habituation effect changes depending on the political context. While these two follow-up hypotheses cannot directly speak to 'how much' of the habituation effect is due to motivational vs. cognitive mechanisms, testing these hypotheses can show that system justification tendencies contribute to the habituation effect.

\subsection{INDIVIDUAL DIFFERENCES}

The motivation to believe in a just world (and the resulting tendency to engage in system justification) is an individual-level variable: some people are more likely to rationalize the status quo than others. The originators of just world theory, Lerner and Miller (1978), showed that there are individual differences in the tendency to believe that the world is just: "those individuals who have the strongest belief that the world is just $[. .$.$] are inclined to derogate innocent$ victims most severely." 9 The origins of individual differences on the Belief in Just World (BJW) scale (Lipkus 1991), which measures the tendency to believe in a just world, are not fully understood but may stem from developmental forces, individual experiences, or socialization. We do know that personality antecedents, such as openness to experience and need for structure influence individual tendencies to justify the social system (Jost and Hunyady, 2005). People with high belief in a just world "see the existing situation as more fair because targets are seen as simply getting what they deserve." ${ }^{10}$ The individual

\footnotetext{
${ }^{9}$ Lerner and Miller (1978, p.1043).

${ }^{10}$ Hafer and Choma (2009, p.110)
} 
tendency to believe in a just world predicts perceptions of the fairness of societal phenomena, such as the distribution of wealth and the occurrence of discrimination against race or gender groups (Hafer and Choma, 2009, Lipkus and Siegler, 1993). Given these trends, it is plausible to hypothesize that individuals who exhibit a high belief in a just world are particularly likely to rationalize income differences as fair.

The individual difference hypothesis: People who score high on the tendency to believe in a just world espouse inequality ideals that are systematically closer to the status quo than do people who score low on the tendency to believe in a just world.

\subsection{SOCIAL CONTEXT AND SYSTEM JUSTIFICATION}

System justification is a motivated psychological process, and it is known that particular social circumstances can activate the motivation to engage in this process: "the perception of a stable and legitimate status quo is a general goal that operates within a motivational network $[. .$.$] when the system justification goal is$ activated, people should strive to imbue the status quo with legitimacy." ${ }^{11}$ System justification theorists argue that the system justification motive is activated under conditions of: "(a) system threat, (b) system dependence, (c) system inescapability, and (d) low personal control." ${ }^{2}$ Because the system justification motive, if successful, reassures the individual that their social world is fair and

\footnotetext{
${ }^{11}$ Liviatan and Jost (2011, p.232).

${ }^{12}$ Kay and Friesen (201 1, p.360).
} 
their life outcomes are under their personal control, perceptions that challenge these conclusions (by telling the individual that she is a) not in control, b) is dependent on the system, or c) is dependent on a threatened system) can trigger the motivation to justify the system.

Prior studies have successfully manipulated these four conditions and have thereby increased the extent to which individuals rationalize the status quo as desirable. Kay et al. (2009) tell their study participants that the participants' social system (Canada) would become more difficult to leave in future years, thus manipulating the escapability of the system. They show that the treatment group is subsequently more likely than the control group to approve of the (status quo) fact that the Canadian House of Representatives is made up primarily of wealthy individuals. Laurin et al. (2010b) use the same inescapability treatment to show that activating the system justification motive leads respondents to ascribe gender inequality to genuine gender differences (as opposed to systemic inequality). The authors also show that this effect is motivated by perceptions of the participant's own social system: the effect only arises when the inescapability treatment refers to the participants' own country. van der Toorn et al (2012) show that activating the system justification motive by manipulating perceptions of the individual's dependence on the social system increases patriotism scores among liberal respondents. Wakslak and Bauer (2011) further show that the system justification motive can be activated for systems other than the broad social system (e.g. the family unit), and that system justification can 'spill over' into rationalizations of systems other than the one immediately under threat. The 
manipulations used in the studies cited here are all expected to activate the system justification motivation among people for whom the motive is not already chronically active; i.e. individuals with a low belief in just world (low BJW). Typically, then, the results involve erasing the differences between individuals with high and low beliefs in a just world by 'moving' the opinion of low BJW individuals (see van der Toorn et al 2012). I am not aware of any studies where the reverse is done (i.e. de-activating the motive among high believers in a just world).

These studies suggest that specific social conditions (believing that one's social system is under threat, difficult to leave or has a high degree of influence on one's individual life outcomes) can affect the extent to which system justification takes place. It is thus plausible to expect that the extent to which income differences are perceived as legitimate may also be subject to the same influences. More specifically, I hypothesize that under conditions that activate the system justification motive, people who are low believers in a just world will become similar to people who are high in belief in just world in the extent to which they perceive income differences as legitimate.

The context hypothesis: Experimentally activating the system justification motive leads participants who score low on belief in a just world to habituate to the status quo (of income differences) as much as individuals who score high on belief in a just world. 


\subsection{CONCLUSION}

Status quo bias and system justification theory are two well-established concepts in the social psychology literature. Both literatures predict that humans are inclined to prefer the status quo over hypothetical alternatives, and thus provide a theoretical foundation to the habituation hypothesis. The concepts inform three distinct hypotheses regarding the influence of the status quo on preferences for income inequality: in the next three chapters, I will present empirical tests of these three hypotheses. 


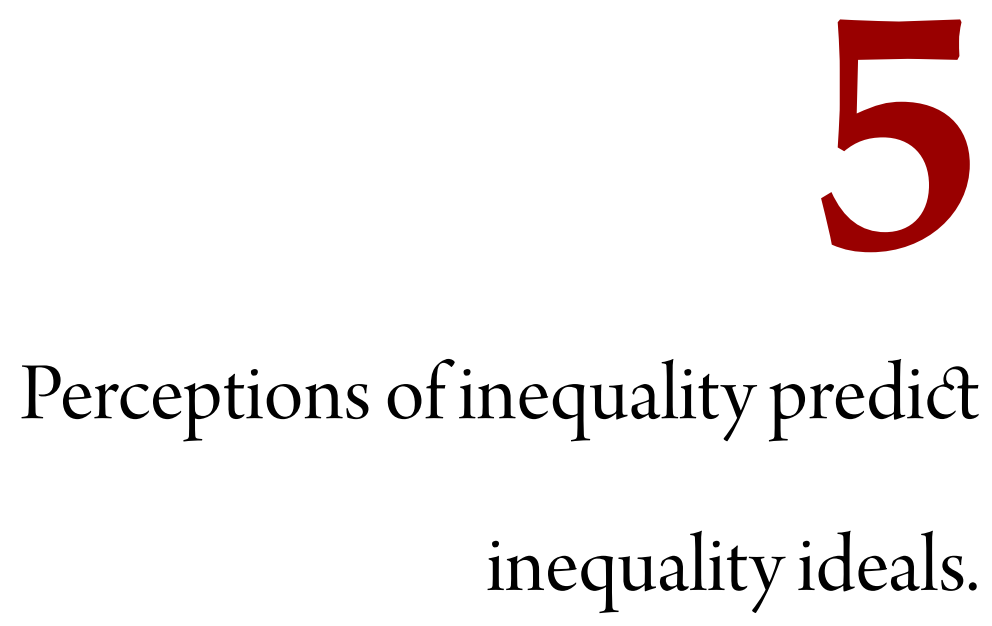

IN SURVEY DATA that asks respondents for their perceptions of income differences, these perceptions are the strongest predictor of the respondents' 
ideal income differences. In this chapter, I replicate this previously discussed finding and show that this predictive pattern holds across countries and when controlling for relevant demographic variables. The pattern is significant in all countries under examination, but the strength of the predictive relationship varies. I examine alternative explanations for this finding and conclude that the most likely explanation for this pattern is provided by the habituation hypothesis.

\subsection{MeAsUring IneQUality ATTItUdes}

The habituation hypothesis predicts that perceptions of income inequality systematically influence preferences for income inequality; testing this hypothesis requires survey questions that can gauge the respondents' preferences and ideals separately, and in a way that makes direct comparisons of perceptions and ideals possible. In addition, the survey questions should be such that respondents can reasonably be expected to be able to reply; for example, a question asking respondents to estimate the Gini index in their country would be too complicated for the average respondent to yield usable data.

As mentioned in Chapter 3, a set of questions that does allow a comparison of perceived and ideal levels of income inequality has been asked in the Social Inequality modules of the International Social Survey Project (ISSP). ${ }^{1}$ In these modules, respondents are asked to guess the incomes of a set of occupations, and then to indicate what these groups ought to earn, irrespective of what they

\footnotetext{
${ }^{1}$ ISSP Research Group, International Social Survey Programme (ISSP). Distributor: GESIS Cologne Germany ZA4850, Data Version 2.0.0 (2009-10-29).
} 
actually do earn. The occupations range in terms of skill and average pay, and include: unskilled factory worker, skilled factory worker, owner of small shop, member of federal cabinet, and CEO of a large national company.

Prior research on perceptions and ideals has concluded that perceptions of income inequality are the single best predictor of inequality ideals; most of that research was published in the early to mid-200o's and used the 1987 and 1992 waves of the ISSP. The Social Inequality module was most recently fielded again in 2009 in 31 countries, ${ }^{2}$ and this is the data that I will be using below. Since the United States did not field this module of the ISSP in 2009, but did field it as part of the 2010 General Social Survey (GSS), ${ }^{3}$ I will be using 2010 data for the United States, bringing the total number of countries to 32 . I will build on previous research, confirm that the predictive relationship between perceptions and ideals persists in 2009 and cross-nationally, and compare the strength of this relationship across countries. I will also consider whether this pattern could be the result of a question wording effect, and present evidence to suggest that it is not.

\footnotetext{
${ }^{2}$ The Social Inequality Module of the 2009 ISSP wave was implemented in: Argentina, Australia, Austria,Belgium, Bulgaria, Chile, Croatia, Cyprus, the Czech Republic, Denmark, Estonia, Finland, France, Great Britain, Hungary, Israel, Japan, Latvia, New Zealand, Norway, the Philippines, Poland, Portugal, Slovakia, Slovenia, South Africa, South Korea, Spain, Sweden, Switzerland and Ukraine.

${ }^{3}$ Smith, Tom W, Peter Marsden, Michael Hout, and Jibum Kim. General social surveys, 1972 2010. Accessible at: http://www3.norc.org/gss+website/.
} 


\subsection{Methodology}

In the questions on occupational earnings, respondents are asked to indicate how much they think that each of 6 occupational groups earns, and then to indicate what they think these groups ought to earn, regardless of what they actually earn. The occupational groups are: unskilled factory worker, skilled factory worker, owner of a small shop, a doctor in general practice, a member of the federal cabinet and $\mathrm{CEO}$ of large national corporation. ${ }^{4}$ To measure perceived and ideal inequality, I use a modified version of the justice index proposed by Jasso (1999). In this index, perceptions and preferences of inequality are captured by computing $\ln$ (income of high prestige occupations / income of low prestige occupations). Since I am focusing purely on perceptions of income inequality, without hypotheses regarding the relative prestige of occupations, I use the highest earning and lowest earning occupations, as defined by the respondent. For each respondent, then, the index of perceived and ideal income differences becomes $\ln$ (highest specified income / lowest specified income). This yields two indices for each person: a perceived income gap index, and an ideal income gap index. The index of ideal income gaps will be the main dependent variable in the analyses below.

In the regressions that examine the impact of perceived inequality on ideal inequality, I will control for a number of demographic variables. Given that we

\footnotetext{
${ }^{4}$ The latest wave of the Social Inequality module includes additional occupations, such as "service worker". I have chosen to use the 6 recurring occupations here to maintain, as closely as possible, comparisons with prior waves of the ISSP and with the survey experiments presented in Chapters 6 and 7.
} 
ask people about their ideal outcomes, we might expect those with higher incomes to support more unequal distributions of income, since it is in their economic interest to do so. For the same reason, it is plausible that poor individuals would support a more equal distribution of incomes. In the regressions below, I therefore control for household income. Since redistributive politics are at the heart of the left-right divide, we would also expect left-wing voters to prefer a more equal distribution of incomes than right-wing voters. I include two dummies for self-reported vote in the last national election: one dummy variable for right-wing vote, and one dummy variable for left-wing vote. I choose to use two dummy variables in order to retain individuals who report not voting or chose not to answer the question in the analysis; these individuals form the baseline comparison group. I also include controls for years of education, years of education squared, sex, age, marital status, age, and age squared. Finally, the main independent variable of interest, the index of perceived income inequality, is included. This analysis is run separately for each country in the dataset, and the results are presented in Table 5.1.

\subsection{Perceptions of INEQUALITy STRONGLY PREDICT IDEAL LEV- ELS OF INEQUALITY}

Perceptions of inequality are a consistently strong predictor of the respondents' ideal income inequality, while demographic predictors are inconsistently significant and their effects are small in magnitude compared to the coefficient on 
Table 5.1: Country-specific regressions predicting respondents' ideal levels of inequality.

Independent variable: index of preferences for inequality, calculated as In(highest suggested income/lowest suggested income). Coefficients in bold are significant at the $95 \%$ level. Additional control variables (not shown): Vote (left), Education ${ }^{2}$, Gender, Age, Age ${ }^{2}$, Marital status. The coefficients for income are based on national currencies (in units of 1,000) and are therefore not directly comparable.

*United States estimates are based on data from the 2010 General Social Survey; due to the structure of the questionnaire, the operationalization of some covariates differs from the other regressions. In particular, the US education variable indicates a college degree, not years of education.

\begin{tabular}{|c|c|c|c|c|c|c|c|c|c|c|}
\hline \multirow[b]{2}{*}{ Country } & \multicolumn{2}{|c|}{ Perceived inequality } & \multicolumn{2}{|c|}{ Income } & \multicolumn{2}{|c|}{ Vote (right) } & \multicolumn{2}{|c|}{ Education (years) } & \multirow[b]{2}{*}{$N$} & \multirow[b]{2}{*}{ Adj. $R^{2}$} \\
\hline & Coef & S.E. & Coef & S.E. & Coef & S.E. & Coef & S.E. & & \\
\hline Argentina & 0.37 & 0.04 & 1.90 & 1.35 & 0.22 & 0.29 & -0.004 & 0.004 & 474 & 0.19 \\
\hline Australia & 0.46 & 0.02 & 3.13 & $<0.001$ & 0.15 & 0.07 & 0.07 & 0.04 & 1073 & 0.36 \\
\hline Austria & 0.47 & 0.03 & 0.11 & 0.03 & 0.03 & 0.06 & 0.02 & $0 . .11$ & 637 & 0.43 \\
\hline Belgium & 0.53 & 0.02 & 5.65 & 0.01 & -0.02 & 0.05 & -0.09 & -0.03 & 783 & 0.46 \\
\hline Bulgaria & 0.46 & 0.06 & 0.03 & 0.03 & -0.07 & 0.10 & 0.03 & 0.05 & 227 & 0.21 \\
\hline Chile & 0.69 & 0.02 & 0.0001 & $<0.001$ & 0.09 & 0.06 & -0.06 & 0.03 & 966 & 0.49 \\
\hline Croatia & 0.38 & 0.03 & 0.01 & $<0.001$ & 0.11 & 0.05 & -0.005 & 0.02 & 668 & 0.18 \\
\hline Cyprus & 0.72 & 0.03 & 0.02 & 0.02 & -0.01 & 0.02 & -0.01 & 0.01 & 819 & 0.50 \\
\hline Czech Republic & 0.43 & 0.03 & 0.004 & 0.001 & 0.17 & 0.06 & 0.05 & 0.04 & 742 & 0.25 \\
\hline Denmark & 0.53 & 0.02 & 0.0002 & $<0.001$ & 0.06 & 0.05 & -0.005 & 0.02 & 1052 & 0.37 \\
\hline Estonia & 0.42 & 0.03 & 0.003 & 0.002 & -0.06 & 0.16 & 0.03 & 0.03 & 706 & 0.19 \\
\hline Finland & 0.50 & 0.03 & 0.02 & 0.006 & 0.13 & 0.06 & 0.04 & 0.02 & 556 & 0.37 \\
\hline France & 0.45 & 0.015 & 0.08 & 0.01 & 0.19 & 0.05 & 0.008 & 0.01 & 1914 & 0.40 \\
\hline Great Britain & 0.48 & 0.03 & 0.006 & 0.002 & 0.32 & 0.08 & 0.05 & 0.04 & 678 & 0.34 \\
\hline Hungary & 0.43 & 0.04 & 0.001 & $<0.001$ & 0.14 & 0.06 & 0.06 & 0.06 & 552 & 0.21 \\
\hline Israel & 0.39 & 0.04 & 0.007 & 0.005 & -0.12 & 0.06 & 0.01 & 0.03 & 581 & 0.18 \\
\hline Japan & 0.68 & 0.04 & 0.0001 & $<0.001$ & 0.04 & 0.09 & 0.22 & 0.14 & 363 & 0.47 \\
\hline Latvia & 0.25 & 0.04 & 0.30 & 0.08 & 0.25 & 0.13 & -0.03 & 0.05 & 517 & 0.14 \\
\hline New Zealand & 0.51 & 0.03 & 0.002 & $<0.001$ & 0.03 & 0.06 & 0.01 & 0.04 & 773 & 0.35 \\
\hline Norway & 0.37 & 0.02 & $<0.001$ & $<0.001$ & 0.10 & 0.05 & -0.02 & 0.03 & 1191 & 0.23 \\
\hline Philippines & 0.65 & 0.02 & -0.007 & 0.015 & -0.06 & 0.08 & -0.06 & 0.03 & 867 & 0.51 \\
\hline Poland & 0.41 & 0.03 & 0.04 & 0.01 & -0.04 & 0.07 & 0.06 & 0.08 & 634 & 0.29 \\
\hline Portugal & 0.33 & 0.05 & 0.11 & 0.07 & 0.07 & 0.10 & -0.02 & 0.02 & 334 & 0.20 \\
\hline Slovakia & 0.42 & 0.03 & 0.04 & 0.04 & 0.006 & 0.07 & -0.05 & 0.06 & 825 & 0.25 \\
\hline South Africa & 0.47 & 0.02 & -0.001 & -0.003 & 0.13 & 0.09 & -0.01 & 0.02 & 1839 & 0.28 \\
\hline South Korea & 0.57 & 0.02 & 0.18 & 0.10 & 0.13 & 0.08 & -0.004 & 0.05 & 1293 & 0.47 \\
\hline Spain & 0.34 & 0.04 & 0.07 & 0.05 & -0.05 & 0.09 & 0.02 & 0.01 & 439 & 0.19 \\
\hline Sweden & 0.36 & 0.02 & 0.004 & $<0.001$ & 0.14 & 0.05 & -0.03 & 0.02 & 891 & 0.36 \\
\hline Switzerland & 0.33 & 0.02 & 0.02 & 0.01 & 0.10 & 0.06 & 0.08 & 0.05 & 646 & 0.38 \\
\hline Ukraine & 0.25 & 0.04 & -0.01 & 0.02 & -0.02 & 0.21 & -0.07 & 0.08 & 523 & 0.08 \\
\hline United States* & 0.51 & 0.04 & 0.01 & 0.001 & 0.26 & 0.12 & -0.12 & 0.08 & 774 & 0.27 \\
\hline
\end{tabular}


perceptions (see Table 5.1). Individual income predicts preferences for inequality in 15 out of 32 countries; this relationship is always in the expected direction whereby those who earn more also think that larger income differences are desirable. ${ }^{5}$ Self-reported vote for a right-wing party in the last parliamentary elections has a significant impact in 10 of 32 countries. Again, the relationship is in the expected direction: people who voted for a right-wing candidate think of higher income inequality as ideal. Other than the income and vote variables, demographic variables contribute little to explain ideal levels of income inequality - a counter-intuitive finding, but one that is consistent with prior analyses of similar data (Austen 2002, Gijsberts 2002, Osberg and Smeeding 2006, Svallfors 2003).

Whether or not these results imply that actual inequality leads to higher preferences for inequality depends on whether public perceptions of inequality are, at least to some extent, accurate. The fact that in post-Communist countries the transition to (more unequal) market economies increased perceptions of income inequality (Kelley and Zagorski 2004) indicates that, when changes in inequality are system-wide and rapid, they are also visible to the public. However, the transition from post-Communism was a unique societal transformation; in the absence of such deep changes in the economic distribution, the evidence is mixed regarding whether inequality is correctly perceived. Kenworthy and McCall (2008), for example, find no relationship between real and perceived inequality in eight capitalist, liberal democratic countries during the 1980's and

\footnotetext{
${ }^{5}$ Note that the income coefficients are based on units of domestic currency (in the respondent's self-reported annual income) and are therefore not comparable across countries.
} 
1990's. As discussed above, while American perceptions of inequality include a fair amount of folk wisdom (Bartels 2008), there also seems to be some signal in the noise (Xu and Garand 2010, McCall 2013). The evidence regarding perceptions is thus mixed; it is unclear what the 'signal to noise ratio' is in reported perceptions of inequality. In addition, it is plausible that there will be important variations in the accuracy of perceptions of inequality within countries and by demographic groups. In the dataset of countries that I am working with here, the number of observations is too small for conclusive analyses of the relationship between real and perceived inequality, but it is possible to explore patterns. The country-level median perceptions of inequality are correlated at 0.43 with the Gini coefficient of disposable incomes, but only at 0.20 with the Gini coefficient of market incomes. ${ }^{6}$ The fact that the correlation is stronger for disposable incomes, which are presumably more visible to regular citizens than pre-tax incomes, suggests that there is some degree of accuracy to perceptions of inequality.

While the question of the accuracy of perceptions of inequality is not well studied, and available evidence is mixed, the existence of the psychological mechanism proposed here does not depend on perceptions being fully accurate, and the regression results clearly indicate that at the individual level, perceptions of inequality are a very strong predictor of preferences for inequality, a pattern that is consistent with the habituation hypothesis.

\footnotetext{
${ }^{6}$ Gini coefficient estimates from: Solt, Frederick. 2009. "Standardizing the World Income Inequality Database.” Social Science Quarterly 90(2):231-242. SWIID Version 3.1, December 2011.
} 
The surprising lack of significance of the demographic and ideological variables, and the fact that the questions regarding perceptions and preferences are asked in immediate succession on the survey, raises the possibility that most of this relationship is due to a survey artifact, whereby the relationship between perceptions and preferences appears stronger because the questions are asked in quick succession and the estimates for perceived inequality are particularly accessible to the respondents when giving their ideal estimates. Anchoring in salient numbers is one of the mechanisms by which the status quo gains its advantage, but if this effect is entirely due to the short-term effect of asking the questions in immediate succession, the implications for real-world adaptation to inequality would be limited.

One way to check whether a short-term anchoring explanation is all that is going on in the data is to compare the relationship between perceptions and ideals across countries. There is no theoretical reason to think that an anchoring effect which occurs because of the design of the survey would vary by country or political/social circumstances; thus, a survey artifact should produce coefficients that are roughly similar across all countries. The data reveals, however, that the impact of perceptions on preferences varies substantially between countries. Figure 5.1 plots the estimated relationship between perceptions and ideals (the coefficients from the first column of Table 5.1), ordered by coefficient magnitude. The variation in coefficients is substantive, from a low of 0.25 in Ukraine and Latvia to a high of around 0.7 in the Philippines, Chile, Japan and Cyprus. This substantive variation suggests that the effect is not only due to a short-term 
anchoring effect because of the way the survey is designed - if it were, we would expect the effect to be uniform across countries.

Given that the relationship between perceptions and ideals varies across nations, we can ask whether this variation is systematically linked to some substantive political or social feature of these societies. The coefficient that links perceptions and ideals can be thought of as the degree to which perceived inequalities are accepted or - the flip side of the coin - the degree to which inequalities are rejected. Osberg and Smeeding (2006), for example, choose to treat this coefficient as an indicator of desire for leveling inequalities. Based on previous literature on the determinants of desire for leveling income inequalities, it would be reasonable to hypothesize that this relationship is related to actual levels of income inequality (per the material self-interest hypothesis), to ethnic fractionalization (see Gilens 2000 or Roemer et al. 2007), or to unionization rates (Rueda and Pontusson 2000).

Figures 5.2-5.4 show the relationship between perceptions and ideals, plotted against income inequality (Figure 5.2), ethnic fractionalization (Figure 5.3) and unionization (Figure 5.4). Each figure also includes an estimated regression line (obtained when all three national-level indicators are entered into a bootstrapped regression that predicts the perception-ideal relationship). None of the three relationships between social indicators and the strength of the perception-ideal relationship are statistically significant. The extent to which perceived inequalities are accepted (or, equivalently, rejected) does not appear to be systematically related to unionization rates, the Gini index of disposable income, or ethnic 


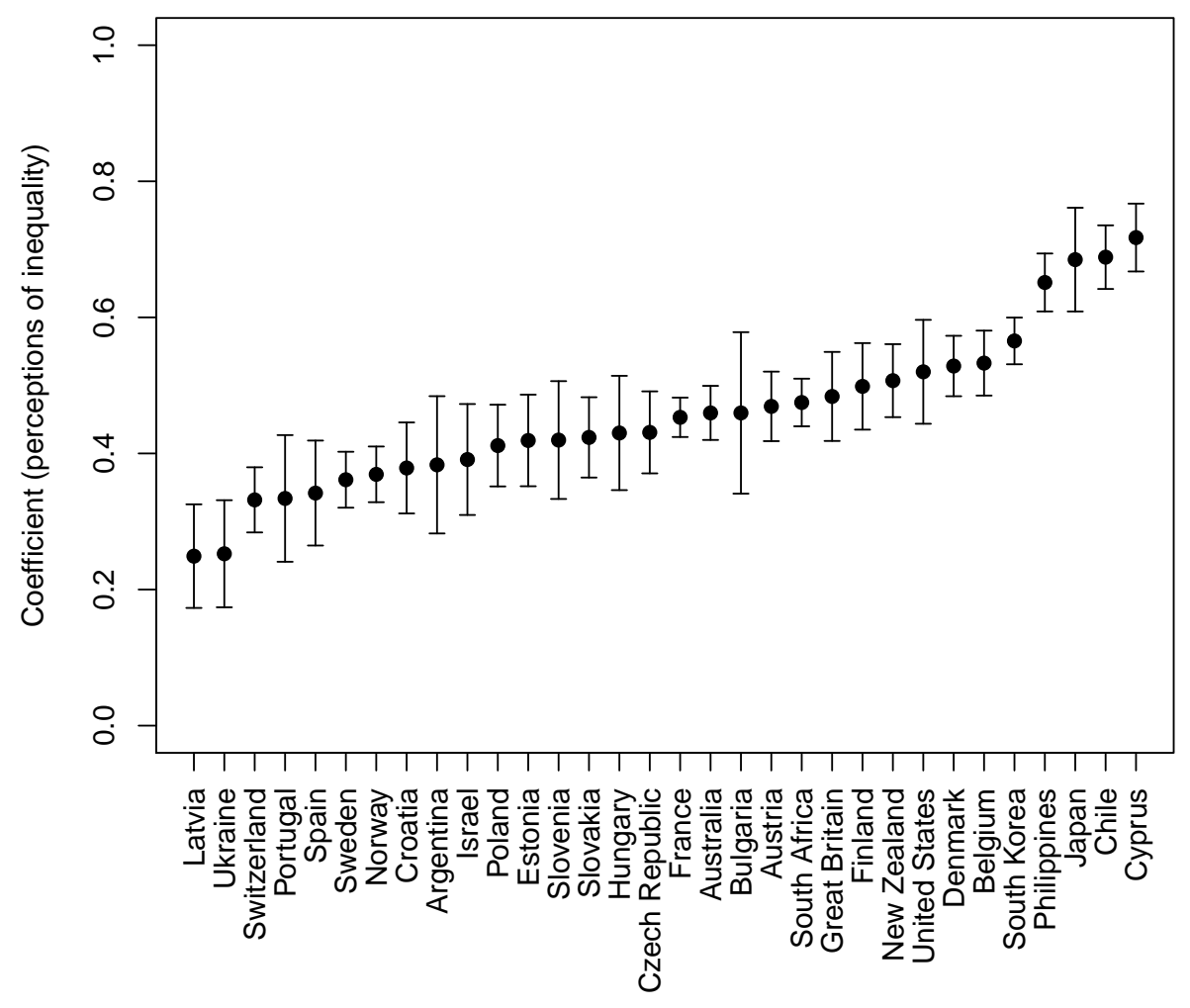

Figure 5.1: Country-specific coefficients for the predictive relationship between inequality perceptions and inequality ideals, ordered by size.

The coefficients are taken from Table 5.1 and are shown with $95 \%$ confidence intervals. 
fractionalization. This pattern holds both when the variables are analyzed together, and when they are analyzed one at a time to reveal pure correlations. In other words, while there is substantial variation in the acceptance/rejection of perceived inequality, this variation is not systematically related to variables that are frequently associated with preferences for leveling incomes.

\subsection{Conclusion}

Perceptions of income inequality are a strong predictor of ideal income inequality in each of 32 countries. This relationship is probably not due to a survey artifact, since this relationship varies substantially across countries. This substantive variation is not significantly predicted by three common explanations for the strength of preferences for leveling incomes: unionization, income inequality, and ethnic fractionalization. The coefficient that links perceptions of inequality to inequality ideals could be interpreted as variation in the desire for leveling of incomes; however, it does not vary systematically with common explanations for redistributive demand, making an interpretation of it as a system justification coefficient, rather than a redistributive demand coefficient, more plausible.

The strong relationship between perceptions and ideals is consistent with the habituation hypothesis, whereby perceptions of inequality affect inequality ideals. The system justification framework predicts that perceptions can influence ideals and that the strength of this relationship depends on factors such as 


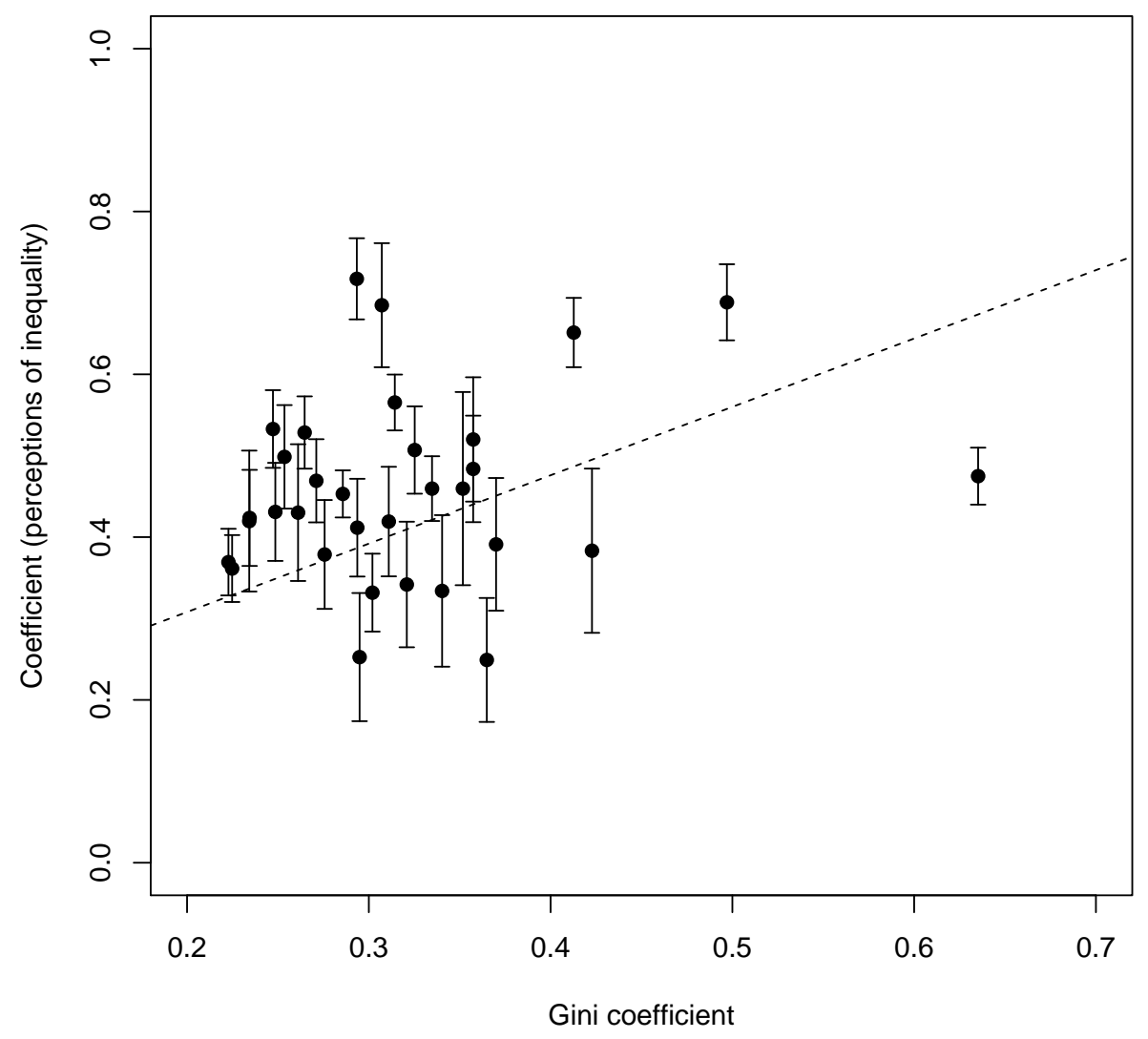

Figure 5.2: Coefficients for the relationship between inequality perceptions and ideals, by income inequality.

Plot of coefficients by the Gini coefficient of disposable income. The regression line is fitted from a bootstrapped regression predicting the strength of the perception-ideal relationship; it is not significantly different from zero. See text for data sources. The coefficients are taken from Table 5.1. 


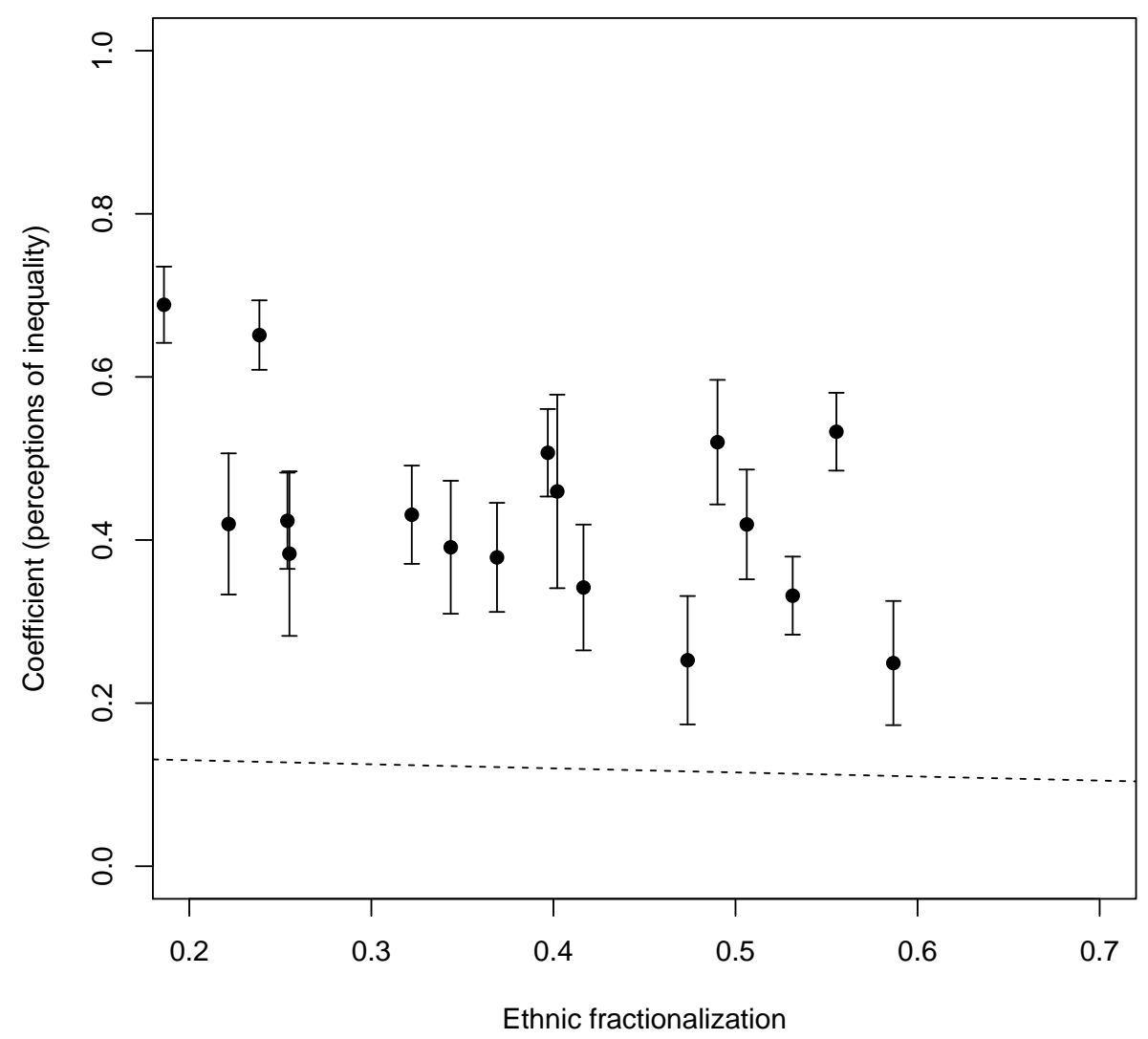

Figure 5.3: Coefficients for the relationship between inequality perceptions and ideals, by ethnic fractionalization.

Plot of coefficients by ethnic fractionalization at the national level. The regression line is fitted from a bootstrapped regression predicting the strength of the perception-ideal relationship; it is not significantly different from zero. See text for data sources. The coefficients are taken from Table 5.1. 


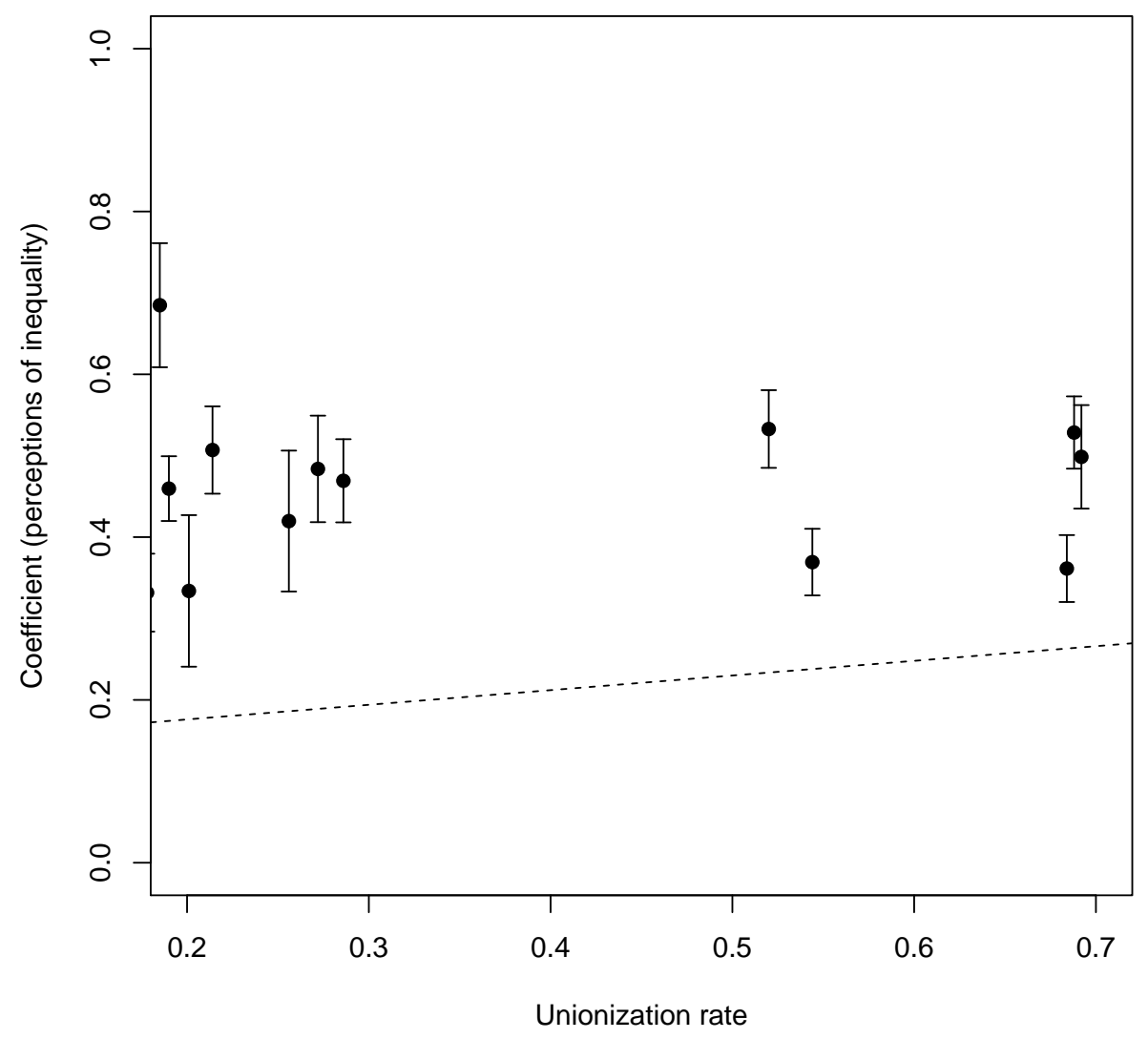

Figure 5.4: Coefficients for the relationship between inequality perceptions and ideals, by unionization rate.

Plot of coefficients by unionization rate at the national level. The regression line is fitted from a bootstrapped regression predicting the strength of the perception-ideal relationship; it is not significantly different from zero. See text for data sources. The coefficients are taken from Table 5.1. 
outside threats to the society, or the (perceived) escapability of the social system. Because of this latter prediction, the system justification explanation is consistent with cross-national variation in the relationship between the (perceived) status quo and the preferred state of society. I will return to this prediction in Chapter 7.

The results presented in this chapter are based on correlational data, and as such they cannot speak to the causality behind the patterns. For example, it is possible that when asked to estimate current levels of inequality, respondents are motivated to see the world as they think it ought to be, thus biasing their estimates of reality in the direction of their ideals, rather than vice versa. To show that the habituation hypothesis is the best available explanation for this pattern, it must be shown that manipulating experiences and/or perceptions of income inequality can change preferences for inequality. The experiments in the next two chapters provide such evidence. 


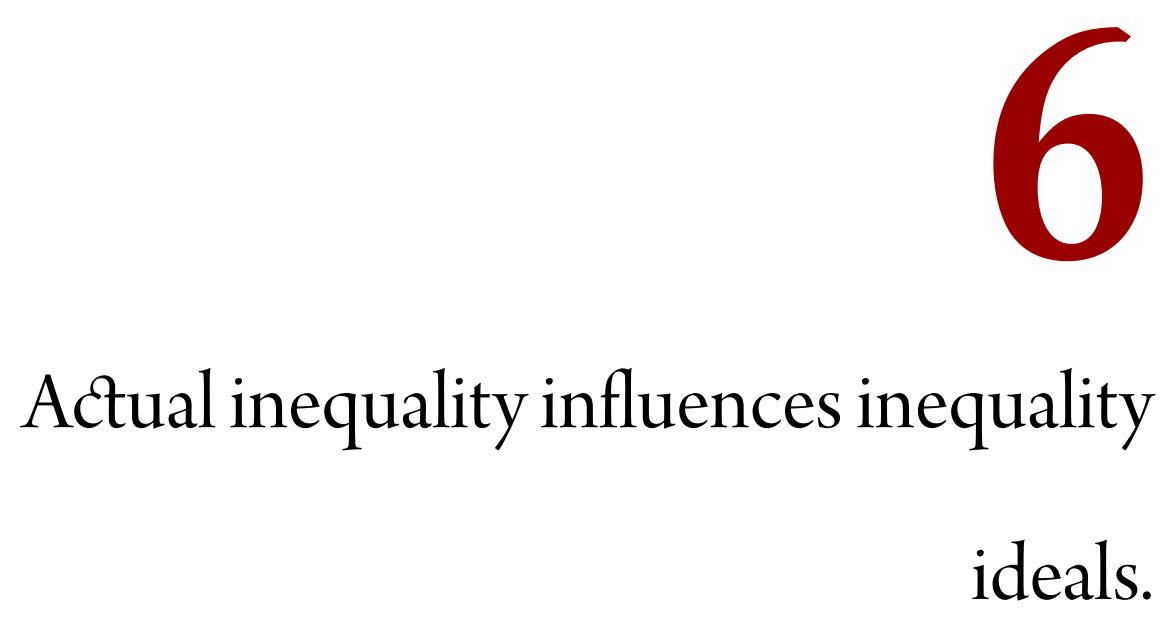

IN THE EXPERIMENTS DESCRIBED IN THIS CHAPTER, both eXperiences and perceptions of the inequality of the status quo are manipulated, and in both cases 
the manipulation changes the participants' estimates of the appropriate level of inequality in their situation. In a laboratory experiment, participants who play an unequal version of a game subsequently design more unequal games than participants in the control group (who play a more equal version of the same game). In a survey experiment, information regarding the high levels of income inequality in the United States causes American respondents to upward revise their estimates of ideal levels of income inequality. At the same time, this information does not change their likelihood of thinking that the government should take action to reduce income differences. This last finding further strengthens the argument that increased inequality does not directly lead to higher demands for redistribution, but does lead to habituation with the new level of inequality.

\subsection{EXPERIMENT 1: EXPERIENCES OF INEQUALITY INFLUENCE PREF- ERENCES FOR INEQUALITY}

The first experimental test of the habituation hypothesis was designed as a test of principle. The aim of this experiment is to show that experiencing a specific level of inequality influences our subsequent estimates of the appropriate level of inequality in that situation. This first test was carried out in a laboratory environment, which provides the experimenter strong control over the environment and enables the manipulation of experiences of inequality.

The study is set up as a competition between two participants, where the winner earns a higher reward than the loser. This set-up, involving 'earning' an 
amount of money before being asked what a fair distribution would be, is designed to bring the concept of desert into the laboratory environment. We know that perceptions of desert influence outcomes in ultimatum games (Barber and English 2012), and that perceptions of desert figure prominently in fairness evaluations with respect to real-life incomes (Lawton et al. 2011). Because the ultimate object of interest in this research project is attitudes toward real income inequalities (for which concepts of desert are highly applicable), desert was deliberately brought into the experiment. Because the outcome of interest is the impact of inequality itself (and not the impact of economic self-interest) on distribution preferences, the experiment is set up so that all participants are disadvantaged by inequality. The habituation hypothesis, in the context of this experiment, is:

Hypothesis: individuals who experience an unequal division of resources will subsequently recommend a more unequal division of the same resources than individuals in the control group.

\subsubsection{METHOD}

65 participants were recruited using the Harvard Psychology Department Study Pool in February - May 2012, for a study that the participants believed was about experiences of competitive situations. When the participant arrived at the location of the experiment, they were told that they would take part in a competition against another study participant (the 'other participant' was in fact a confederate of the researcher). The participants first filled in a background 
survey that included only the Big Five personality measures, the Global Belief in a Just World scale, the Social Dominance Orientation scale and demographic variables including ideology and partisanship. The participants then 'competed' in a 4-minute anagram solving competition. The competition introduced the randomly assigned treatment condition: an extra monetary prize, to be distributed between the winner and the loser of the challenge. In the 'unequal' condition, the winner was to get $\$ 9$ and the loser was to get $\$ 1$. In the 'equal' condition, the winner was to get $\$ 6$ and the loser was to get $\$ 4$. The researcher verbally pointed out the existence of a monetary prize in the competition; however, the exact dollar amount was only specified on the written instructions received by the participant prior to the anagram task. Both the researcher and the confederate were blind to the experimental condition until the debrief.

The words in the anagram task were neutral with respect to inequality (e.g. 'rat', 'elbow', 'ocean'). The anagram task was designed to be challenging, and most participants reported that they experienced the task to be 'somewhat' to 'very' difficult. After the anagram task, participants filled in a second battery of Big Five questions while the researcher scored the task. The participants scored between 0 and 32 points on the anagram task (roughly equivalent to solving o to 12 anagrams), and the confederate always 'scored' 2 points more than the participant. ${ }^{1}$ When the scores were announced, the participants were reminded that they would get the second-place award while the confederate would get the winner's award. They then filled in the final questionnaire of the experiment

\footnotetext{
${ }^{1}$ Except in the case of very low participant scores, 0-5 points, in which case the confederate 'scored' 1 point more than the participant.
} 
which was ostensibly about their experience of the competition. Included on the final questionnaire was a question on the fairness of the payment received by the participant, and a question on how the participant herself would distribute the $\$ 10$ between the competitors, were she to design the game. The participants were then asked whether they recalled what their monetary payment was going to be (manipulation check), asked for any suspicions regarding the purpose of the experiment, debriefed, and paid. They kept the money payment they had been promised during the experiment.

The 65 participants completed the study for a cash payment of $\$ 5$ ( 55 participants) or course credit (10 participants) plus the cash payment earned during the experiment. 12 participants were excluded from the analysis due to one or a combination of: guessing the purpose of the experiment, guessing that the confederate was not a true participant, and/or treatment failure (such as not remembering the payment of the winner and loser). Including these participants does not change the results of the experiment. The remaining 53 participants were a combination of college students and community members. Ages ranged from 15 to 56 (mean 30 , median 24 ). 25 were female and 28 male. $55 \%$ of participants were White, $17 \%$ were African American, $11 \%$ were Hispanic, $13 \%$ were Asian and 2 participants reported 'Other'. 26 participants were in the 'unequal' condition (\$1-\$9) and 28 in the 'equal' condition (\$4-\$6). 


\subsubsection{Results}

The main dependent variable was the amount of money the participant would award to the winner of the competition, were he to design the game. The amount of money awarded to the winner is used as a direct measure of how unequal the participant would make the division, as the participants were constrained to divide exactly $\$ 10$ between the winner and loser. The results are shown in Figure 6.1: participants in the 'equal' condition would, on average, give the winner $\$ 6.15$, while participants in the 'unequal' condition would, on average, give the winner $\$ 7.77$. The difference is significant at $\mathrm{p}<0.001$. Individuals in the $\$ 9$ condition report with a significantly $(\mathrm{p}=0.02)$ higher probability that their payment was not fair, and the average dollar amount allocated to the winner is below the $\$ 9$ status quo in the experimental condition. Despite this difference in perceived fairness, individuals in the unequal condition recommend that the allocation of money should be more unequal than individuals who had experienced a more equal division of resources. This speaks to the power of the status quo in an unequal environment: when incomes are earned (as they are in the real world) and when the concept of desert is only an imperfect guide to how much inequality is appropriate (as it usually is), estimates for fair inequality depend on the status quo. Even when the status quo is experienced as unfair, and even when we prefer there to be less inequality than we experience, preferred inequality remains higher than it would be in a more equal situation.

This main result supports the habituation hypothesis: the participants' 


\section{Money allocation to the winner}

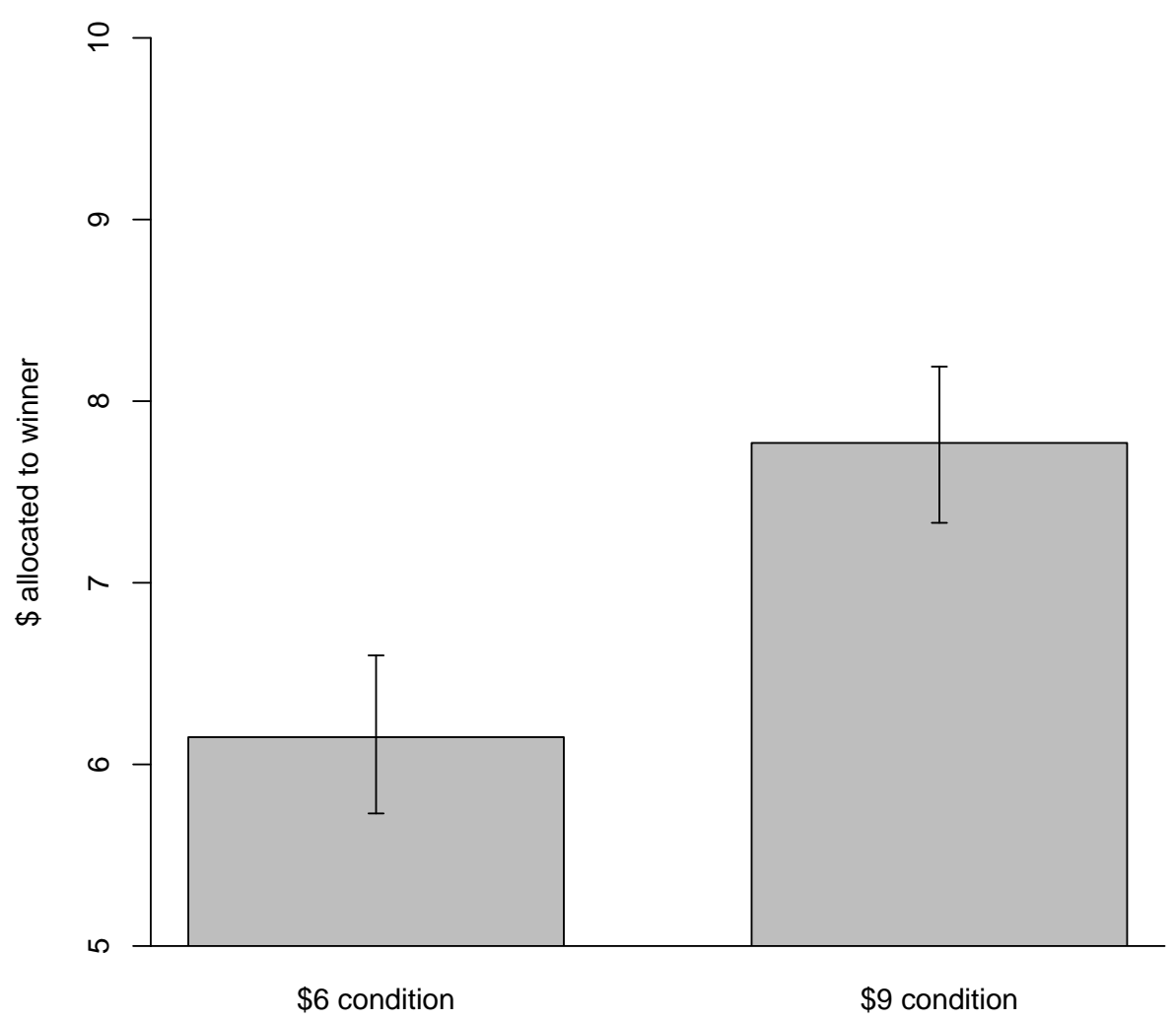

Figure 6.1: Laboratory experiment results: money allocation to the winner by inequality condition.

Showing the amount of money (out of $\$ 10$ ) that participants allocated to the winner of an anagram competition, by experimental condition. In the $\$ 6$ condition, the winner received $\$ 6$ and in the unequal condition, the winner received $\$ 9$. The difference is significant at $p<0.001$. 
opinion regarding appropriate levels of inequality in the competition was influenced by the inequality they had just experienced.

\subsubsection{THE ROLE OF BELIEFS IN A JUST WORLD}

As discussed above, the habituation hypothesis is a combination of status quo effects and motivated reasoning due to the motivation to believe in a just world. The individual difference hypothesis, derived from the motivated reasoning literature, predicts that individuals who score high on the tendency to believe in a just world will be more likely to accept existing inequality levels as fair; belief in just world scores were collected at the beginning of the experiment to enable an evaluation of this hypothesis.

The belief in a just world (BJW) scale (Lipkus 1991) includes eight items such as 'I feel that the world treats people fairly' and 'I feel that when people meet with misfortune, they have brought it upon themselves'. Theoretically, individuals who score higher on belief in a just world should be more likely to accept inequalities as justified, and thus be more likely to recommend unequal distributions of the prize money. This is indeed what we see in Figure 6.2, where the experimental results are broken down into groups of respondents who were below/above the median score on the belief in just world scale. ${ }^{2}$ As can be seen in Figure 6.2, high BJW respondents recommend more unequal distributions of money in both conditions. Controlling for experimental condition, those high in BJW would

\footnotetext{
${ }^{2}$ The BJW scale ranges from 1 to 6 , where higher scores indicate higher beliefs that the world is just. In my sample, the responses ranged from 1.25 to 5.62 , with a mean of 3.23 and median of 3.25 .
} 
Money allocation to the winner

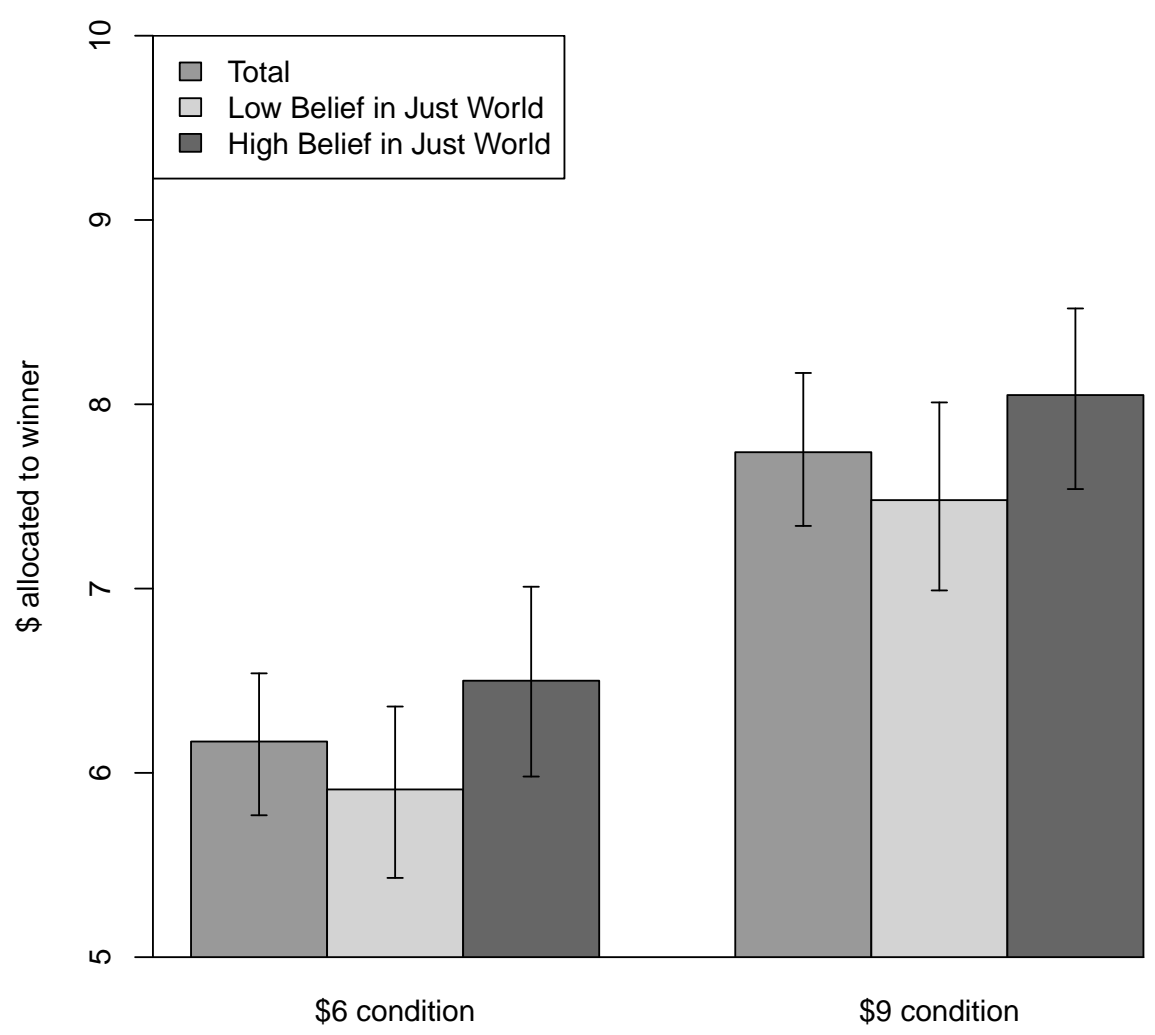

Figure 6.2: Laboratory experiment results: money allocation to the winner by inequality and belief in just world.

Showing the amount of money (out of $\$ 10$ ) that participants allocated to the winner of an anagram competition, by experimental condition and the respondent's score on the Belief in Just World scale. In the $\$ 6$ condition, the winner received $\$ 6$ and in the unequal condition, the winner received $\$ 9$. 
give the winner $\$ 0.56$ more $(\mathrm{p}=0.06)$. In other words, acceptance of inequality in both conditions - is related to the extent to which a person believes that the world is a fair place. This result suggests that high belief in a just world enables an acceptance (and recommendation) of inequality in both conditions. The individual difference hypothesis is supported only in the high inequality condition, where high belief in just world individuals are closer to the status quo (\$9) than low belief in just world individuals. In the low inequality condition, high BJW individuals also recommend higher inequality, and this moves them further away from the status quo than low BJW individuals. It is plausible that this is due to a general tendency of high BJW individuals to think of differential rewards as 'earned'. The impact of this individual difference variable will be considered further in the survey experiments below. It is also interesting to note that the pattern of differential acceptance of inequality does not occur with self-reported conservative-liberal ideology; political conviction does not appear to play a role in producing these results. ${ }^{3}$ In sum, the acceptance of inequality appears to be influenced by prior tendencies to believe the world is just, and the implications of this finding will be further examined in Chapter 7.

\subsubsection{Conclusion}

This experiment demonstrates that existing inequality has an impact on people's preferences for inequality. In addition, this effect is present even though the perceived fairness of the unequal game is lower. In other words, even when

\footnotetext{
${ }^{3}$ There were too few $(8)$ self-reported Republicans in my sample to allow a test with partisanship.
} 
people think of a situation as unfair, and want to diminish the unfairness of it (in this case, by not offering the winner a full \$9), their attempt at equalizing the outcomes still 'falls short' of the answers they would have given had they been in a more equal environment to begin with. In other words, even when people perceive a situation as unfair and attempt to correct for that, they may not endorse a distribution that is as equal as the one endorsed by people who start out with a relatively equal status quo.

\subsection{EXPERIMENT 2: INFORMATION REGARDING EXISTING INEQUAL-} ITY INFLUENCES INEQUALITY IDEALS

The laboratory experiment shows that it is possible for experienced inequality to impact preferences for inequality. However, the situation in a laboratory experiment is artificial and the 'income' under consideration in Experiment 1 is the pay from participating in a competition, not income in the sense we usually mean when discussing income inequality. An ideal experiment with real-life income inequality would involve randomly assigning people to various levels of income inequality in their society. Such an experiment is (of course) not feasible. In lieu of an ideal design, the survey experiment in this chapter randomly assigns (American) individuals to find out that income inequality in their society is higher than they thought. Given the high rates of popular underestimation of income inequality, this treatment is reminiscent of increased media attention to high income inequality. The specific form of the habituation hypothesis in this experiment is: 
Hypothesis: participants who are randomly assigned to find out that their society is more unequal than previously believed will increase their estimates of how much income inequality is desirable.

\subsubsection{StUdy DESIGN}

Attitudes toward income inequality will be measured by asking questions regarding perceived and ideal levels of pay for six occupations; this measure of inequality is taken from the International Social Survey Project and was used for regression analysis in Chapter 5. As before, these questions are used because they are intuitively easy to understand and respond to. In addition, using the same measure that was used to establish a correlation between perceptions and ideals gives us a precise test of whether the causality behind the already established correlation is in the direction of the habituation hypothesis. In sum, can new information regarding inequality move inequality ideals?

The respondents are thus asked how much money they believe that people in a list of occupations make in a year, and then they are asked how much they believe that these occupations ought to earn in a year. This provides estimates of the respondents' perceived level of income inequality and of their ideal level of income inequality. The occupational groups are the same as in Chapter 5: unskilled factory worker, skilled factory worker, owner of a small shop, a doctor in general practice, a member of the federal cabinet and a CEO of a large national corporation. The outcome variable of interest will be the index of 'ideal income inequality', calculated as $\ln$ (highest specified income / lowest specified income). The 
$\log$ transformation is used in all regressions (due to the skewed distribution of the data, with a long tail toward extremely high estimates); however, for ease of interpretation, all Figures present unlogged ratios of highest to lowest suggested income. These ratios can conveniently be interpreted as answers to the question "how many times more than the lowest earning occupation should the highest earning occupation be paid?"

The treatment variable in this study is factual information regarding income inequality in the United States. The aim of the information treatment is to inform participants that income inequality is different than they previously thought, and to measure whether their ideal distributions of income change as a result. Based on data from the ISSP, an overwhelming majority of respondents underestimates the true extent of income inequality. This finding is replicated in the survey sample used for this experiment: about $93 \%$ of respondents guess that the true ratio of highest to lowest incomes is lower than it really is. Based on the 2010 ratio of the incomes of unskilled factory workers to the incomes of CEO's of Standard and Poor's 500 companies, the true high-to-low income ratio is slightly above 470 ; less than $1 \%$ of respondents think that a ratio of this magnitude or higher is ideal. Thus, the impact of the factual information treatment, for an overwhelming majority of respondents, is to inform them that inequality is higher than they estimated it to be. If ideals are adjusted in the direction of this new (ly perceived) position of the status quo, we should observe higher ideal estimates for income inequality in the treatment group than in the control group. 


\subsubsection{METHOD}

407 U.S. participants were recruited on Amazon's Mechanical Turk ${ }^{4}$ in August 2012 to answer an "Opinion survey". The mean age of participants was 30, 63\% were female, $55 \%$ had a college degree or higher, $77 \%$ were Caucasian, and $20 \%$ self-identified as Republican. The participants answered some basic demographic questions and the scale on belief in a just world (Lipkus 1991), followed by questions regarding perceived and ideal income inequality. Half (204) of the participants were in the control group and received no factual information about inequality; half (203 participants) received information regarding the current income inequalities in the U.S., as shown in Figure 6.3. ${ }^{5}$ This information was inserted immediately after the participants gave their guesses for existing income inequality, and immediately before they gave their responses for how large income inequality ought to be. All respondents then indicated their annual income and answered some political attitude questions, including questions on whether income differences in America are too large and whether it is the

\footnotetext{
${ }^{4}$ See Berinsky et al (2012) for a summary on the use of Amazon's Mechanical Turk as a platform for social science experiments.

${ }^{5}$ All information is factually correct. The pay numbers for doctor in general practice, owner of a small shop, skilled factory worker, and unskilled factory worker come from the May 2010 National Occupational Employment and Wage Estimates United States by the Bureau of Labor Statistics (accessed Jan 082012 at http://www.bls.gov/ oes/current/oes_nat.htm). The information for members of the federal cabinet comes from payscale.com (accessed at http://jobs.aol.com/articles/2010/11/02/ federal-government-pay-scale/ on Jan 18 2012). The information for CEO of large national company comes from the AFL-CIO's analysis of Standard and Poor 500 companies in 2010 (accessed at the Executive Paywatch section of http://www.afl-cio.org on Jan 18 2012).
} 
Sources: Bureau of Labor Statistics, AFL-CIO,

Payscale.com

Figure 6.3: Information treatment in survey experiment.

The information manipulation was administered to a randomly selected half of respondents. All information is factually correct (see footnote 5, this chapter, for data sources).

responsibility of the government to reduce income differences. ${ }^{6}$

\subsubsection{Results}

The results of the survey experiment are summarized in Figure 6.4. In the absence of information about inequality, respondents thought that the best paid occupation should earn 9 times more than the least well paid occupation. This is reasonably close to the national average preference of 11 times more, based on similar questions asked in the 2010 GSS. Given that the Mechanical Turk sample is more liberal than the national average, the preference for somewhat lower income inequality is something we might expect.

\footnotetext{
${ }^{6}$ The six political attitude questions were: 'How often do you trust the government in Washington to do what is right?', 'Differences in income in America are too large.,' 'Large differences in income are necessary for America's prosperity.', 'It is the responsibility of the government to reduce the differences in income between people with high incomes and people with low incomes.', 'The rich pay too much in taxes.' and 'The government has a responsibility to help the poor.'
} 


\section{Suggested income ratios (highest to lowest salary)}

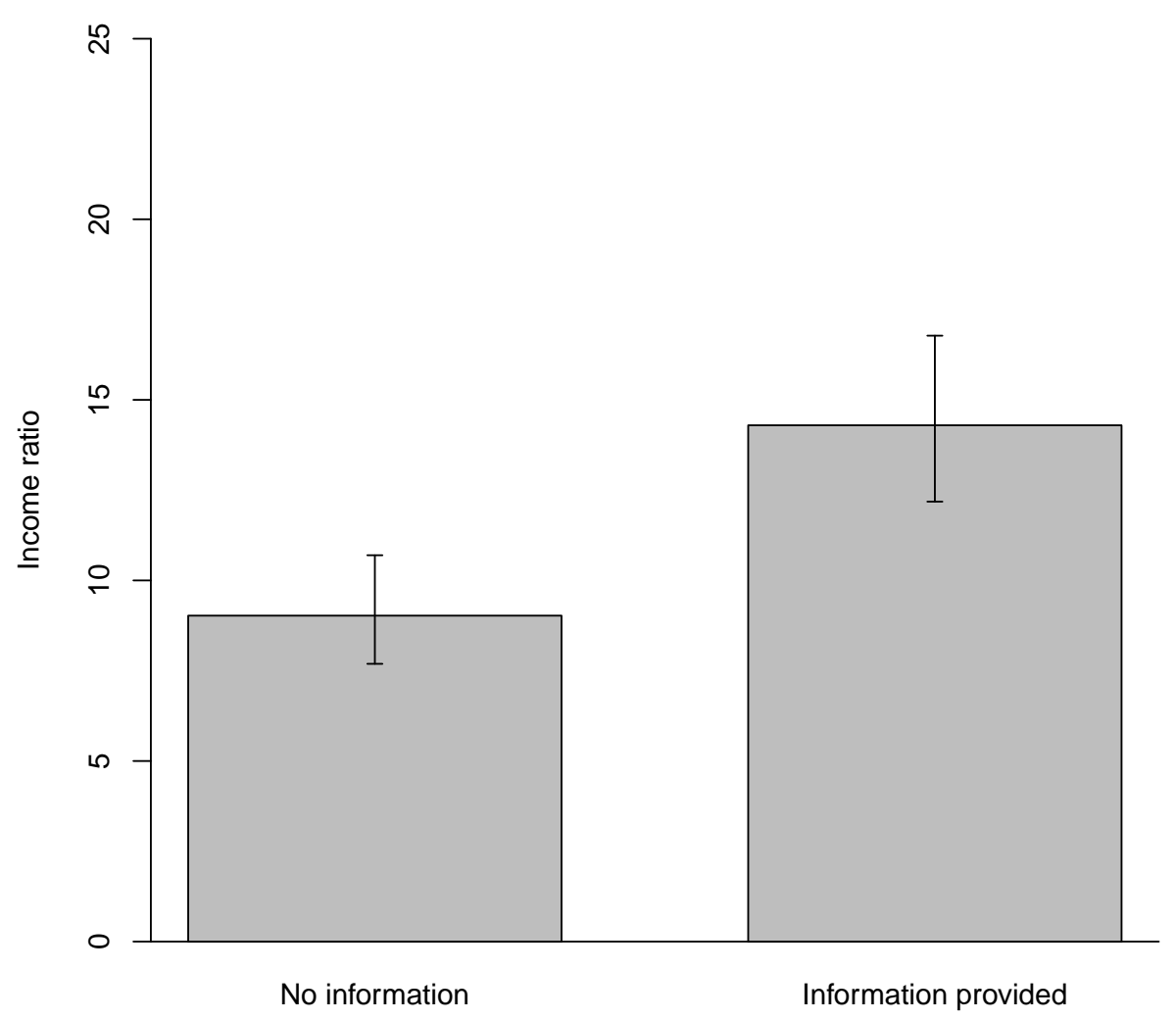

Figure 6.4: Survey experiment results: recommended inequality by information condition.

Showing the recommended ratio of highest to lowest salaries, by information treatment group. The difference is significant at $p<0.001$. 
Table 6.1: Survey experiment results: regression coefficients predicting inequality ideals.

Showing regression coefficients from a linear least squares model; outcome variable is the index of preferred income inequality, calculated as In (highest specified income/lowest specified income). The coefficients in bold are significant at the $95 \%$ level. The information treatment variable is a dummy variable. Belief in a just world is a dummy variable indicating above median scores on the belief in just world scale. Democrat is a dummy variable for selfidentifying as a Democrat, or as an independent who leans Democratic.

\begin{tabular}{|l|cc|cc|cc|}
\hline & \multicolumn{2}{|c|}{ Model 1 } & \multicolumn{2}{c|}{ Model 2 } & \multicolumn{2}{c|}{ Model 3 } \\
Variable & Coef & S.E. & Coef & S.E. & Coef & S.E. \\
\hline Intercept & $\mathbf{2 . 2 0}$ & 0.08 & $\mathbf{2 . 0 5}$ & 0.10 & $\mathbf{2 . 5 1}$ & 0.12 \\
Information treatment & $\mathbf{0 . 4 7}$ & $\mathbf{0 . 1 2}$ & $\mathbf{0 . 4 8}$ & 0.12 & $\mathbf{0 . 4 9}$ & 0.12 \\
Belief in just world & & & $\mathbf{0 . 2 9}$ & 0.12 & & \\
Democrat & & & & $-\mathbf{0 . 4 8}$ & 0.12 \\
N & 407 & 407 & \multicolumn{2}{|c|}{403} \\
Adj. $\mathbf{R}^{2}$ & 0.03 & 0.05 & 0.07 \\
\hline
\end{tabular}

After exposure to information regarding true income differences, the preferred income ratio rises to 14.3 - a more than $50 \%$ increase from control group preferences, a highly statistically significant difference (see Table 6.1 for coefficient estimates). The information that income inequality is higher than previously thought thus caused an upward adjustment in estimates of how much income inequality is desirable. ${ }^{7}$

It is important to note that while preferences regarding inequality move up, only two out of 203 respondents in the treatment group recommend a division that is as or more unequal than the status quo that has just been described to

\footnotetext{
${ }^{7}$ In this experiment, the effect is driven by adjustments made to preferences for CEO pay. However, basing estimates for fair pay on information regarding actual pay is not limited to exceptionally high incomes: a similar adjustment effect, but with respect to the recommended amount of state aid to families below the poverty line, is demonstrated in Iyengar (1990).
} 
them. Most respondents start from a position of believing there is more inequality than they think is ideal, and they still think that inequality is higher than it should be after the information treatment. The change occurs in their estimates of the magnitude of acceptable inequalities; system justification theory predicts that this adjustment occurs in order to mitigate the alternative conclusion that the U.S. social system is (even) more unfair than previously thought. The observed result is consistent with the observation that, just as all inequalities are not rejected, not all inequalities are accepted either, and resistance to inequalities certainly exists in the political world. Rather than arguing that all inequality is automatically accepted, my argument here is more modest: increased inequality increases, on average, our perception of how much inequality is acceptable.

When belief in just world scores are added as an explanatory factor (Model 2 in Table 6.1; predicted values shown in Figure 6.5), the information treatment remains unchanged, but belief in just world scores have an independent effect in the expected direction: high belief in just world predicts a higher preference for inequality. There is no interaction effect between belief in just world and the information treatment. In other words, the adjustment process occurs both for high and low belief in just world individuals: there is an across the board adjustment in the level of inequality that is thought of as just. This result is consistent with the occurrence of the cognitive adjustments predicted by status quo bias. 
Suggested income ratios (highest to lowest salary)

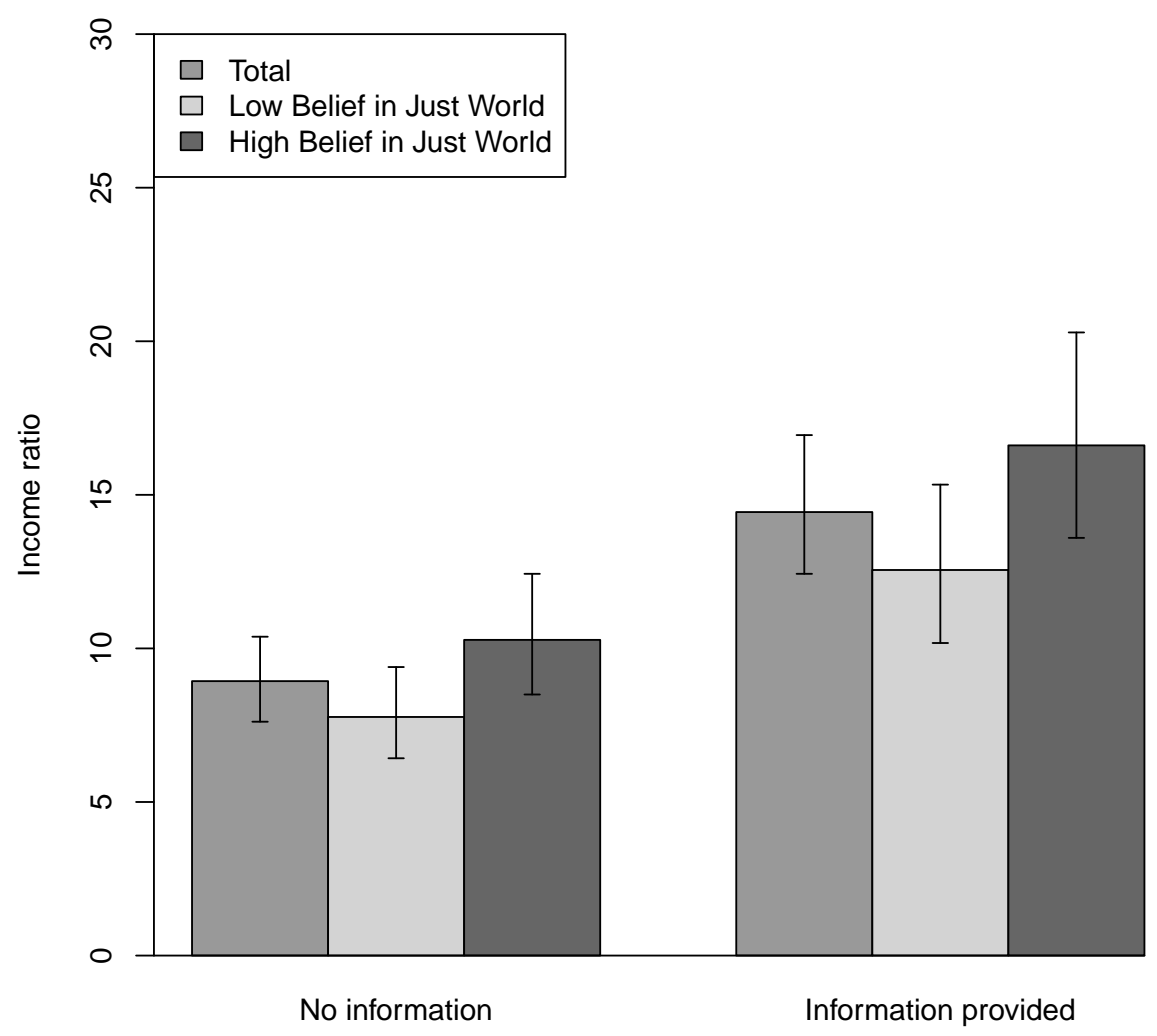

Figure 6.5: Survey experiment results: recommended inequality by information condition and belief in just world.

Showing the recommended ratio of highest to lowest salaries, by treatment group and belief in a just world score (respondents divided at the median score). Values shown are predicted from Model 2 in Table 6.1. 


\section{Suggested income ratios (highest to lowest salary)}

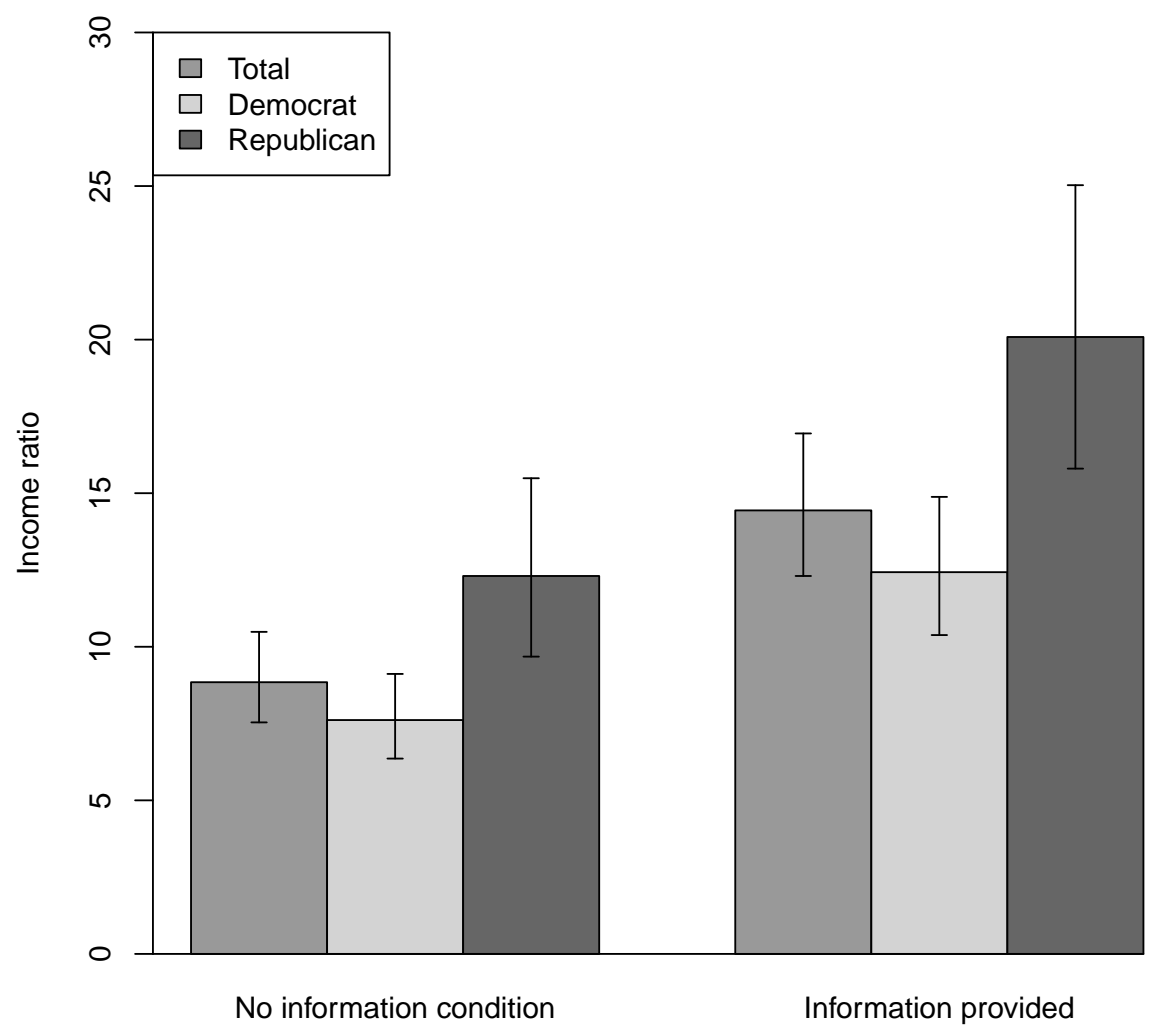

Figure 6.6: Survey experiment results: recommended inequality by information condition and partisanship.

Showing the recommended ratio of highest to lowest salaries, by treatment group and partisanship. Values shown are predicted from Model 3 in Table 6.1 . 
Because most respondents enter the survey believing that inequality in the U.S. is (too) high, it is possible that the motivated aspect of thought (which predicts that high belief in just world individuals would, in an unequal system, be more likely to endorse inequality) has already been incorporated into the stable difference between high- and low belief in just world individuals in this sample. The presence of a motivation to think that the unequal world is fair would explain why there is a stable gap between the two groups in Figure 6.5. The results of this experiment are consistent with the existence of motivated habituation to inequality (as perceived prior to entering the experiment), but the data cannot directly prove that this is the case. In the next chapter, I turn to directly manipulating the moderator (motivation to believe in a just world) to explore the plausibility of this explanation for why the individual difference hypothesis is only partly supported.

In addition to the theoretically interesting division between low- and high belief in just world individuals, it is of practical interest to break down the results by party identification. The results of this division are shown in Model 3 in Table 6.1 and in Figure 6.6. Because belief in just world is known to correlate with conservative identification (Jost et al. 2003), we would expect Republicans to prefer higher income inequality. In addition, given the emphasis that conservative ideology places on the importance of economic incentives to work hard, it is reasonable to expect a positive relationship between Republican identification and inequality preferences. This relationship is indeed what we find: in the information as well as the control condition, Democrats prefer significantly less 
inequality than Republicans. The information treatment moves both groups up; the adjustment is equivalent to multiplying the original estimate of ideal income differences by 1.60. This adjustment is roughly the same size as the difference between partisans. As a result, after receipt of information Democrats prefer a level of inequality that is preferred by Republicans before receipt of information. This result highlights the problematic nature of assuming that pure information about income inequalities would increase opposition to inequality. The adjustment in preferred ideals leaves the relative positions of Democrats and Republicans unchanged (the political 'landscape' does not change), but there has been a subtle upward adjustment in the inequality preferences of all partisans.

\subsection{INFORMATION ABOUT INEQUALITY AND ATTITUDES TOWARD RE- DISTRIBUTION}

The upward adjustments in inequality preferences is, of course, one step removed from questions directly addressing redistributive policies. Because of this, it is theoretically possible that the upward adjustment of inequality preferences co-occurs with an increase in demands for redistributive policies designed to reach this new (albeit updated) preference for inequality. After all, a plausible hypothetical link between increasing income inequality and increasing demands for redistribution is that, as people are made aware of inequality, they start demanding that the government do something about it. Crucially, this opinion change may occur even as individuals update their estimates of acceptable inequality. The habituation hypothesis, however, predicts that the adjustment in 
inequality ideals occurs precisely to prevent the respondents from arriving at the (psychologically more uncomfortable) conclusion that their social system is more unfair than they previously thought. As such, the adjustment of inequality preferences acts as a buffer and prevents the otherwise plausible reaction to too high inequality: increased demands for redistribution.

In order to test whether the information treatment causes greater opposition to existing inequality, my respondents were asked a number of policy attitude questions at the end of the survey. They were asked their degree of agreement with the statements: 'It is the responsibility of the government to reduce the differences in income between the rich and the poor', 'Differences of income in America are too large' and 'Large differences in income are necessary for America's prosperity' The results were virtually identical for all three questions: there were no significant differences between the control group and the information treatment group. Figure 6.7 presents the results for the question regarding government responsibility to reduce income differences, which had the largest treatment effect point estimate (o.18, S.E. o.1 1). The responses are presented by partisanship and experimental condition, and while there are substantial differences between Republicans and Democrats in the expected direction, neither group moves in their response to this question.

Thus, while the information treatment successfully caused respondents to upward revise their thoughts on how large income differences are acceptable, it did not have a discernible impact on attitudes toward the necessity of government redistribution or even whether differences of income in America are too large. 
Agreement that government should reduce income differences

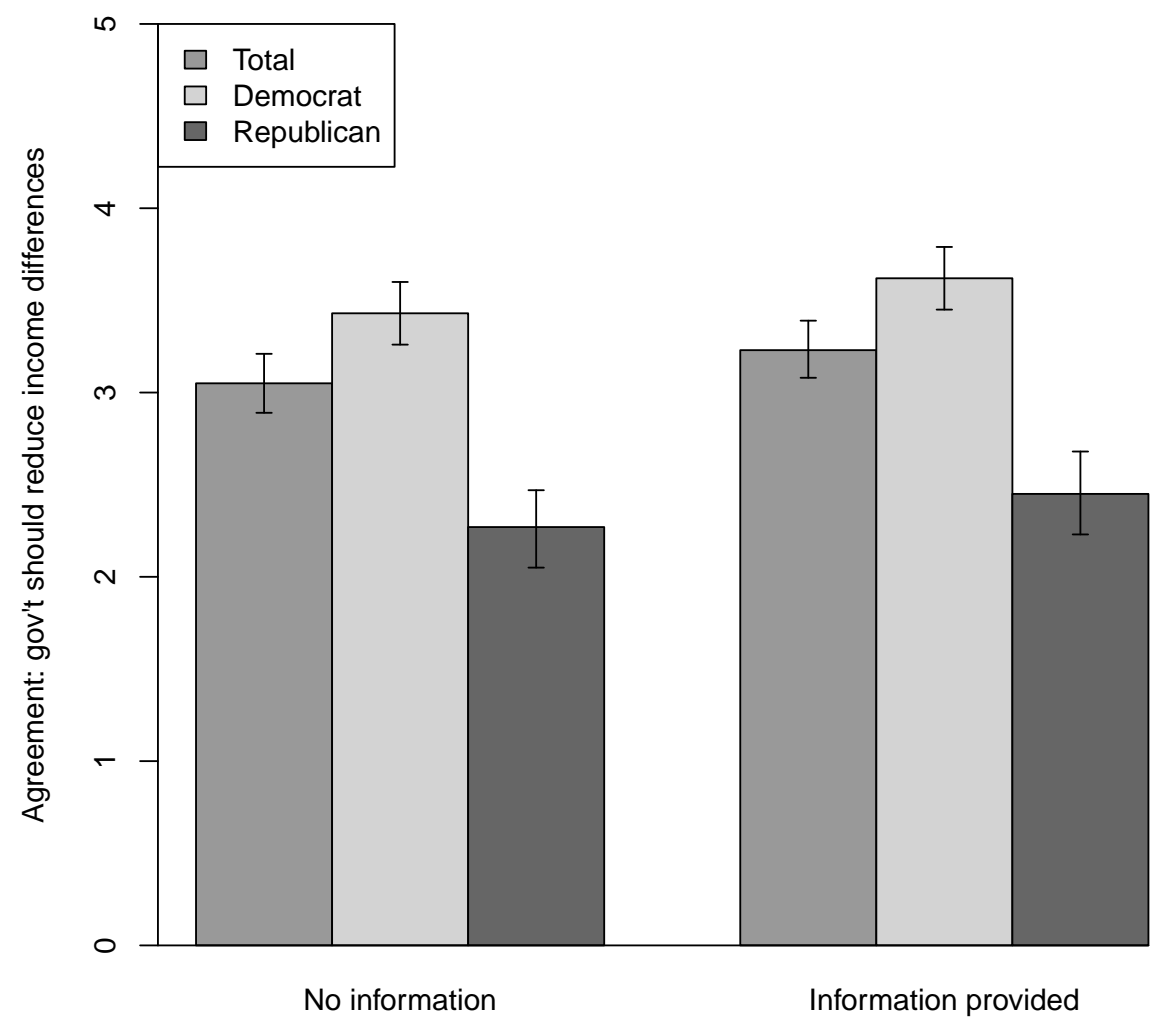

Figure 6.7: Survey experiment results: support for redistribution by partisanship and experimental condition.

Showing agreement (on a 1-5 scale) with the statement that "It is the responsibility of the government to reduce the income differences in income between people with high incomes and people with low incomes." 
The implication is that as (perceptions of) income inequality increase, individual citizens habituate to the new status quo by upward revising their views on how much inequality is acceptable, while not changing their minds on questions that more directly address government redistribution. The relative position of Democrats and Republicans, or individuals who are high/low on belief in just world, does not change after the information treatment, nor does the balance of survey respondents who think that inequality is too high. This means that the receipt of information leaves the political opinion 'landscape' looking very similar to the 'landscape' before the information treatment - but yet there has been a change in public opinion in estimates of 'fair' inequality. The results support the habituation hypothesis, and the experimental effect is consistent with the observation that public opinion in more unequal times and places is not more likely to favor redistribution or to think of current levels of inequality as unfair. 


\section{7 \\ Changing the landscape: society and status quo acceptance.}

I HAVE SO FAR SHOWN THAT ESTIMATES for ideal inequality are subject to the habituation effect. In the current economic situation of the United States, where 
most people a) underestimate the extent of inequality and b) think that there should be less inequality than they perceive, accurate information regarding pay differences will not necessarily result in increased agreement that inequality is too high. Instead, a subtle adjustment of expectations can occur, an adjustment that leaves demands for change, well, unchanged. Importantly, the 'landscape' of political opinion also remains unchanged: the habituation process is proportional to individual starting points, meaning that the relative positions of groups do not change even as average preferences for inequality increase. In this chapter, I will examine whether it is possible to experimentally manipulate not only average preferences for inequality, but also to change the 'landscape of opinion' by moving groups with respect to each other.

In order to manipulate the relative position of groups, I will draw on the third and final hypothesis presented in Chapter 4: the context hypothesis. I will use experimental manipulations that are known to activate the system justification motive and show that perceptions of certain features of the social system can influence the strength of the habituation process. In particular, perceptions of a) the social system as being under threat from the outside, b) difficult to escape, or c) having a lot of influence on valued individual outcomes, can all impact individual tendencies to think of the system as just, and by extension to habituate to the status quo of income differences. 


\subsection{MOTIVATION: CHANGING THE STRENGTH OF THE HABITUATION} EFFECT

It is known that the strength of the system justification motivation not only varies across individuals, but also has situational determinants. Jost and Hunyady (2002) argue that system justifying tendencies provide a "palliative function in that they reduce anxiety, guilt, dissonance, discomfort, and uncertainty." The particular discomforts that are reduced by engaging in system justification are feelings of low personal control and/or high dependence on a (capricious, unfair, or unpredictable) social system. As such, system justification has been shown to be activated under conditions of: “(a) system threat, (b) system dependence, (c) system inescapability, and (d) low personal control." ${ }^{2}$ When the social system is under threat (particularly from the outside, e.g. foreign criticism or military threat), the predictability and stability of one's social environment are in peril. This perception is psychologically uncomfortable, and to counter this discomfort, the system justification motive is activated. The activation of system justification reduces anxiety by increasing faith in the social system as fair and predictable; this adjustment involves re-appraising salient features of the social system as fair and desirable. A similar logic applies to situations where the individual feels more, rather than less, dependent on the social system: when the individual cannot escape the social system, when their personal valued outcomes depend on the social system, or when they feel low in personal control regarding

\footnotetext{
Jost and Hunyadyn (2002, p.111)
}

${ }^{2}$ Kay and Friesen $(2011$, p.360) 
their outcomes, they increase the extent to which they justify the system and think of the system as fair.

These situational determinants of the motivation to justify the social system can be experimentally manipulated (see Kay et al. 2009 for an overview of experiments in this framework). The experimental manipulations used in this literature are designed to temporarily increase the system justification motivation (Kay et al. 2009). Experimentally increasing the motivation tends to be most effective for individuals in whom this motivation is not chronically active, i.e. individuals who are low on the tendency to system justify, low on the tendency to believe in a just world and/or who identify as liberals (see for example van der Toorn 2012). ${ }^{3}$

Building on this research, I chose to use two previously established experimental treatments, both of which manipulate the system justification motive: one treatment manipulates perceptions of dependency on the social system, and the other manipulates perceptions of the inescapability of the social system (Kay et al. 2009). I hypothesize that reading a paragraph that temporarily increases the system justification motivation will induce individuals who are initially low in belief in just world to increase the extent to which they accept income inequalities.

Hypothesis: For individuals who are initially low in belief in just world, exposure to a system justification activation paragraph will increase habituation to the status quo of income inequality.

\footnotetext{
${ }^{3}$ That political conservatism is associated with a higher tendency to engage is system justification has been suggested by Jost et al. (2003) and Napier and Jost (2008).
} 


\subsection{STUDY DESIGN: ACTIVATING THE SYSTEM JUSTIFICATION MOTI-}

\section{VATION}

The study will be a replication of the survey experiment in chapter 6, with the added experimental condition of reading either a system-justification-increasing paragraph, or in the control condition, reading a reverse-worded paragraph that is not expected to increase the motivation to justify the system. The experimental design thus has a 2 (information about income inequalities) x 2 (system justification manipulation) $\mathrm{x} 2$ (belief in just world) set-up. The system justification manipulation is expected to impact low- but not high-BJW individuals. Below, the terms "control" and "treatment" condition will refer to the type of paragraph read by the participant (and not whether or not the participant saw the information treatment), unless otherwise specified.

The system dependency manipulation is adapted from Kay et al. (2009), who show that reading this paragraph subsequently increases the extent to which participants who are told that there are few women in politics think of this state of affairs as ideal, desirable, and representative of the way things should be. van der Toorn et al. (2012) also use this paragraph and show that exposure to the high system dependency manipulation removes the otherwise robust correlation between political orientation and national attachment by increasing the patriotism of liberal respondents but not changing the position of conservatives. The text of the treatment [control] reads as follows:

Do political decisions actually matter? Yes [not really], suggests a 
recent study showing that the government's decisions play a major role [only play a minor role] in determining the average American's quality of life. Dr. Michael Johnson, a UCLA sociology professor, says, "Trends over the last fifty years show that federal government policies have enormously broad [very limited] effects on the life and well-being of Americans. In terms of financial well-being, for instance, the taxes you pay, the job and investment opportunities made available to you, the general state of the economy — to a large extent, these things are under the control of the federal government [rarely affected by government decisions].” Over the past several decades, the United States has seen many different governments. Though they often appear similar [different], many governments' decisions are drastically different from [fairly similar to] one another. Because of this, one's social and personal well-being are fairly dependent on [often unaffected by] which political party is in power. For example, the quality of social services [e.g., health and education] are [in]dependent on [of] government decisions. "In their approach to many issues, political parties vary widely [differ only on minor points], so which party is in power can make a dramatic difference [often makes little difference] in one's everyday life," says Dr. Johnson. Finally, a 2009 Pew survey suggests that many older Americans now see how their lives were [un] affected by changes in government. "Looking back, I see how my quality of life 
depended [didn't depend] on which government was in power," said one survey respondent. In short, these studies suggest that decisions in Washington greatly affect [have little effect on] one's quality of life, and have considerable [only minor] influence on your day-to-day activities.

The second treatment manipulates the respondents' sense of the escapability of the social system, in other words how easy it is to leave the relevant system (in this case, the United States). This manipulation was used by Kay et al. (2009) to increase the treated participants' agreement with the notion that the Canadian House of Representatives should be composed largely of wealthy people (the status quo). Laurin et al. (2010b) use this inescapability manipulation and show that exposure to the treatment causes respondents to ascribe gender inequality to genuine differences (as opposed to systemic inequality).

The treatment [control] paragraphs read as follows:

Since the 1950's, a group at Harvard University, in Cambridge, has been using current political and international trends to predict patterns of population movements. Recent reports by this group of experts have indicated that people who wish to move out of the United States will find it increasingly difficult [easy] to do so, in the coming years. Thus, even if the number of Americans wishing to leave and settle elsewhere remains constant, we should expect a significant slow-down [increase] over the next few years in terms of those who actually are able to do so. 
The study was set up to replicate the survey experiment presented in chapter 6, with the addition of a randomly assigned paragraph, presented as a "reading comprehension task". The paragraph was placed in the survey before the first question about income inequality.

802 participants were recruited Amazon's Mechanical Turk in January 2013 to answer an "Opinion survey". The mean age of respondents was 31 years, with a median of 28 and a range from 19 to $72.59 \%$ were female, $55 \%$ had a college degree, and 60\% identified as Democrats (including independents who lean Democratic). $78 \%$ self-identified as Caucasian, $9 \%$ as Asian and $6 \%$ as African American. On the belief in just world Scale, which ranges from 1-6, the mean response was 3.32 and the median response was 3.38 . In the analyses below, respondents were split into "high" and "low" belief in just world groups based on whether they were above or below the median score.

\subsection{RESUltS: ACTIVATING THE SYSTEM JUSTIFICATION MOTIVE RE- DUCES THE PARTISAN GAP IN INEQUALITY IDEALS}

As hypothesized, the system justification activation paragraphs increase the level of inequality recommended by low belief in just world individuals. The effect is large enough to render the otherwise-robust difference between low- and high-belief in just world individuals statistically insignificant. The results are presented in detail Table 7.1 and Figure 7.1.

As Table 7.1 shows, the two treatment paragraphs had similar effects: both 
Table 7.1: Survey experiment results: impact of system justification manipulations on inequality preferences.

Showing regression coefficients from a linear least squares model; outcome variable is the index of preferred income inequality, calculated as In(highest specified income / lowest specified income). The coefficients in bold are significant at the $95 \%$ level. In Model 3, the dependency and inescapability treatments are collapsed to increase power. The information treatment variable is a dummy variable. Belief in a just world is a dummy variable indicating above median scores on the belief in just world scale.

\begin{tabular}{|c|c|c|c|c|c|c|c|c|}
\hline \multirow[b]{2}{*}{ Variable } & \multicolumn{2}{|c|}{ Model 1} & \multicolumn{2}{|c|}{ Model 2} & \multicolumn{2}{|c|}{ Model 3} & \multicolumn{2}{|c|}{ Model 4} \\
\hline & Coef & S.E. & Coef & S.E. & Coef & S.E. & Coef & S.E. \\
\hline Intercept & 1.91 & 0.13 & 2.03 & 0.15 & 1.96 & 0.10 & 2.06 & 0.09 \\
\hline Information treatment & 0.81 & 0.13 & 0.47 & 0.12 & 0.64 & 0.09 & 0.61 & 0.09 \\
\hline Belief in just world (BJW) & 0.46 & 0.18 & 0.38 & 0.17 & 0.42 & 0.12 & & \\
\hline Republican identification & & & & & & & 0.55 & 0.15 \\
\hline High dependency & 0.18 & 0.18 & & & & & & \\
\hline High dependency $\mathrm{x}$ BJW & -0.13 & 0.25 & & & & & & \\
\hline High inescapability & & & 0.32 & 0.18 & & & & \\
\hline High inescapability x BJW & & & -0.34 & 0.24 & & & & \\
\hline Inescapability or dependency & & & & & 0.25 & 0.13 & 0.20 & 0.11 \\
\hline Inescapability or dependency $\mathrm{x}$ BJW & & & & & -0.23 & 0.18 & -0.31 & 0.21 \\
\hline & 39 & & 394 & & 79 & & 66 & \\
\hline Adj. $R^{2}$ & 0. & & 0.0 & & 0. & & 0.0 & \\
\hline
\end{tabular}


Suggested income ratios (highest to lowest salary)

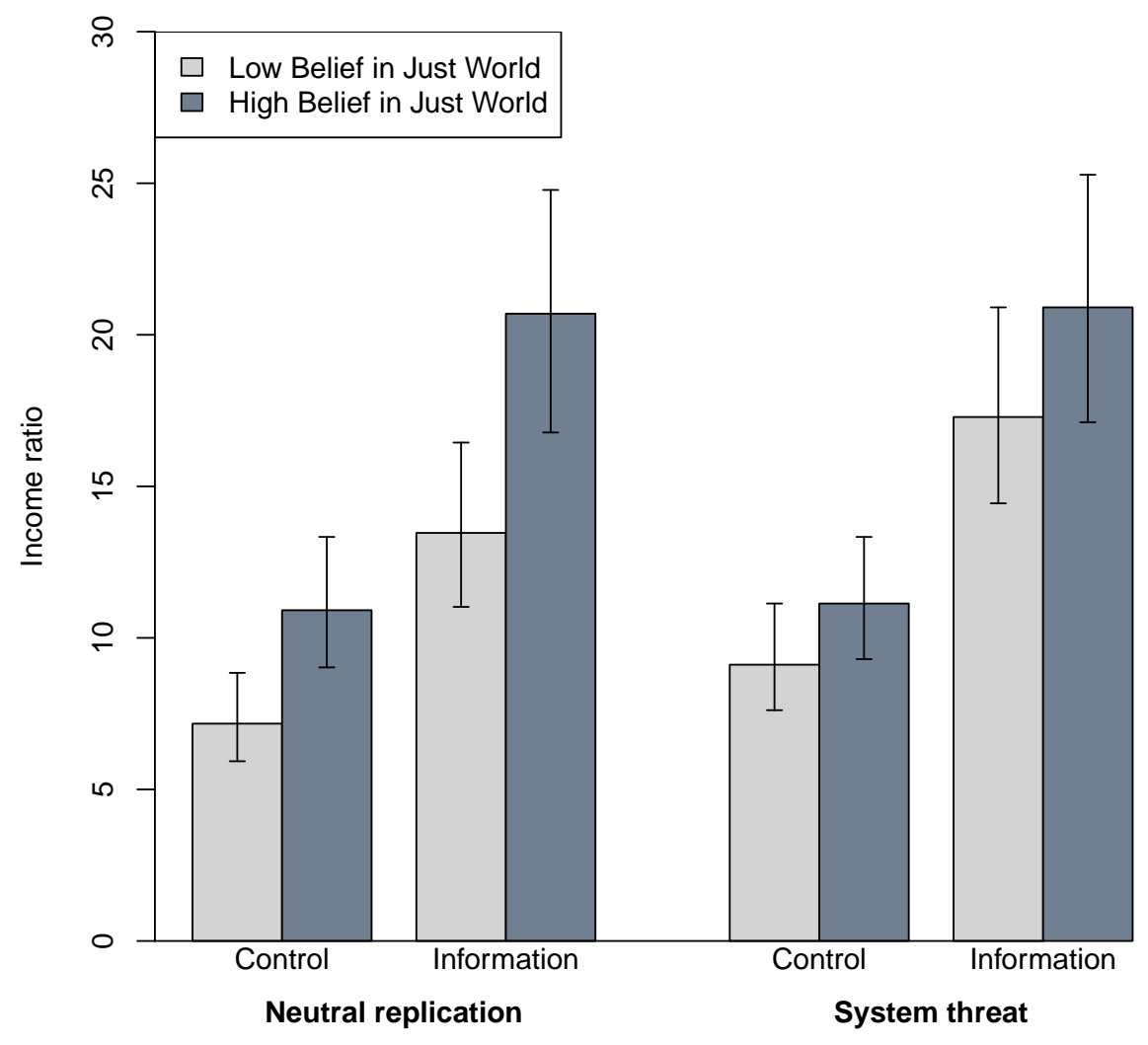

Figure 7.1: Survey experiment results by belief in just world and system justification manipulation.

Showing the recommended ratio of highest to lowest salaries. Values shown are predicted from Model 3 in Table 7.1. The "system threat" condition indicates receipt of either a system dependency or a system inescapability treatment. 
increase the level of inequality recommended by low BJW individuals, but do not affect the inequality ideal of high BJW individuals. When the treatments are analyzed one at a time, the system dependency manipulation exhibits the expected pattern of results, but the impact is statistically insignificant. The inescapability treatment has a somewhat stronger effect, and this effect is marginally significant (at the $\mathrm{p}<0.10$ ) level. When the two treatments are combined, the power that is gained from combining participants reduces the standard error without changing the average treatment effect, and the combined effect is statistically significant at the $95 \%$ level (see Column 3 of Table 7.1). This model is used to calculate the predicted values presented in Figure 7.1. In the figure, receipt of either the high inescapability or the high dependency treatment paragraph is referred to as the "system threat" condition. There are significant differences between high and low BJW individuals in the control condition (where the participants read one of the reverse-worded, non-threatening paragraphs). Receiving one of the treatment paragraphs moves the inequality preferences of low BJW individuals up enough to make these differences between low and high BJW individuals insignificant. The system justification activation condition, on average, causes the low BJW respondents to recommend an inequality ratio that is 1.3 times higher than in the control condition. In other words, the political 'landscape' of inequality attitudes changes when the perceived social environment increases the motivation to engage in system justification.

It is interesting to note that the impact of the combined 'system threat' treatment is the same both in the information condition and the condition 
without any information on actual inequality. As shown previously, most respondents think that there is a high level of inequality in the U.S; they just underestimate just how much there is of it. In this sample, as before, $91 \%$ of the respondents in the no-information group believe that there is more income inequality in the United States than would be ideal. Thus, it is plausible that this knowledge of high inequality is enough to push expectations for inequality up when the system justification motive is experimentally activated. Even in the no-information condition, respondents are asked to indicate their best estimates for actual income inequality, and this question (even in the absence of factual information) serves to highlight this particular aspect of the United States society. In other words, this question makes income inequality a salient feature of the social system, subject to the activated system justification impulse. It is possible that in the absence of this 'highlighting' impact of the income inequality estimate question, the threat paragraphs would have a smaller impact on estimates of income inequality, as some other aspect of the system may be justified instead.

These results show that manipulating the system justification motive has a direct impact on preferences for income inequality. The fact that high BJW respondents do not change their mind about inequality in the treatment condition supports the notion that, for these individuals, the motivation is already chronically active.

Jost et al. (2003) have argued that the individual level tendency to justify the system is related to conservative political beliefs. In my sample of respondents, there is indeed a positive, although not striking, correlation between beliefs in 
just world and republican identification (0.18). However, the possibility that the 'system threat' manipulation may cause the political landscape to change in terms of the differences between partisan identifiers is an intriguing one. Model 4 in Table 7.1 and Figure 7.2 show the results of analyzing the impact of the information and system threat treatments on Republican identifiers (including independents who lean Republican) as compared to Democrats (including independents who lean Democrat). ${ }^{4}$ The threat treatment is marginally significant $(\mathrm{p}=0.07)$ for Democrats and has an insignificant impact on Republicans. As Figure 7.2 illustrates, the impact of the treatment paragraphs is sufficient to increase Democratic preferences for income inequality and render the otherwise robust difference between Republicans and Democrats insignificant. In other words, the (manipulated) social context changes the size and significance of partisan disagreement regarding income inequality.

\subsection{ConcLusion}

When the system justification motive is experimentally manipulated, the extent to which respondents think of income inequalities as desirable changes. The change occurs in particular among those who are chronically low in the motivation to justify the system, i.e. individuals with a low belief in a just world. Because Democrats tend to have lower belief in just world scores, this effect carries over into the political realm: in the presence of system inescapability or

\footnotetext{
${ }^{4}$ In the presented results, complete independents are excluded. The results are similar but with a somewhat weaker statistical significance if independents are included.
} 
Suggested income ratios (highest to lowest salary)

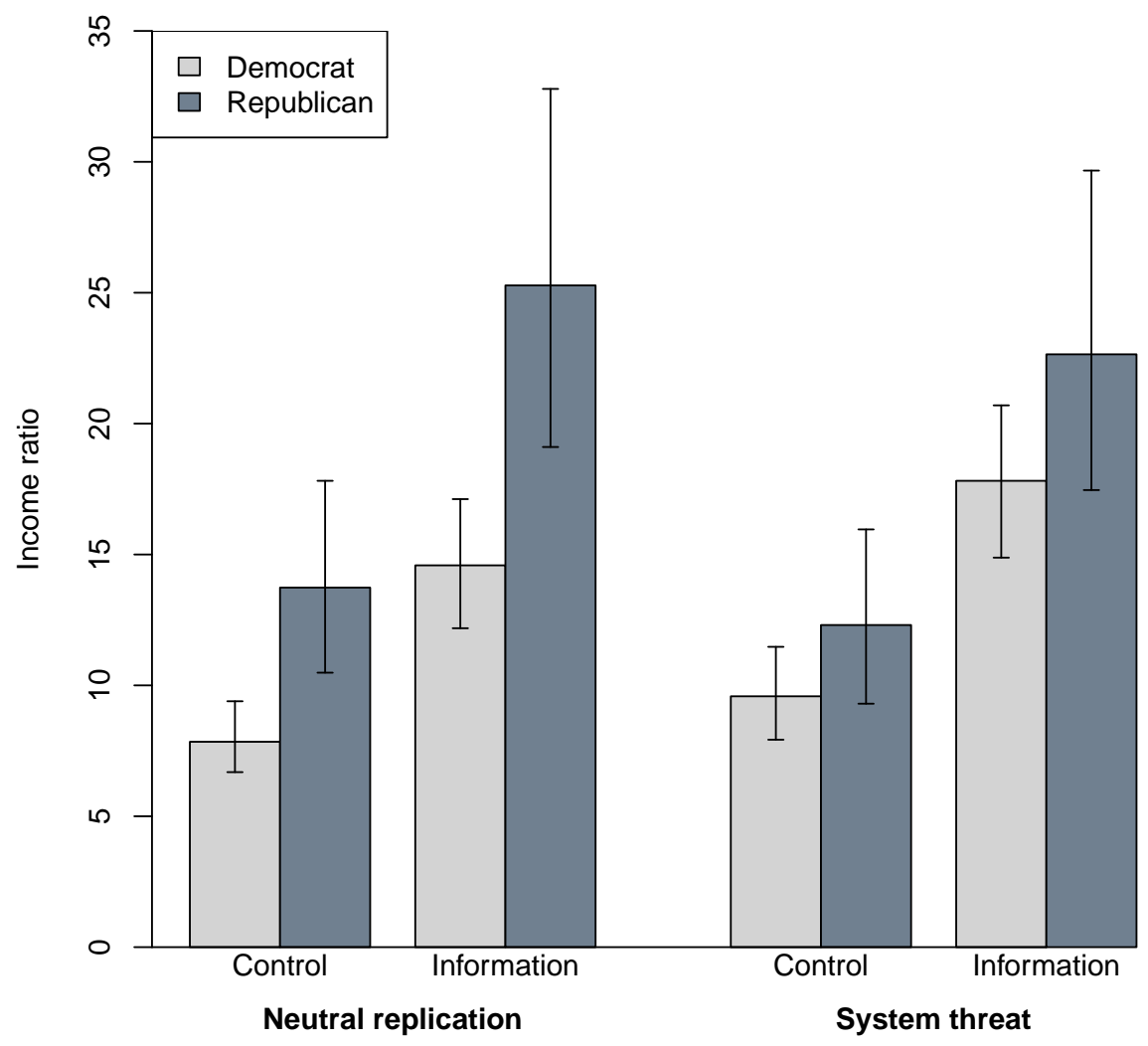

Figure 7.2: Survey experiment results by partisanship and system justification manipulation.

Showing the recommended ratio of highest to lowest salaries. Values shown are predicted from Model 4 in Table 7.1. The "system threat" condition indicates receipt of either a system dependency or a system inescapability treatment. 
dependence messages, Democrats think of higher levels of income inequality as justified.

The paragraphs used to achieve this manipulation of the political 'landscape' and to change the relative positions of partisan groups are, importantly, political and yet removed from the topic of income inequality. The topics discussed in typical system justification manipulations, including possibilities for migration, the degree to which individual outcomes depend on the social system, and outside threats to the social system, are profoundly political. They are the type of topics that may readily be discussed on the front pages of national newspapers possibly alongside reports about historically high levels of CEO pay. The fact that statements about the state of society have counter-intuitive impacts on the formation of public opinion on a different aspect of society is striking. There are potentially important consequences here for the study of political rhetoric as well as the dynamic by which public opinion develops and changes.

The suggestion that an outside threat may boost approval ratings of the domestic system is not new; the 'rally around the flag' effect is well known, but until now it has not been connected to the psychological mechanisms involved in status quo bias and system justification. The findings presented here suggest that system justification theory may be useful for research into the conditions under which the 'rally around the flag' effect occurs and how the phenomenon subsides.

There are important questions to be asked regarding the durability of the effects demonstrated in this experiment. What is the long-term impact of exposure to rhetoric, say, about outside threats to the social system? For example, 
how do perceptions of serious threats such as the Cold War or terrorism influence the dynamics of public opinion on domestic issues like income inequality? This is where political science research meets the current 'edge' of social psychology research on system justification. The long-term social determinants of the salience of the system justification motive are not yet well understood (Jost and Hunyady, 2002). While we know that short-term manipulations can temporarily increase the motivation, the impact of repeated exposure to these messages is unclear. As a case in point, consider that an “economic threat" paragraph, used to manipulate American respondents' sense of system threat in Kay et al. (2009) is no longer a reliable manipulation; it fails to produce the temporary boost previously found reliably with this particular manipulation. ${ }^{5}$ The paragraph in question reports that the American economy is not doing well and that Americans are increasingly worried about their economic prospects. After the financial crash of 2008 , of course, such reporting became commonplace in the media, and this is the likely cause for the drop in the paragraph's effectiveness: the 'news' in this paragraph is no longer 'news' to most Americans. We do not know, however, whether the drop in effectiveness has occurred because American respondents have gotten so used to the message that their system justification tendencies have regressed back to the mean, or whether knowledge of this information has resulted in chronically higher levels of the system justification motive for American respondents. Improving our understanding of long-term relationships between (perceptions of) the political

\footnotetext{
${ }^{5}$ Personal communications with Jaime Napier, November 2012.
} 
system, the system justification motive, and attitudes toward the status quo (including income inequality) is an important task for future research. 


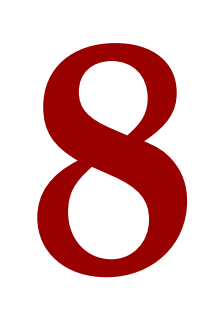

\section{Discussion and conclusion}

How ARE ATTITUDES TOWARD ECONOMIC INEQUALITY FORMED? How are these attitudes influenced by the society that surrounds the individual? Why is it the case that everywhere we look, there is less demand for redistribution than we might expect given material self-interest motivations? This dissertation has 
argued that due to the habituation effect, attitudes toward income inequality are endogenous to actual income inequality in ways that have previously not been appreciated.

The habituation hypothesis states that our ideas of which income inequalities are 'fair' are systematically skewed toward the status quo. As economic inequality changes, estimates of fair and appropriate levels of inequality move in the same direction as the factual change in inequality. The habituation process occurs because beliefs about 'fair' inequality are subject to status quo bias and the motivation to believe in a just world. This process is strengthened by the fact that universally endorsed concepts like 'desert' are subjective and difficult to translate into specific income amounts. When we are faced with information that income inequality is different than we expected (either because we were previously misinformed or because inequality has changed), a convenient mental adjustment to 'what is deserved' can be performed instead of concluding that our social system is unexpectedly unfair. The habituation mechanism can thus explain why income inequality can increase without producing corresponding increases in beliefs that inequality is 'too high'.

In modern societies, where income inequality is a) higher than people perceive it to be, b) higher than people think it should be and c) increasing, receiving information about income inequality typically involves finding out that inequality is higher than one previously thought. As a consequence, the habituation hypothesis predicts that the public subtly adjusts expectations for how large differences in income are fair, and that this adjustment can explain why increased 
income inequality has not produced increased demands for redistribution.

\subsection{Limitations}

The habituation hypothesis, by definition, cannot explain opposition to and rejection of economic inequality. In this sense, it is similar to the economic self-interest hypothesis, which by definition cannot explain acquiescence with economic inequality. In real political environments, both acceptance and rejection of economic inequality occur side by side, and both aspects of behavior need to be explained for a full description of political life. If both a material self-interest motive and a habituation process exist, their respective limitations produce new and interesting research questions: how do these motives interact in real political environments, and what happens when they conflict on an individual level?

The evidence presented in this dissertation is aimed specifically at understanding the relationship between perceived and preferred income inequality. This leaves several important and related questions open for future research. For example, the experiments presented here do not address whether the phenomenon extends to other types of economic inequality (e.g. wealth) or even non-economic inequalities (e.g. education, health outcomes). Another outstanding task is to 'complete the circle' by examining whether perceptions of inequality are sufficiently accurate for the habituation process to truly explain differences in preferences for inequality (and, by extension, demands for redistribution) across countries. The habituation hypothesis may be important 
for explaining the development and change of redistributive demands cross-nationally and over time, but the complete sequence of links between real inequality, perceptions of inequality, preferences for inequality and, finally, redistributive demand needs to be better understood before we can say with confidence that the habituation concept can explain demands for government redistribution in real political contexts.

\subsection{IMPLICATIONS FOR INTERPRETATIONS OF INEQUALITY ATTITUDES}

The habituation hypothesis speaks to the empirical finding that in unequal countries, more inequality is thought of as acceptable (Evans and Kelley 2007). The knowledge that existing inequality can impact preferences for inequality can serve as a partial guide to interpretation of survey data when the latter shows that in more unequal countries, people think of larger income differences as acceptable. If causality could only flow from public opinion through public policy to income inequality, such data would be a strong basis for concluding, as Evans and Kelley (2007) do, that it would be plainly undesirable and undemocratic to intervene with high levels of inequality. As long as the population thinks of inequality as justifiable, "outsiders might not like [it $]$, [...] but it would take a very authoritarian philosopher-king to wish to impose their personal views on an unwilling citizenry. Moreover, the attempt is likely to be futile in a democracy."

Knowing that higher inequality predisposes citizens to think of higher inequality as justifiable highlights the difficulties of interpreting comparative

\footnotetext{
${ }^{1}$ Evans and Kelley (2007, p.15).
} 
public opinion as the product of a single causal direction: from public opinion to reality on the ground. Of course, all democratic opinion is subject to subconscious influences from facts and events. The fact that attitudes toward inequality are also subject to such influences does not invalidate these opinions any more than it invalidates democratic opinion more generally. However, we would do well to pay attention to subconscious influences where we know they exist, in order to avoid subscribing to unfounded counter-factuals, such as the conclusion that if inequality were to change then public opinion would automatically demand its restoration to the current (and presumed ideal) level.

\subsection{IMPLICATIONS FOR PUBLIC DISCOURSE ABOUT INCOME INEQUAL-} ITY

What are the implications of this work for current public discourse regarding increasing income inequality? One important implication is that increasing public awareness of the 'pure numbers' of income inequality will not necessarily change public opinion about the necessity of government intervention, or even change the sentiment that income inequality is 'too high'. Media coverage that highlights the historically high levels of (top) income inequality in the United States may have a counter-intuitive impact on public opinion by contributing to the habituation effect. This observation may give pause to political commentators who hope to promote liberal viewpoints by highlighting facts regarding the status quo of income inequality.

The observation that media coverage may increase the public's preferred levels 
of inequality comes with caveats. First of all, all experiments discussed here presented information regarding inequality in a neutral way; in particular, the information was neutral with respect to partisanship. In real political life, communications are rarely neutral, so an important next step for research should be to explore what happens to the habituation process when information about the status quo is provided in a clearly approving or disapproving context, or with clear party labels attached. If party labels make the creation of political opposition to inequality easier - as they probably will - the importance of political leadership and rhetoric, including the presence of a strong Social Democratic party, take on renewed importance as determinants of public resistance to high inequality.

Second, there are many ways to discuss inequality. To avoid the habituation process (if that is desired), it is possible to discuss inequality in terms of several alternative future hypotheticals instead of emphasizing the status quo. Going beyond discussions of facts regarding existing income inequality alone, one way to engage with related issues may be to focus on the consequences rather than the existence of inequality. McCall (2013), for example, argues that Americans care about inequality insofar as existing inequality is seen as evidence of unequal opportunities. Indeed, one of the consequences of income inequality - decreasing equality of political voice - is a consequence that most Americans are likely to feel strongly about (see Hochschild 1981 for a discussion of the importance of political equality to Americans, and how this contrasts with attitudes toward economic inequality). As McCall (2013) shows, while perceptions of factual inequality hit their all-time high in 2010 , concern about economic inequality was 
highest in the early 1990's, a time of high media coverage regarding the political consequences of economic inequality. Her results suggest that public opinion is sensitive to inequalities of opportunity and outcome, and that these issues may be separated from factual perceptions of income inequality. Yet another approach for discussing the consequences of income inequality may be to pay particular attention to the assumption of fair rewards for work. Based on focus group work on attitudes toward income inequality in the United Kingdom, Bamfield and Horton (2009) discuss strategies for building greater support for equality. They conclude that "many do not find abstract arguments for greater equality convincing, but instead prefer arguments for greater equality framed in terms of proportionate rewards for one's efforts and contribution." ${ }^{2}$ Actively questioning whether rewards for work are fair may create psychological discomfort (as per the system justification hypothesis), but this process could also make the alternative adjustment (to justify existing incomes) less readily available.

\subsection{FutURe DireCtions}

The impact of the political environment on the strength of the habituation process was discussed in Chapter 7 , but the findings presented there open up more questions than they answer. The notion that, for example, foreign policy situations affect the strength of partisan divisions on the subject of income inequality is potentially consequential for how we think about over-time changes in public opinion. However, because we have very limited knowledge of the

\footnotetext{
${ }^{2}$ Bamfield and Horton (2009, p.7).
} 
long-term effects of activating the system justification motive, we do not yet know how extensive the impact of the political environment can be. It is possible that, given a sufficiently long exposure to system threat messages (e.g. the war on terror), a population chronically becomes more likely to think that their (national) social system is fair. Alternatively, these shocks may have only a temporary effect, whereby the public moves back to some steady, pre-existing level of status quo acceptance, simply having 'habituated' to the messages instead of the status quo. What happens to public opinion during prolonged exposure to system-threatening messages is an important question for future research.

It is also interesting to note that a sense of political efficacy could plausibly be a moderator of the system justification motivation and its impact on accepting the status quo. If the habituation effect occurs because it is psychologically uncomfortable to think of one's social system as unfair, then a belief in one's own ability to change the social system may make it less uncomfortable to consider systemic unfairness. Thereby, a strong sense of political efficacy may attenuate the habituation effect. Whether or not there is a relationship between efficacy and the habituation process is an empirical question for future research.

In conclusion, this dissertation has shown that preferences for income inequality are influenced by existing levels of income inequality. The broader aim of this project is to improve our understanding of the psychological mechanisms of public opinion formation. My results, broadly speaking, call into question assumptions regarding the causal relationship at work in cases where public opinion lines up with the status quo. The results may help us understand why, 
across time and place, there is less opposition to economic inequality than we would expect based on the material self-interest motive. How the habituation mechanism interacts with other political forces to produce a balance of acquiescence and opposition to economic inequality is an important outstanding question, and I hope that this dissertation has contributed toward future research on this topic. 


\section{References}

[1] Daron Acemoglu and James A Robinson. Economic Origins of Dictatorship and Democracy. Cambridge University Press, Cambridge, 2006.

[2] Alberto F. Alesina and George-Marios Angeletos. Fairness and Redistribution: US versus Europe. SSRN Electronic Journal, 2002. URL http: / /www . ssrn. com/abstract $=346545$.

[3] Alberto F Alesina and Edward Glaeser. Fighting Poverty in the U.S. and Europe: A World of Difference. Oxford University Press, Oxford, 2004.

[4] Robert Andersen and Tina Fetner. Economic Inequality and Intolerance: Attitudes toward Homosexuality in 35 Democracies. American Journal of Political Science, 52(4):942-958, 2008.

[5] Lisa R Anderson, Jennifer M Mellor, and Jeffrey Milyo. Inequality and Public Goods Provision (Working Paper). 2004.

[6] N. H. Anderson. A functional theory of cognition. Lawrence Erlbaum Associates, Hillsdale, NJ, 1996.

[7] Solomon E Asch. Forming impressions of personality. Journal of Abnormal and Social Psychology, 41:1230-1240, 1946.

[8] A.B. Atkinson. Income Inequality in OECD Countries: Data and Explanations. Economic Studies, 49(4):479-514, 2003.

[9] Anthony B Atkinson, Thomas Piketty, and Emmanuel Saez. Top Incomes in the Long Run of History. Journal of Economic Literature, 49(1):3-71, 2011.

[10] Orazio Attanasio. The Evolution of Income, Consumption, and Leisure Inequality in The US, 1980-2010 (Working Paper). 2012. 
[1 1] Orazio P Attanasio, Erich Battistin, and Mario Padula. Inequality in Living Standards since 1980: Evidence from Expenditure Data (Working Paper). 2009.

[12] Siobhan Austen. An international comparison of attitudes to inequality. International Journal of Social Economics, 29(3):2 18-237, 2002. doi: 10.1108/03068290210417106. URL http://www. emeraldinsight.com/10 .1108/03068290210417106.

[13] Jeffrey Ayres. Searching for the supposed benefits of higher inequality. American Review of Canadian Studies, 34(4):621-647, December 2004. doi: 10.1080/02722010409481692.

[14] Louise Bamfield and Tim Horton. Understanding attitudes to tackling economic inequality. Technical report, Joseph Rowntree Foundation, London, 2009.

[15] Benjamin S. IV Barber and William English. Divide Our Dollars, Not Divide The Dollar: Redistribution, Fairness, and the Ultimatum Game (Working Paper). 2012.

[16] Larry M Bartels. Unequal Democracy: The Political Economy of the New Gilded Age. Princeton University Press, Princeton, 2008.

[17] Jason Beckfield. Does income inequality harm health? New cross-national evidence. Journal of health and social behavior, 45 (3):231-48, September 2004. URL http: //www.ncbi.nlm.nih.gov/pubmed/15595505.

[18] Roland Benabou and Efe A. Ok. Social mobility and the demand for redistribution: the poum hypothesis. Quarterly Journal of Economics, (May):447-487, 2001.

[19] Roland Benabou and Jean Tirole. Belief in a Just World and Redistributive Politics. Quarterly Journal of Economics, 121 (2):699-746, May 2006. doi: 10.1162/qjec.2006.121.2.699. URL http://qje. oxfordjournals . org/lookup/doi/10.1162/qjec.2006.121.2.699.

[20] Adam J Berinsky, Gregory A Huber, and Gabriel S Lenz. Using Mechanical Turk as a Subject Recruitment Tool for Experimental Research (Working Paper). 2012. 
[2 1] Carles Boix. Democracy and Redistribution. Cambridge University Press, Cambridge, 2003.

[22] Katharine Bradbury and Jane Katz. Are lifetime incomes growing more unequal? Looking at new evidece on family income mobility. Regional Review, $\left(\mathrm{Q}_{4}\right): 2-5,2002$.

[23] Andrea Brandolini. Political Economy and the Mechanics of Politics. Politics \& Society, $38(2): 212-226$, May 2010. doi: 10.1177/0032329210365045. URL http://pas. sagepub.com/cgi/doi/10.1177/0032329210365045.

[24] Clem Brooks, Paul Nieuwbeerta, and Jeff Manza. Cleavage-based voting behavior in cross-national perspective: evidence from six postwar democracies. Social Science Research, 35(1):88-128, March 2006. doi: 10.1016/j.ssresearch.2004.06.005. URL http: // linkinghub . elsevier.com/retrieve/pii/Soo49089X0400081X.

[25] Richard V Burkhauser. Presidential Address: Evaluating the Questions That Alternative Policy Success Measures Answer. Journal of Policy Analysis and Management, 30(2):205-215, 2011 . doi: 10.1002/pam20564.

[26] Robert A Dahl. Polyarchy. Yale University Press, New Haven, 1971.

[27] U. Dallinger. Public support for redistribution: what explains cross-national differences? Journal of European Social Policy, 20(4): 333-349, October 2010. doi: 10.1177/0958928710374373. URL http://esp. sagepub.com/cgi/doi/10.1177/0958928710374373.

[28] Angus Deaton and Darren Lubotsky. Mortality, inequality and race in American cities and states. Social science of medicine (1982), 56(6):

1139-53, March 2003. URL http://www.ncbi.nlm.nih.gov/pubmed/12600354.

[29] Angus Deaton and Darren Lubotsky. Income inequality and mortality in U.S. cities: Weighing the evidence. A response to Ash. Social science \& medicine (1982), 68(11):1914-7, June 2009. doi:

10.1016/j.socscimed.2009.02.039. URL http://www.ncbi.nlm.nih.gov/pubmed/19345462. 
[30] Michelle L. Dion and Vicki Birchfield. Economic Development, Income Inequality, and Preferences for Redistribution. International Studies Quarterly, 54(2):315-334, June 2010. doi: 10.1111/j.1468-2478.2010.00589.x. URL http://doi.wiley.com/10.1111/j.1468-2478.2010.00589.x.

[31] Scott Eidelman and Christian S. Crandall. A Psychological Advantage for the Status Quo. In John T. Jost, Aaron C. Kay, and Hulda Thorisdottir, editors, Social and psychological bases of ideology and system justification, chapter 4, pages 85-106. Oxford University Press, Oxford, 2009.

[32] M.D.R. Evans and Jonathan Kelley. Population Size, Economic Development, and Attitudes Towards Inequality: Evidence from 30 Nations. Population Review, 46(2):1-21, 2007.

[33] Armin Falk, Igo Menrath, Pablo Emilio Verde, and Johannes Siegrist. Cardiovascular Consequences of Unfair Pay. Institute for the Study of Labor Discussion Paper, (5720), 2011.

[34] James Fearon and David Laitin. Ethnicity, Insurgency, and Civil War. American Political Science Review, 97(1):75-90, 2003.

[35] Henning Finseraas. Income Inequality and Demand for Redistribution: A Multilevel Analysis of European Public Opinion. Scandinavian Political Studies, 32(1):94-1 19, March 2009. doi: 10.1111/j.1467-9477.2008.00211.x. URL http://doi.wiley.com/10.1111/j .1467-9477 •2008.00211.x.

[36] APSA Task Force. American Democracy in an Age of Rising Inequality. Perspectives on Politics, 2(4):65 1-666, 2004.

[37] Robert H Frank. Falling Behind: How Rising Inequality Harms the Middle Class. University of California Press, Berkeley, 2007.

[38] Robert H Frank, Adam Seth Levine, and Oege Dijk. Expenditure Cascades (Working Paper). 2011.

[39] Thomas Frank. What's the Matter with Kansas. Metropolitan Books, New York, 2004.

[40] Richard B. Freeman. (Some) Inequality Is Good for You. In David B. Grusky and Tamar Kricheli-Katz, editors, The New Gilded Age: The Critical 
Inequality Debates of Our Time, pages 63-87. Stanford University Press, Stanford, 2012.

[41] Sandro Galea, Melissa Tracy, Katherine J Hoggatt, Charles Dimaggio, and Adam Karpati. Estimated Deaths Attributable to Social Factors in the United States. American journal of public health, June 2011 . doi: 10.2105/AJPH.2010.300086. URL http://www.ncbi.nlm.nih.gov/pubmed/21680937.

[42] Andrew Gelman, David Park, Boris Shor, and Jeronimo Cortina. Red State, Blue State, Rich State, Poor State: Why Americans Vote the Way They Do. Princeton University Press, Princeton, 2008.

[43] Andreas Georgiadis and Alan Manning. Spend it like Beckham? Inequality and redistribution in the UK, 1983-2004. Public Choice, 151 (3-4):537-563, January 2012. doi: 10.1007/s11127-010-9758-7. URL http:

//www. springerlink. com/index/10.1007/s11127-010-9758-7.

[44] Mérove Gijsberts. The Legitimation of Income Inequality in State-socialist and Market Societies. Acta Sociologica, 45 (4):269-285, December 2002. doi: 10.1080/o00169902762022860. URL http://www . informaworld. com/openurl?genre= article\&do $i=10.1080 / 000169902762022860 \&$ magi $c=$ crossref $\mid$ I D404A21 $\mathrm{D}_{5} \mathrm{BB}_{53} \mathrm{O}_{5} \mathrm{~B}_{1} \mathrm{~A}_{640 \mathrm{OFFD}} 44 \mathrm{AE}_{3}$.

[45] Martin Gilens. Why Americans hate welfare: race, media, and the politics of antipoverty policy. University of Chicago Press, Chicago, 2000.

[46] Martin Gilens. Affluence and Influence: Economic Inequality and Political Power in America. Princeton University Press, Princeton, 2012.

[47] Peter Gottschalk and Sheldon Danziger. Inequality of Wage Rates, Earnings and Family Income in the United States, 1975-2002. Review of Income and Wealth, 51(2):231-254, 2005.

[48] Jeffrey Edward Green. Rawls and the Forgotten Figure of the Most Advantaged: In Defense of Reasonable Envy toward the Superrich. American Political Science Review, 107(01):123-138, January 2013. doi: 10.1017/Sooo3055412000585. URL http:

//www.journals.cambridge.org/abstract_Soo03055412000585. 
[49] J. S. Hacker and P. Pierson. Winner-Take-All Politics: Public Policy, Political Organization, and the Precipitous Rise of Top Incomes in the United States. Politics \& Society, 38(2):1 52-204, May 2010. doi: 10.1177/0032329210365042. URL http://pas. sagepub.com/cgi/content/abstract/38/2/152.

[50] M. Hadler. Why Do People Accept Different Income Ratios? A Multi-level Comparison of Thirty Countries. Acta Sociologica, 48(2): 131-154, June 2005. doi: 10.1177/0001699305053768. URL http://asj. sagepub.com/cgi/doi/10.1177/0001699305053768.

[5 1] Carolyn L. Hafer and Becky L. Choma. Belief in a Just World, Perceived Fairness, and Justification of the Status Quo. In Social and psychological bases of ideology and system justification, chapter 5, pages 107-125. Oxford University Press, Oxford, 2009.

[52] Barbara Heyns. Emerging Inequalities in Central and Eastern Europe. Annual Review of Sociology, 31 (1):163-197, August 2005. doi: 10.1146/annurev.soc.30.012703.110637. URL http://www . annualreviews .org/doi/abs/10.1146/annurev . soc.30.012703.110637.

[53] Jennifer Hochschild. What's Fair? American Beliefs about Distributive Justice. Harvard University Press, Cambridge, 1981.

[54] Torben Iversen and David Soskice. Electoral Institutions and the Politics of Coalitions: Why Some Democracies Redistribute More Than Others. American Political Science Review, 100(2):165-181, 2006.

[55] Shanto Iyengar. Framing Responsibility for Political Issues: The Case of Poverty. Political Behavior, 12(1):19-40, 1990.

[56] Lawrence R. Jacobs and Theda Skocpol. Inequality and American Democracy: What We Know and What We Need to Learn. Russell Sage Foundation, 2005.

[57] Guillermina Jasso. How Much Injustice is There in the World? Two New Justice Indexes. American Sociological Review, 64(1):133-168, 1999.

[58] Guillermina Jasso. Trends in the Experience of Injustice: Justice Indexes About Earnings in Six Societies, 1991 - 1996. Social Justice Research, 13 (2):101-122, 2000. 
[59] Charles I. Jones and Peter J. Klenow. Beyond GDP? Welfare across Countries and Time. NBER Working Paper Series, September 2010. URL http://papers.nber.org/papers/w16352.

[6o] John Jost and Orsolya Hunyady. The psychology of system justification and the palliative function of ideology. European Review of Social Psychology, 13(1):111-153, 2002.

[61] John T Jost and Mahzarin R Banaji. The role of stereotyping in system-justification and the production of false consciousness . British Journal of Social Psychology, 33:1-27, 1994.

[62] John T. Jost and Orsolya Hunyady. Antecedents and Consequences of System-Justifying Ideologies. Current Directions in Psychological Science, 14 (5):260-265, October 2005. doi: 10.1111/j.0963-7214.2005.00377.x. URL http: //cdp. sagepub.com/lookup/doi/10.1111/j.0963-7214. $2005 \cdot 00377 \cdot \mathrm{x}$.

[63] John T Jost, J Glaser, A W Kruglanski, and F Sulloway. Political conservatism as motivated social cognition. Psychological Bulletin, 129: $339-375,2003$.

[64] John T Jost, Mahzarin R Banaji, and Brian A Nosek. A Decade of System Justification Theory: Accumulated Evidence of Conscious and Unconscious Bolstering of the Status Quo. Political Psychology, 25 (6): $881-919,2004$.

[65] Robert S Kahn, Paul H Wise, Bruce P Kennedy, and Ichiro Kawachi. State income inequality, household income, and maternal mental and physical health: cross sectional national survey. British Medical Journal, 321 :

$1311-1315,2000$.

[66] Daniel Kahneman and Amos Tversky. Prospect Theory: An Analysis of Decision under Risk. Econometrica, 47(2):263-291, 1979. URL http: //www . jstor .org/stable/1914185.

[67] E. Karakoc and B. Baskan. Religion in Politics: How Does Inequality Affect Public Secularization? Comparative Political Studies, 45 (12): 1510-1541, August 2012. doi: 10.1177/0010414012453027. URL http: //cps . sagepub.com/cgi/doi/10 .1177/0010414012453027. 
[68] Terry Lynn Karl. Economic Inequality and Democratic Instability. Journal Of Democracy, 1 1(1):149-156, 2000.

[69] Robert R. Kaufman. Inequality and Redistribution: Some Continuing Puzzles. PS: Political Science \& Politics, 42(04):657, September 2009. doi: 10.1017/S1049096509990060. URL http://www . journals . cambridge.org/abstract_S1049096509990060.

[70] Ichiro Kawachi and Bruce Kennedy. Health, Inequality, and Economic Development. Journal of Economic Literature, XLI(March):1 13-158, 2003.

[71] A. C. Kay and J. Friesen. On Social Stability and Social Change: Understanding When System Justification Does and Does Not Occur. Current Directions in Psychological Science, 20(6):360-364, December 2011 . doi: 10.1177/0963721411422059. URL http: //cdp.sagepub.com/lookup/doi/10.1177/0963721411422059.

[72] Aaron C Kay, Danielle Gaucher, Jennifer M Peach, Kristin Laurin, Justin Friesen, Mark P Zanna, and Steven J Spencer. Inequality, discrimination, and the power of the status quo: Direct evidence for a motivation to see the way things are as the way they should be. Journal of personality and social psychology, 97(3):421-34, September 2009. doi: 10.1037/a0015997. URL http://www.ncbi.nlm.nih.gov/pubmed/19685999.

[73] J Kelley and K Zagorski. Economic Change and the Legitimation of Inequality: the Transition From Socialism To the Free Market in Central-East Europe. Research in Social Stratification and Mobility, 22: 319-364, 2004. doi: 10.1016/So276-5624(04)22011-X. URL http: // linkinghub.elsevier.com/retrieve/pii/So27656240422011X.

[74] Jonathan Kelley and M. D. R. Evans. The Legitimation of Inequality: Occupational Earnings in Nine Nations. American Journal of Sociology, 99 (1):75, July 1993. doi: 10.1086/230230. URL http: //www. journals . uchicago . edu/doi/abs/10 . 1086/230230.

[75] Nathan J. Kelly and Peter K. Enns. Inequality and the Dynamics of Public Opinion: The Self-Reinforcing Link Between Economic Inequality and Mass Preferences. American Journal of Political Science, 54(4):855-870, July 2010. doi: 10.1111/j.1540-5907.2010.00472.x. URL http://doi.wiley.com/10.1111/j.1540-5907.2010.00472.x. 
[76] B P Kennedy, I Kawachi, R Glass, and D Prothrow-Stith. Income distribution, socioeconomic status, and self rated health in the United States: multilevel analysis. BMJ (Clinical research ed.), 317 (7163):917-21, October 1998. URL

http: //www . pubmedcentral .nih.gov/articlerender.fcgi?

artid $=28675 \&$ tool=pmcentrez\&rendertype=abstract.

[77] L. Kenworthy and L. McCall. Inequality, public opinion and redistribution. Socio-Economic Review, 6(1):35-68, December 2008. doi: 10.1093/ser/mwmoo6. URL http:

//ser.oxfordjournals.org/cgi/doi/10.1093/ser/mwmoo6.

[78] James R Kluegel and E. R. Smith. Beliefs about inequality: Americans' views of what is and what ought to be. Aldine De Gruyter, New York, 1986.

[79] Naoki Kondo, Ichiro Kawachi, S V Subramanian, Yasuhisa Takeda, and Zentaro Yamagata. Do social comparisons explain the association between income inequality and health?: Relative deprivation and perceived health among male and female Japanese individuals. Social science \& medicine (1982), 67(6):982-7, September 2008. doi: 10.1016/j.socscimed.2008.06.002. URL http://www . pubmedcentral .nih.gov/articlerender .fcgi? artid=2791046\&tool=pmcentrez\&rendertype=abstract.

[8o] Carl Everett Ladd and Karlyn H. Bowman. Attitudes Toward Economic Inequality. American Enterprise Institute, Washington, D.C., 1998.

[81] Robert E. Lane. The Fear of Equality. The American Political Science Review, 53(1):35- 51, 1959. URL http: //www. jstor.org/stable/1951729.

[82] Kristin Laurin, Grainne M. Fitzsimons, and Aaron C. Kay. Social disadvantage and the self-regulatory function of justice beliefs. Journal of Personality and Social Psychology, $2010 a$.

[83] Kristin Laurin, Steven Shepherd, and Aaron C Kay. Restricted emigration, system inescapability, and defense of the status quo: system-justifying consequences of restricted exit opportunities. Psychological science, 21 (8): 1075-82, August 201 ob. doi: 10.1177/0956797610375448. URL http://www.ncbi.nlm.nih.gov/pubmed/20585053. 
[84] Kayte Lawton, Nick Pearce, Tony Dolphin, Glenn Gottfried, and Andy Stuckey. Getting What We Deserve? Technical report, Institute for Public Policy Research, London, 2011.

[85] Robyn a LeBoeuf and Eldar Shafir. Anchoring on the "here" and "now" in time and distance judgments. Journal of experimental psychology. Learning, memory, and cognition, 35 (1):81-93, January 2009. doi: 10.1037/aoo13665. URL http: //www.ncbi.nlm.nih.gov/pubmed/19210082.

[86] Andrew Leigh, Christopher Jencks, and Timothy M Smeeding. Health and Economic Inequality. In W Salverda, B Nolan, and T Smeeding, editors, The Oxford Handbook of Economic Inequality, chapter 16, pages 384-405. Oxford University Press, Oxford, 2011.

[87] Melvin J. Lerner and Dale T. Miller. Just world research and the attribution process: Looking back and ahead. Psychological Bulletin, 85 (5):1030-1051, 1978. doi: 10.1037/0033-2909.85.5.1030. URL http: //content .apa.org/journals/bul/85/5/103o.

[88] Isaac Lipkus. The Construction and Preliminary Validation of a Global Belief in a Just World Scale and the Exploratory Analysis of the Multidimensional Belief in a Just World Scale. Journal of Personality, 12 (11):1171-1178, 1991 .

[89] Isaac Lipkus and Ilene C. Siegler. The Belief in a Just World and Perceptions of Discrimination. The Journal of Psychology, 127(4): 465-474, 1993.

[90] Ola Listhaug and Toril Aalberg. Comparative Public Opinion on Distributive Justice. International Journal of Comparative Sociology, 40: 117-140, 1999.

[91] Ido Liviatan and John T. Jost. Special Issue: System Justification Theory. Motivated Social Cognition in the Service of the Status Quo. Social Cognition, 29(3):231-237, 2011.

[92] Matthew Loveless and Stephen Whitefield. Being unequal and seeing inequality: Explaining the political significance of social inequality in new market democracies. European Journal of Political Research, 50(2): 239-266, March 2011 . doi: 10.1111/j.1475-6765.2010.01929.x. URL http://doi.wiley.com/10.1111/j.1475-6765.2010.01929.x. 
[93] Xiaobo Lü. Public Goods Provision, Inequality of Opportunity, and Attitudes Toward Income Inequality (Working Paper). 2010.

[94] Noam Lupu and Jonas Pontusson. The Structure of Inequality and the Politics of Redistribution. American Political Science Review, 105(2):1-2 1, May 2011. doi: 10.1017/Sooo3055411000128. URL http:

//www.journals.cambridge.org/abstract_Soo03055411000128.

[95] Erzo F. P. Luttmer and Monica Singhal. Culture, Context, and the Taste for Redistribution. NBER Working Paper, 2008. URL http://www. nber.org/papers/w14268.

[96] Vincent A Mahler. Economic Globalization, Domestic Politics, and Income Inequality in the Developed Countries. Comparative Political Studies, 37(9):1025-1053, 2004.

[97] Jeff Manza. Unequal Democracy in America: The Long View. In David Grusky and Tamar Kricheli-Katz, editors, The New Gilded Age: The Critical Inequality Debates of Our Time, pages 131-160. Stanford University Press, Stanford, 2012.

[98] Isabela Mares. Social Protection around the World: External Insecurity, State Capacity and Domestic Political Cleavages. Comparative Political Studies, 38(6):623-51, 2005.

[99] Gordon Marshall, Adam Swift, David Routh, and Carole Burgoyne. What Is and What Ought to Be: Popular Beliefs About Distributive Justice in Thirteen Countries. European Sociological Review, 15(4):349-367, 1999.

[100] Karl Marx and Friedrich Engels. The Communist Manifesto. Oxford University Press, 1993.

[101] Leslie McCall. The Undeserving Rich: Beliefs about Inequality, Opportunity, and Redistribution in American Society. Cambridge University Press, Cambridge, 2013.

[102] Leslie McCall and Lane Kenworthy. Americans' Social Policy Preferences in the Era of Rising Inequality. Perspectives on Politics, 7(03):459, August 2009. doi: 10.1017/S1537592709990818. URL http:

//www.journals.cambridge.org/abstract_S1537592709990818. 
[103] Leslie McCall and Christine Percheski. Income Inequality: New Trends and Research Directions. Annual Review of Sociology, 36(1):329-347, June 2010. doi: 10.1146/annurev.soc.012809.102541. URL http: //www . annualreviews . org/doi/abs/10 .1146/annurev . soc.012809.102541.

[104] By Elizabeth McNichol, Douglas Hall, David Cooper, and Vincent Palacios. A State-by-State Analysis of Income Trends. Technical report, Center on Budget and Policy Priorities, Washington, D.C., 2012.

[105] Jennifer M. Mellor and Jeffrey Milyo. Income Inequality and Health Status in the United States: Evidence from the Current Population Survey. The Journal of Human Resources, 37(3):510, 2002. doi: 10.2307/3069680. URL http: //www . jstor .org/stable/306968o?origin=crossref.

[106] Allan H Meltzer and Scott F Richard. A Rational Theory of the Size of Government. Journal of Political Economy, 89(5):914-927, 1981.

[107] Tamar Mendelson, Rebecca C Thurston, and Laura D Kubzansky. Affective and cardiovascular effects of experimentally-induced social status. Health psychology : official journal of the Division of Health Psychology, American Psychological Association, 27(4):482-9, July 2008. doi: 10.1037/0278-6133.27.4.482. URL http://www.ncbi.nlm.nih.gov/pubmed/18643006.

[108] B Milanovic. The median-voter hypothesis, income inequality, and income redistribution: an empirical test with the required data. European Journal of Political Economy, 16(3):367-410, September 2000. doi: 10.1016/So176-268o(oo)ooo14-8. URL http: // linkinghub. elsevier.com/retrieve/pii/So176268000000148.

[109] Edward N Muller. Democracy, Economic Development and Income Inequality. American Sociological Review, 53 (1):50-68, 1988.

[1 10] Edward N Muller. Economic Determinants of Democracy. American Sociological Review, 6o(6):966-982, 1995.

[ 1111$]$ Jaime L Napier and John T Jost. Why are conservatives happier than liberals? Psychological science, $19(6): 565-72$, June 2008. doi: 10.1111/j.1467-9280.2008.02124.x. URL http://www.ncbi.nlm.nih.gov/pubmed/19035826. 
[112] Kathryn M. Neckerman and Florencia Torche. Inequality: Causes and Consequences. Annual Review of Sociology, 33(1):335-357, August 2007. doi: 10.1146/annurev.soc.33.040406.131755. URL http://www . annualreviews .org/doi/abs/10.1146/annurev . soc. $33 \cdot 040406 \cdot 131755$.

[113] Mani Nepal, Alok K. Bohara, and Kishore Gawande. More Inequality, More Killings: The Maoist Insurgency in Nepal. American Journal of Political Science, 55(4):886-906, July 201 1. doi: 10.1111/j.1540-5907.2011.00529.x. URL http://doi.wiley.com/10.1111/j.1540-5907 ·2011 .00529.x.

[114] Michael I. Norton and Dan Ariely. Building a Better America - One Wealth Quintile at a Time. Perspectives on Psychological Science, 6(1):9-12, 2010.

[1 15] L. Osberg and T. Smeeding. "Fair" Inequality? Attitudes toward Pay Differentials: The United States in Comparative Perspective. American Sociological Review, 71 (3):450-473, June 2006. doi:

10.1177/000312240607100305. URL http://asr . sagepub.com/cgi/doi/10.1177/000312240607100305.

[116] Benjamin I. Page and Lawrence R. Jacobs. Class War: What Americans Really Think About Economic Inequality. University of Chicago Press, Chicago, 2009.

[1 17] Benjamin I. Page, Larry M. Bartels, and Jason Seawright. Democracy and the Policy Preferences of Wealthy Americans. Perspectives on Politics, 11 (o 1):51-73, March 2013. doi: 10.1017/S15375927120036oX. URL http: //www. journals . cambridge.org/abstract_S153759271200360X.

[1 18 ] Marii Paskov and Caroline Dewilde. Income inequality and solidarity in Europe. Research in Social Stratification and Mobility, 30(4):41 5-432, December 2012. doi: 10.1016/j.rssm.2012.06.002. URL http:// linkinghub.elsevier.com/retrieve/pii/So276562412000285.

[119] Thomas Piketty. Social Mobility and Redistributive Politics. The Quarterly Journal of Economics, $110(3): 551-584,1995$.

[120] Thomas Piketty and Emmanuel Saez. The Evolution of Top Incomes: A Historical and International Perspective. American Economic Review, 96 
(2):200-205, May 2006. doi: 10.1257/000282806777212116. URL

http://pubs . aeaweb.org/doi/abs/10.1257/000282806777212116.

[121] Jonas Pontusson. Inequality and Economic Growth in Comparative Perspective. In David Grusky and Tamar Kricheli-Katz, editors, The New Gilded Age: The Critical Inequality Debates of Our Time, pages 88-114. Stanford University Press, Stanford, 2012.

[122] John E. Roemer, Woojin Lee, and Karine van der Straeten. Racism, xenophobia, and distribution: multi-issue politics in advanced democracies. Russell Sage Foundation, New York, 2007.

[123] Jesper Roine and Daniel Waldenström. The Evolution of Top Incomes in an Egalitarian Society; Sweden, 1903-2004. Research Institute of Industrial Economics Working Paper, (667), 2006.

[124] David Rueda and Jonas Pontusson. Wage Inequality and Varieties of Capitalism. World Politics, 52(3):350-383, 2000.

[125] E. Saar. Different Cohorts and Evaluation of Income Differences in Estonia. International Sociology, $23(3): 417-445$, May 2008. doi: 10.1177/0268580908088899. URL http://iss. sagepub. com/cgi/doi/10.1177/0268580908088899.

[126] W. Samuelson and Richard J Zeckhauser. Status-quo bias in decision making. Journal of Risk and Uncertainty, 1:7-59, 1988.

[127] Kenneth Scheve and David Stasavage. Religion and Preferences for Social Insurance. Quarterly Journal of Political Science, 1(May):255-286, 2006. doi: $10.561 / 100.00005052$.

[128] Kay Lehman Schlozman, Sidney Verba, and Henry Brady. The Unheavenly Chorus: Unequal Political Voice and the Broken Promise of American Democracy. Princeton University Press, Princeton, 2012.

[129] Ian Shapiro. Why the Poor Don't Soak the Rich. Daedalus, 13 1(1): $118-128,2002$.

[130] Moses Shayo. A Model of Social Identity with an Application to Political Economy: Nation, Class, and Redistribution. American Political Science Review, 103(2):147-174, 2009. URL doi :10.1017/Soo03055409090194. 
[131] Timothy M. Smeeding. Public Policy, Economic Inequality, and Poverty: The United States in Comparative Perspective. Social Science Quarterly, 86 (s1):955-983, December 2005. doi: 10.1111/j.0038-4941.2005.00331.x. URL http://doi.wiley.com/10.1111/j.0038-4941.2005.00331.x.

[132] Hillel David Soifer. The Redistributive Threat: State Power and the Effect of Inequality on Democracy. Brooks World Poverty Institute Working Paper, 2009.

[133] Frederick Solt. Standardizing the World Income Inequality Database. Social Science Quarterly, 90(2):231-42, 2009.

[134] Frederick Solt. Does Economic Inequality Depress Electoral Participation? Testing the Schattschneider Hypothesis. Political Behavior, 32(2):285-301, 2010. doi: 10.1007/s11109-010-9106-o. URL http: //www. springerlink.com/index/10.1007/s11109-010-9106-o.

[135] Fredrick Solt. Economic Inequality and Democratic Political Engagement. American Journal of Political Science, 52(1):48-60, 2008.

[136] Alfred Stepan and Juan J. Linz. Comparative Perspectives on Inequality and the Quality of Democracy in the United States. Perspectives on Politics, 9(04):841-856, December 2011 . doi: 10.1017/S1537592711003756. URL http:

//www.journals. cambridge.org/abstract_S1537592711003756.

[137] S V Subramanian and Ichiro Kawachi. The association between state income inequality and worse health is not confounded by race. International Journal of Epidemiology, 32(6):1022-1028, 2003. doi: 10.1093/ije/dyg245.

[138] Stefan Svallfors. Dimensions of Inequality : A Comparison of Attitudes in Sweden and Britain. European Sociological Review, 9(3):267-287, 1993.

[139] Stefan Svallfors. Worlds of Welfare and Attitudes to Redistribution: A Comparison of Eight Western Nations. European Sociological Review, 13 (3):283-304, 1997.

[140] E Thorbecke. Economic Inequality and Its Socioeconomic Impact. World Development, 30(9):1477-1495, September 2002. doi: 10.1016/So305-75oX(o2)ooo52-9. URL http: // linkinghub . elsevier.com/retrieve/pii/So305750X02000529. 
[141] Amos Tversky and Daniel Kahneman. Judgment under uncertainty: Heuristics and biases. Science, 185:1124-1131, 1974.

[142] Jojanneke van der Toorn, Paul R. Nail, Ido Liviatan, and John T. Jost. My Country, Right or Wrong: Activating System Justification Motivation Eliminates the Liberal-Conservative Gap in Patriotic Attachment (Working Paper). 2012.

[143] Sidney Verba and Gary Orren. Equality in America: The View from the Top. Harvard University Press, Cambridge, MA, 1985.

[144] Roland Verwiebe and Bernd Wegener. Social Inequality and the Perceived Income Justice Gap. Social Justice Research, 13(2):123-149, 2000.

[145] Sarah Voitchovsky. Inequality and Economic Growth. In Wiemer Salverda, Brian Nolvan, and Timothy M. Smeeding, editors, Oxford Handbook of Economic Inequality, chapter 22, pages 549-574. Oxford University Press, Oxford, 2009.

[146] Cheryl J Wakslak and Patrick Bauer. Spreading Rationalization: Increased Support for Large-Scale and Small-Scale Social Systems Following System Threat. Social Cognition, 29(2):288-302, 2011.

[147] Eva Wegner and Miquel Pellicer. Demand for Redistribution in South Africa (Working Paper). 2011.

[148] Richard G. Wilkinson and Kate Pickett. The spirit level: why more equal societies almost always do better. Penguin, London, 2010.

[149] Ping Xu and James C Garand. Economic Context and Americans' Perceptions of Income Inequality. Social Science Quarterly, 91(5): 1220-1242, 2010.

[150] Jong-sung You. Social Trust: Fairness Matters More Than Homogeneity. Political Psychology, 33(5):701-72 1, July 2012. doi: 10.1111/j.1467-9221.2012.00893.x. URL http://doi.wiley.com/10.1111/j.1467-9221.2012.00893.x.

[151] R. B. Zajonc. Attitudinal effects of mere exposure. Journal of Personality and Social Psychology Monograph, 9(2 (Pt. 2)):1-27, 1968. 
[152] Emily M Zitek and Larissa Z Tiedens. The fluency of social hierarchy: The ease with which hierarchical relationships are seen, remembered, learned, and liked. Journal of personality and social psychology, September 2011. doi: 10.1037/aoo25345. URL

http://www.ncbi.nlm.nih.gov/pubmed/21910553. 


\title{
Colophon
}

\author{
7 HIS THESIS WAS TYPESET \\ using $\mathrm{ET}_{\mathrm{E}} \mathrm{X}$, originally developed by \\ Leslie Lamport and based on Donald
}

Knuth's TEX. The body text is set in 11 point

Arno Pro, designed by Robert Slimbach in

the style of book types from the Aldine Press

in Venice, and issued by Adobe in 2007. A

template, which can be used to format a $\mathrm{PhD}$

thesis with this look and feel, has been

released under the permissive MIT (X11)

license, and can be found online at

github.com/suchow/ or from the template

author atsuchow@post.harvard.edu. 